Florida International University FIU Digital Commons

7-25-2002

\title{
Analysis of coaxial fed U-slot patch antennas using finite difference time domain method
}

Chandrasekhar Cherukuri

Florida International University

DOI: $10.25148 /$ etd.FI14060190

Follow this and additional works at: https://digitalcommons.fiu.edu/etd

Part of the Electrical and Computer Engineering Commons

\section{Recommended Citation}

Cherukuri, Chandrasekhar, "Analysis of coaxial fed U-slot patch antennas using finite difference time domain method" (2002). FIU

Electronic Theses and Dissertations. 2158.

https://digitalcommons.fiu.edu/etd/2158

This work is brought to you for free and open access by the University Graduate School at FIU Digital Commons. It has been accepted for inclusion in FIU Electronic Theses and Dissertations by an authorized administrator of FIU Digital Commons. For more information, please contact dcc@fiu.edu. 
FLORIDA INTERNATIONAL UNIVERSITY

Miami, Florida

\section{ANALYSIS OF COAXIAL FED U-SLOT PATCH ANTENNAS USING FINITE DIFFERENCE TIME DOMAIN METHOD}

A thesis submitted in partial fulfillment of the requirements for the degree of MASTER OF SCIENCE in ELECTRICAL ENGINEERING by

Chandrasekhar Cherukuri 
To: Dean Vish Prasad

College of Engineering

This thesis, written by Chandrasekhar Cherukuri, and entitled Analysis of Coaxial Fed Uslot Patch Antennas using Finite Difference Time Domain Method, having been approved in respect to style and intellectual content, is referred to you for judgment.

We have read this thesis and recommend that it be approved.

Subbarao V. Wunnava

Jean Andrian

Tadeusz M. Babij, Major Professor

Date of Defense: July 25, 2002

The thesis of Chandrasekhar Cherukuri is approved.

Dean Vish Prasad College of Engineering

Dean Douglas Wartzok University Graduate School

Florida International University, 2002 


\section{DEDICATION}

I dedicate this thesis to my parents and friends. Without their patience, understanding, support, and most of all love, the completion of this work would not have been possible. 
ABSTRACT OF THE THESIS

ANALYSIS OF COAXIAL FED U-SLOT PATCH ANTENNAS USING FINITE

DIFFERENCE TIME DOMAIN METHOD

by

Chandrasekhar Cherukuri

Florida International University, 2002

Miami, Florida

Professor Tadeusz M. Babij, Major Professor

The objective of this thesis was to analyze a Coaxial-Fed U-slot Rectangular Patch Antenna using Finite Difference Time Domain (FDTD) method. Important parameters such as S-parameters and Input Impedance of the antenna were simulated using XFDTD software and were analyzed. An important goal of this thesis was to provide design information about the U-slot antenna. For this purpose the effects of antenna layout on the resonant frequency and the bandwidth of the antenna were investigated. First the effect of varying slot width on the S-parameters, Voltage Standing Wave Ratio (VSWR) and Input Impedance were studied. Next the length of the slot was varied and effect of changing this design parameter of the antenna was analyzed. Finally the substrate thickness was varied and its effect on the antenna parameters is studied. This work concluded that by varying antenna dimensions such as slot width, slot length and substrate thickness, higher bandwidth could be achieved with required impedance matching. 


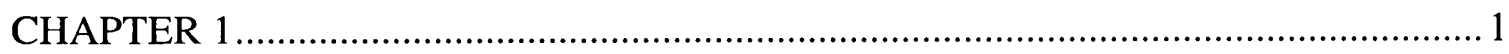

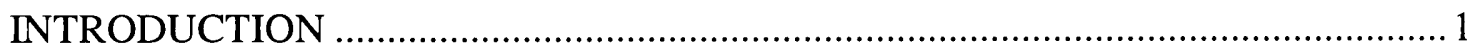

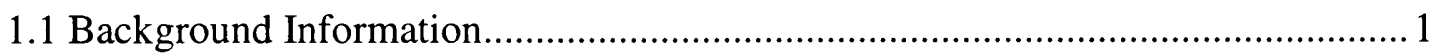

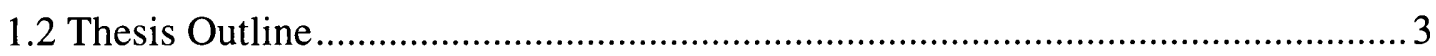

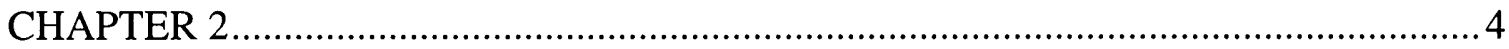

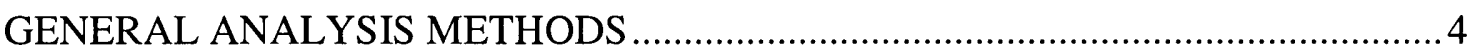

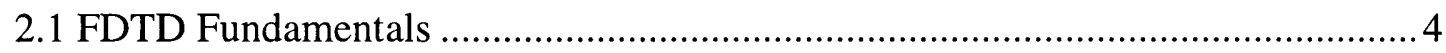

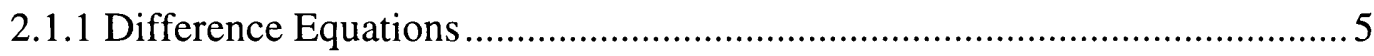

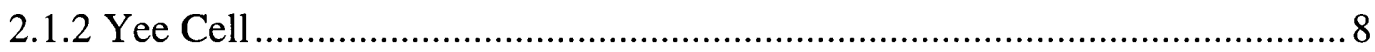

2.1.3. The strengths of the FDTD Technique .................................................... 10

2.1.4 The weaknesses of the FDTD Technique................................................ 11

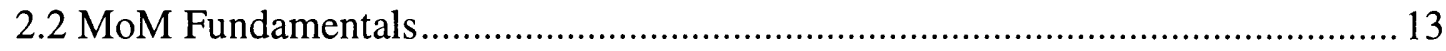

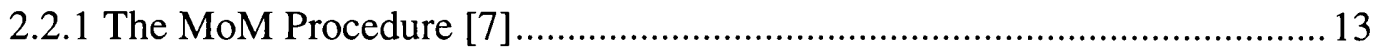

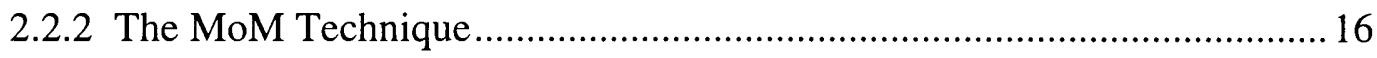

2.2.3 The Strengths of MoM Technique ............................................................ 16

2.2.4 The weaknesses of MoM Technique ...................................................... 17

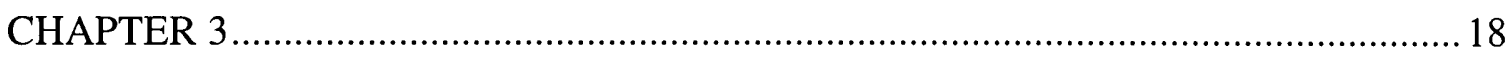

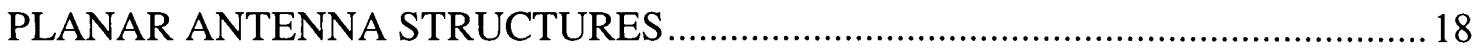

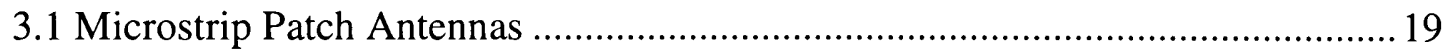

3.1.1 Advantages and Limitations of Microstrip Antennas................................. 19

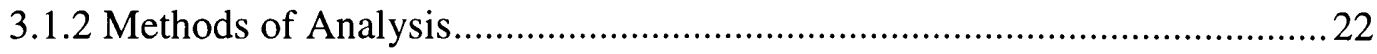

3.1.3 Coax Fed Microstrip Patch Antenna ………..........................................23

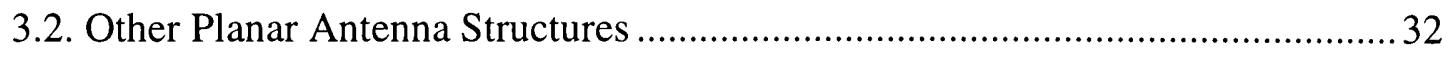

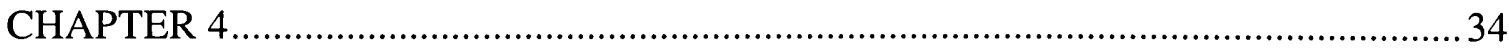

COAXIALLY FED U-SLOT RECTANGULAR PATCH ANTENNA …......................34

4.1 Coaxial fed U-slot Rectangular patch Antenna Geometry ...................................34 


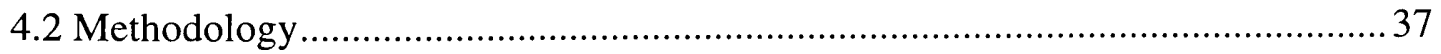

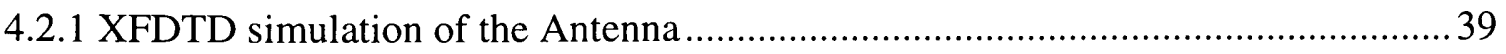

4.3 Variations in Coaxial fed U-slot Patch Antenna Geometry..................................43

4.3.1 Variations in the slot width 'a' of the antenna ..............................................43

4.3.2 Variations in the slot length ' $b$ ' of the antenna ..........................................53

4.3.3 Variations in substrate thickness ' $h$ ' of the antenna....................................62

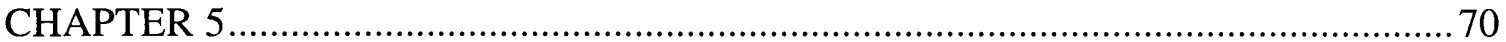

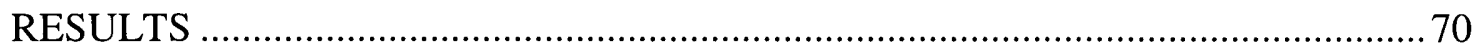

5.1 Effect of the changes in the Slot Width on Antenna Parameters......................... 70

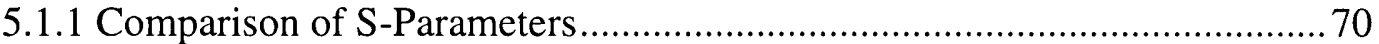

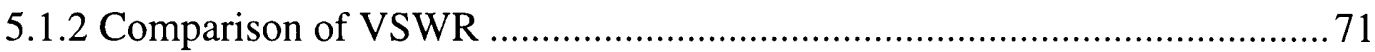

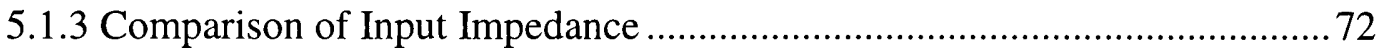

5.2 Effect of the changes in the Slot Length on Antenna Parameters ......................... 74

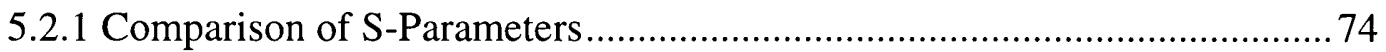

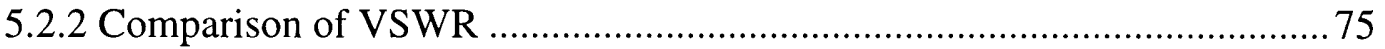

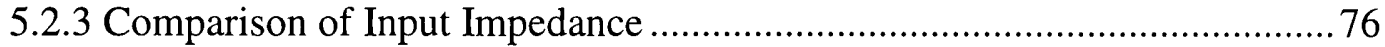

5.3 Effect of the changes in the Substrate Thickness on Antenna Parameters ........... 79

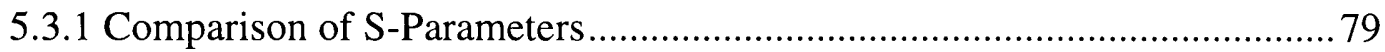

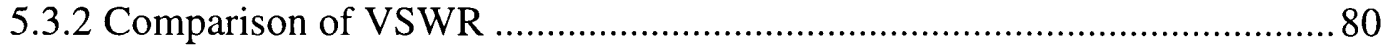

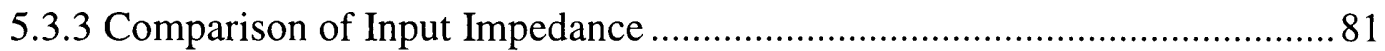

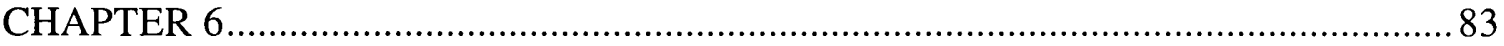

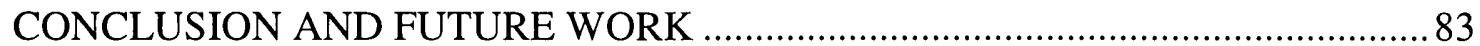

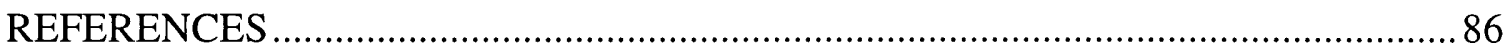




\section{LIST OF FIGURES}

FIGURE

PAGE

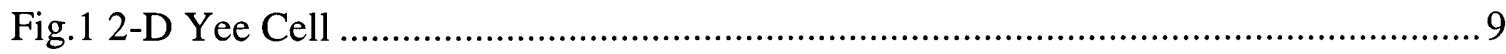

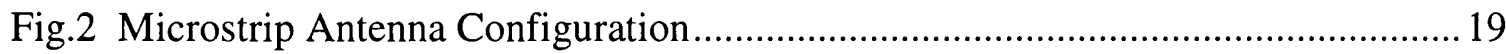

Fig. 3 Geometry of Coaxial line fed Microstrip Patch Antenna .......................................24

Fig.4 Geometry of Coaxial line fed Microstrip Patch Antenna for XFDTD Simulation.. 25

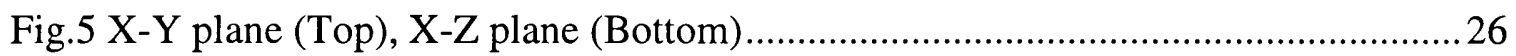

Fig.6 IS 11/ Vs Frequency for Single Coax fed Patch Antenna....................................... 27

Fig.7 Input Impedance Vs Frequency for Single Coax fed Patch antenna....................... 27

Fig.8 Final settings for the Simulation using MultiSTRIP program ...............................2 28

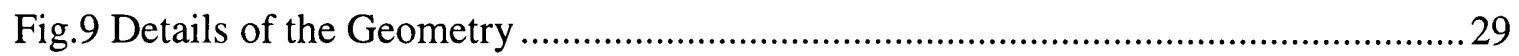

Fig.10 IS11I Vs. Frequency for Coax-fed microstrip patch from MoM ...........................29

Fig.11 Plot of VSWR Vs. Frequency obtained using the MoM Technique .......................30

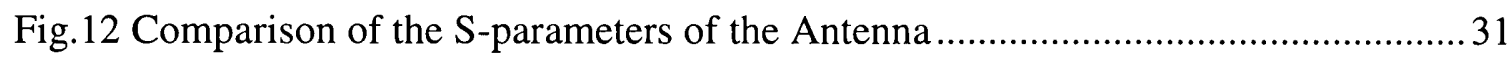

Fig.13 Geometry of Coaxial fed U- Slot Rectangular Patch Antenna [13].......................35

Fig.14 Geometry of coaxial -fed U-slot antenna under study[13] .................................... 36

Fig.15 FDTD geometry of Coaxial fed U-slot Antenna under study ................................38

Fig.16 XFTD geometry, X-Y plane view (Top) \& X-Z plane view (Bottom).................. 39

Fig.17 Stimulus setting for coaxially Fed U-slot Patch Antenna ......................................40

Fig.18 Boundary conditions for Coaxially fed U-slot Patch Antenna ............................ 40

Fig.19 IS11| vs. Frequency for Coaxial fed U-slot Antenna............................................ 41

Fig.20 VSWR Vs Frequency for U-slot Patch antenna....................................................42

Fig.21 Input Impedance Vs Frequency for U-slot Patch Antenna ...................................43

Fig.22 XFDTD geometry of Coaxial fed U-slot antenna with slot width of $10 \mathrm{~mm}$..........44

Fig.23 IS11| vs. Frequency for Coaxial fed U-slot antenna with a slot width of $10 \mathrm{~mm}$....45

Fig.24 VSWR vs. Frequency for Coaxial fed U-slot antenna with a slot width of

$10 \mathrm{~mm}$.

Fig.25 Input Impedance vs. Frequency for Coaxial fed U-slot antenna with a slot width of $10 \mathrm{~mm}$ 
Fig.26 XFDTD geometry of coaxial fed U-slot antenna with slot width of $12 \mathrm{~mm}$. 47

Fig.27 IS11I vs. Frequency for Coaxial fed U-slot antenna with a slot width of

$12 \mathrm{~mm}$ .47

Fig.28 VSWR vs. Frequency for Coaxial fed U-slot antenna with a slot width of $12 \mathrm{~mm} 48$

Fig.29 Input Impedance vs. Frequency for Coaxial fed U-slot antenna with a slot width of $12 \mathrm{~mm}$ .48

Fig.30 XFDTD geometry of coaxial fed U-slot antenna with slot width of $14 \mathrm{~mm}$ .49

Fig.31 IS11I vs. Frequency for Coaxial fed U-slot antenna with a slot width of $14 \mathrm{~mm}$

Fig. 32 VSWR vs. Frequency for Coaxial fed U-slot antenna with a slot width of $14 \mathrm{~mm} 50$ Fig.33 Input Impedance vs. Frequency for Coaxial fed U-slot antenna with a slot width of $14 \mathrm{~mm}$ 50

Fig.34 XFDTD geometry of coaxial fed U-slot antenna with slot width of $8 \mathrm{~mm}$............51 Fig.35 IS11| vs. Frequency for Coaxial fed U-slot antenna with a slot width of $8 \mathrm{~mm}$.....51 Fig.36 VSWR vs. Frequency for Coaxial fed U-slot antenna with a slot width of $8 \mathrm{~mm} . .52$ Fig.37 Input Impedance vs. Frequency for Coaxial fed U-slot antenna with a slot width of $8 \mathrm{~mm}$ 52

Fig.38 XFDTD geometry of coaxial fed U-slot antenna with slot length of $14 \mathrm{~mm}$ 54

Fig.39 IS11I vs. Frequency for Coaxial fed U-slot antenna with a slot length of $14 \mathrm{~mm}$..54 Fig.40 VSWR vs. Frequency for Coaxial fed U-slot antenna with a slot length of $14 \mathrm{~mm}$ .55

Fig.41 Input Impedance vs. Frequency for Coaxial fed U-slot antenna with a slot length of $14 \mathrm{~mm}$ .55

Fig.42 XFDTD geometry of coaxial fed U-slot antenna with slot length of $16 \mathrm{~mm}$ .56

Fig.43 IS11I vs. Frequency for Coaxial fed U-slot antenna with a slot length of $16 \mathrm{~mm} . .56$ Fig.44 VSWR vs. Frequency for Coaxial fed U-slot antenna with a slot length of $16 \mathrm{~mm}$. .57

Fig.45 Input Impedance vs. Frequency for Coaxial fed U-slot antenna with a slot length of $16 \mathrm{~mm}$ 
Fig.46 XFDTD geometry of coaxial fed U-slot antenna with slot length of $18 \mathrm{~mm}$..........58

Fig.47 IS11I vs. Frequency for Coaxial fed U-slot antenna with a slot length of $18 \mathrm{~mm}$.. 58

Fig.48 VSWR vs. Frequency for Coaxial fed U-slot antenna with a slot width of $18 \mathrm{~mm} 59$

Fig.49 Input Impedance vs. Frequency for Coaxial fed U-slot antenna with a slot

length of $18 \mathrm{~mm}$ 59

Fig.50 XFDTD geometry of coaxial fed U-slot antenna with slot length of $20 \mathrm{~mm}$ 60

Fig.51 IS11| vs. Frequency for Coaxial fed U-slot antenna with a slot length of $20 \mathrm{~mm} .60$ Fig.52 VSWR vs. Frequency for Coaxial fed U-slot antenna with a slot width of $20 \mathrm{~mm} 61$ Fig.53 Input Impedance vs. Frequency for Coaxial fed U-slot antenna with a slot width of $20 \mathrm{~mm}$ 61

Fig.54 XFDTD geometry of coaxial fed U-slot antenna with substrate thickness of $5 \mathrm{~mm}$ $\mathrm{X}$-Y plane view 62

Fig.55 XFDTD geometry of coaxial fed U-slot antenna with substrate thickness of $5 \mathrm{~mm}$

$\mathrm{X}-\mathrm{Z}$ plane view.

Fig.56 IS11I Vs Frequency of U-slot antenna with substrate thickness of $5 \mathrm{~mm}$...............63

Fig.57 VSWR of U-slot antenna with substrate thickness of $5 \mathrm{~mm}$...................................6

Fig.58 Input Impedance of U-slot antenna with substrate thickness of $5 \mathrm{~mm}$....................64

Fig.59 XFDTD geometry of coaxial fed U-slot antenna with substrate thickness of

$6.4 \mathrm{~mm}, \mathrm{X}-\mathrm{Y}$ plane view

Fig.60 XFDTD geometry of coaxial fed U-slot antenna with substrate thickness of

$6.4 \mathrm{~mm}, \mathrm{X}-\mathrm{Z}$ plane view.

Fig.61 IS11I Vs Frequency of U-slot antenna with substrate thickness of $6.4 \mathrm{~mm}$............66

Fig.62 VSWR of U-slot antenna with substrate thickness of $6.4 \mathrm{~mm}$...............................6

Fig.63 Input Impedance of U-slot antenna with substrate thickness of $6.4 \mathrm{~mm}$.................67

Fig.64 XFDTD geometry of coaxial fed U-slot antenna with substrate thickness of $8 \mathrm{~mm}$,

$\mathrm{X}-\mathrm{Y}$ plane view

Fig.65 XFDTD geometry of coaxial fed U-slot antenna with substrate thickness of $8 \mathrm{~mm}$,

$\mathrm{X}-\mathrm{Z}$ plane view .68

Fig. 66 IS11| Vs Frequency of U-slot antenna with substrate thickness of $8 \mathrm{~mm}$................68

Fig.67 VSWR of U-slot antenna with substrate thickness of $8 \mathrm{~mm}$. 
Fig.68 Input Impedance of U-slot antenna with substrate thickness of $8 \mathrm{~mm}$ 69

Fig.69 Comparison of S-parameters for U-slot antenna with different slot widths .......... 70 Fig.70 Comparison of VSWR for U-slot antenna with different slot widths....................71

Fig.71 Comparison of Input Resistance for U-slot antenna with different slot widths.....73

Fig. 72 Comparison of Input Reactance for U-slot antenna with different slot widths ..... 73

Fig.73 Comparison of S-parameters for U-slot antenna with different slot lengths ......... 74

Fig.74 Comparison of VSWR for U-slot antenna with different slot lengths...................75

Fig.75 Comparison of Input Resistance for U-slot antenna with different slot lengths.... 77

Fig.76 Comparison of Input Reactance for U-slot antenna with different slot lengths..... 77

Fig.77 Comparison of Measured and Computed Input Impedance for U-slot Antenna with

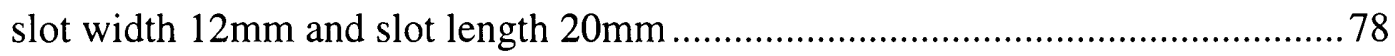

Fig.78 Comparison of S-parameters for U-slot antenna with different substrate

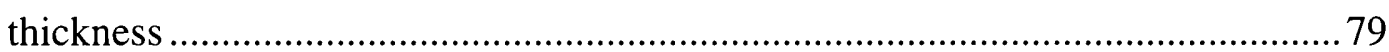

Fig.79 Comparison of VSWR for U-slot antenna with different substrate thicknesses.... 80 Fig.80 Comparison of Input Resistance for U-slot antenna with different substrate thicknesses.

Fig.81 Comparison of Input Reactance for U-slot antenna with different substrate

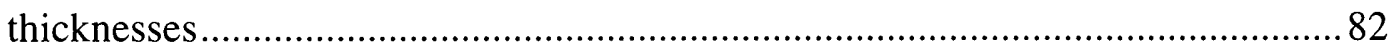

Fig. 82 Geometry of two-element array of U-slot patches ............................................ 85 


\section{CHAPTER 1}

\section{INTRODUCTION}

\subsection{Background Information}

In today's age of wireless communications, perhaps no component is as essential as the antenna. Without the antenna, it would be virtually impossible to have any form of wireless communication. Instead, communications would be achieved by cumbersomely connecting wires between every transmitter and receiver. The world would be proliferated by an abundance of wires, and the range of available communications would be very limited to say the least. Obviously the scenario is impractical and emphasizes the importance of antennas in the world of wireless communication.

The history of the antenna is a relatively young one [1]. In 1864, James Clerk Maxwell presented what we presently refer to as Maxwell's equations before the royal society; Maxwell's equations form the basis of modern day antenna technology and microwave engineering. In 1885, Thomas Edison patented a communications system that utilized top-loaded, vertical antennas for telegraphy. Two years later, Heinrich Hertz used his "Hertzian dipole" to experimentally validate Maxwell's claim that electromagnetic waves propagate through the air. Guglielmo Marconi is generally credited in 1898 with developing radio commercially and pioneering transcontinental communications.

Ever since the pioneering work of the $19^{\text {th }}$ century, antennas have been used for a variety of applications ranging from radar to home entertainment. The proliferation of antennas in today's world is also quite evident. Satellites in orbital space relay information around the globe. Radar, an application of antennas, allows air traffic 
controllers to track and safely guide aircraft to their destinations around the world. More recently, antennas serve as vital components on pagers and cellular phones, devices that are a part of a wireless revolution that is still evolving as we speak today. The brief introduction on antennas serves to demonstrate the wide variety and uses of antennas in operation today. In this sense, it can be said that antennas serve as link to our past and the key to our future.

More recently, a great deal of attention has been devoted to a class of antennas that can be classified as planar antennas. As the name implies, planar antennas are antennas that can be entirely fabricated on one plane. Typically, these antennas are fed by microstrip line, coplanar stripline (CPS), or coplanar waveguide (CPW) feeding structures.

Planar antennas provide a number of advantages over other non-planar antennas. First, planar antennas are typically more compact in size and thus lighter in weight than non-planar antennas. These characteristics simplify design and manufacturing requirements, which inturn lowers the overall manufacturing costs. In many applications, these compact and low profile antennas offer an inexpensive solution to previous generations of waveguide or reflector-based antennas systems. Second, due to planar nature of these structures, these antennas are easily amenable to different contours and shapes. As proof, planar antennas today can be found conformably mounted against the side of buildings and even integrated onto the exterior of the aircraft. The flexibility of planar antennas is further demonstrated by the fact that they are readily integrated with microwave circuit components. Finally, an addition benefit that arises from uni-planar nature of these antennas is that they can be easily synthesized in array configurations 
without many of the issues and uncertainties that go along with non-planar or more complex antenna structures. This is particularly true for arrays to be operated at higher microwave frequency ranges. It would not be improper to mention that development of planar antenna technology and fundamentally changed the microwave communication fields.

\subsection{Thesis Outline}

In this thesis, a broadband U-slot Rectangular Patch Antenna is examined. All this antenna structures are analyzed using FDTD method and XFDTD software (from REMCOM) is used for the purpose.

Chapter 2 introduces the basic concepts of the FDTD method and MoM techniques and compares the two.

Chapter 3 discusses some of the most popular planar antenna structures in use for personal communication devices. Among the antennas discusses are strongly resonant antennas such as the patch antenna. A single coax-fed patch antenna is simulated and its parameters are studied in detail in this chapter.

Chapter 4 investigates the broadband U-slot Rectangular Patch Antennas. The fundamental operation of the U-slot antenna is explained, and the most relevant characteristics of the antenna under investigation are thoroughly investigated.

Chapter 5 concludes the thesis by comparing the various results obtained during the analysis of the antenna. 


\section{CHAPTER 2}

\section{GENERAL ANALYSIS METHODS}

This chapter describes the general numerical methods used to model the problem geometries discussed in this thesis. The basics of Finite Difference Time Domain (FDTD) and Method of Moments (MoM) techniques are discussed here. The geometries best suited to each method are also discussed.

Hence, this chapter aims at the introduction of two of the most popular numerical methods for problem solving in Electromagnetics.

\subsection{FDTD Fundamentals}

The Finite Difference Time Domain (FDTD) technique is one of the most popular means of analyzing transient and frequency-domain electromagnetic problems [3][4]. Due to its formulation, it can be used to model combinations of several materials configured in arbitrary structures. In addition, because the results are in time domain, they can be Fourier transformed to the frequency domain, yielding information over a wide range of frequencies. Another advantage of this method is the absence of matrices, which are typically found in other techniques, thereby eliminating the need for extensive matrix inversion techniques.

The finite difference method was first suggested by Yee in 1966 [2], but was dismissed as an accurate but impractical numerical method due to the state of computational systems at that time. With the explosive growth of computational power, 
the method was reconsidered in the early 1990's and has now become the most popular numerical technique for electromagnetic simulations.

Background information on FDTD method, sufficient for an understanding of the proposed hybrid technique, is presented in this section. For additional information references [3] and [5] can be consulted.

\subsubsection{Difference Equations}

The FDTD technique is based on Maxwell's curl equations (2.1) and (2.2), which describe the behavior of fields at all coordinates and at all times.

$$
\begin{aligned}
& \nabla \times E=-\frac{\partial B}{\partial t} \\
& \nabla \times H=-\frac{\partial D}{\partial t}+J
\end{aligned}
$$

Where,

$$
\begin{aligned}
& D=\varepsilon E \\
& B=\mu H
\end{aligned}
$$

The terms $D$ and $B$ are the electric and magnetic flux densities, $J$ is the current density and $E$ and $H$ are the electric and magnetic fields, respectively. The permittivity and permeability denoted as $\varepsilon$ and $\mu$, respectively, in the above relations can be expressed as second-order tensors to accommodate the general case of anisotropic materials and can 
also be time varying. However, for the time-varying case, a time convolution technique is required [6] within the conventional FDTD algorithm.

In the FDTD method, the equation (2.1) and (2.2) are transformed into equivalent difference equations. The curl of the magnetic field $H$ in Cartesian coordinates is given by

$$
\nabla \times H=\hat{x}\left(\frac{\partial H_{z}}{\partial y}-\frac{\partial H_{r}}{\partial z}\right)+\hat{y}\left(\frac{\partial H_{x}}{\partial z}-\frac{\partial H_{z}}{\partial x}\right)+\hat{z}\left(\frac{\partial H_{r}}{\partial x}-\frac{\partial H_{x}}{\partial y}\right)
$$

Derivatives in equation are converted to difference equations as follows,

$$
\frac{\partial H_{z}}{\partial_{r}} \rightarrow \frac{H_{z}\left(x, y+\frac{\Delta y}{2}, z ; t\right)-H_{z}\left(x, y+\frac{\Delta y}{2}, z ; t\right)}{y}
$$

The curl of the electric field $E$ in the equation (2.1) is also expanded in the manner shown for the field in equation (2.5).

Following the above transformation, the right hand side of equation (2.1) and (2.2) can be expressed in difference equation form, in which the material is assumed isotropic, as follows:

$$
\begin{aligned}
& J(r, t)+\varepsilon(r) \frac{\partial}{\partial t} E(r, t) \rightarrow J(r, t)+\varepsilon(r) \frac{E\left(r, t+\frac{\Delta t}{2}\right)-E\left(r, t-\frac{\Delta t}{2}\right)}{\Delta t} \\
& -\mu(r) \frac{\partial}{\partial t} H(r, t) \rightarrow-\mu(r) \frac{H\left(r, t+\frac{\Delta t}{2}\right)-H\left(r, t-\frac{\Delta t}{2}\right)}{\Delta t}
\end{aligned}
$$


The spatial derivatives contained in the curl of the magnetic field shown in equation (2.5) are approximated as in equation (2.6) for each component, while equation (2.7) and (2.8) show the time derivatives in difference equation form.

The difference equations shown in (2.7) and (2.8) are in the form known as central differences, as both the time and spatial derivatives are centered about the coordinates of interest (i.e., the time and spatial derivatives are centered about time $\mathrm{t}$ and coordinates $(x, y, z)$, respectively). This numerical approximation of the derivative results in second order accuracy: a decrease in the discretization size (time or space) by a factor $k$ improves the accuracy of the calculation by the factor $k^{2}$. The FDTD update equations for electric fields located within isotropic materials appear in the equations (2.9)-(2.11),

$$
E_{x, i, j, k}^{n+1}=E_{x, i, j, k}^{n}+\frac{\Delta t}{\varepsilon \cdot \Delta y}\left(H_{z, i, j+1, k}^{n+\frac{1}{2}}-H_{z, i, j, k}^{n+\frac{1}{2}}\right)-\frac{\Delta t}{\varepsilon \cdot \Delta z}\left(H_{y, i, j, k+1}^{n+\frac{1}{2}}-H_{y, i, j, k}^{n+\frac{1}{2}}\right)
$$

$$
E_{y, i, j, k}^{n+1}=E_{y, i, j, k}^{n}+\frac{\Delta t}{\varepsilon \cdot \Delta z}\left(H_{x, i, j, k+1}^{n+\frac{1}{2}}-H_{x, i, j, k}^{n+\frac{1}{2}}\right)-\frac{\Delta t}{\varepsilon \cdot \Delta z}\left(H_{z, i+1, j, k}^{n+\frac{1}{2}}-H_{z, i, j, k}^{n+\frac{1}{2}}\right)
$$

$$
E_{z, i, j, k}^{n+1}=E_{z, i, j, k}^{n}+\frac{\Delta t}{\varepsilon \cdot \Delta x}\left(H_{y, i+1, j, k}^{n+\frac{1}{2}}-H_{y, i, j, k}^{n+\frac{1}{2}}\right)-\frac{\Delta t}{\varepsilon \cdot \Delta z}\left(H_{x, i, j+1, k}^{n+\frac{1}{2}}-H_{x, i, j, k}^{n+\frac{1}{2}}\right)
$$

In the above equations the subscripts and superscripts represent the polarization direction and time index, respectively. 
The update equations for magnetic fields located within isotropic materials are given in equations (2.12)-(2.14)

$$
\begin{aligned}
& H_{x, i, j, k}^{n+\frac{1}{2}}=H_{x, i, j, k}^{n-\frac{1}{2}}+\frac{\Delta t}{\mu \cdot \Delta z}\left(E_{y, i, j, k}^{n}-E_{y, i, j, k-1}^{n}\right)-\frac{\Delta t}{\mu \cdot \Delta y}\left(E_{z, i, j, k}^{n}-E_{z, i, j-1, k}^{n}\right) \\
& H_{y, i, j, k}^{n+\frac{1}{2}}=H_{y, i, j, k}^{n-\frac{1}{2}}+\frac{\Delta t}{\mu \cdot \Delta x}\left(E_{z, i, j, k}^{n}-E_{y, i-1, j, k}^{n}\right)-\frac{\Delta t}{\mu \cdot \Delta y}\left(E_{x, i, j, k}^{n}-E_{z, i, j, k-1}^{n}\right) \\
& H_{z, i, j, k}^{n+\frac{1}{2}}=H_{z, i, j, k}^{n-\frac{1}{2}}+\frac{\Delta t}{\mu . \Delta y}\left(E_{x, i, j, k}^{n}-E_{x, i, j-1, k}^{n}\right)-\frac{\Delta t}{\mu \cdot \Delta y}\left(E_{y, i, j, k}^{n}-E_{z, i-1, j, k}^{n}\right)
\end{aligned}
$$

\subsubsection{Yee Cell}

In the conversion from differential to difference equations, both time and space are transformed from a continuum of infinitesimal point coordinates into discrete cells with finite dimensions. The convention adopted by FDTD researchers to define these discrete field locations and polarizations is known as Yee cell, named in honor of the researcher who devised this numerical technique [2]. 


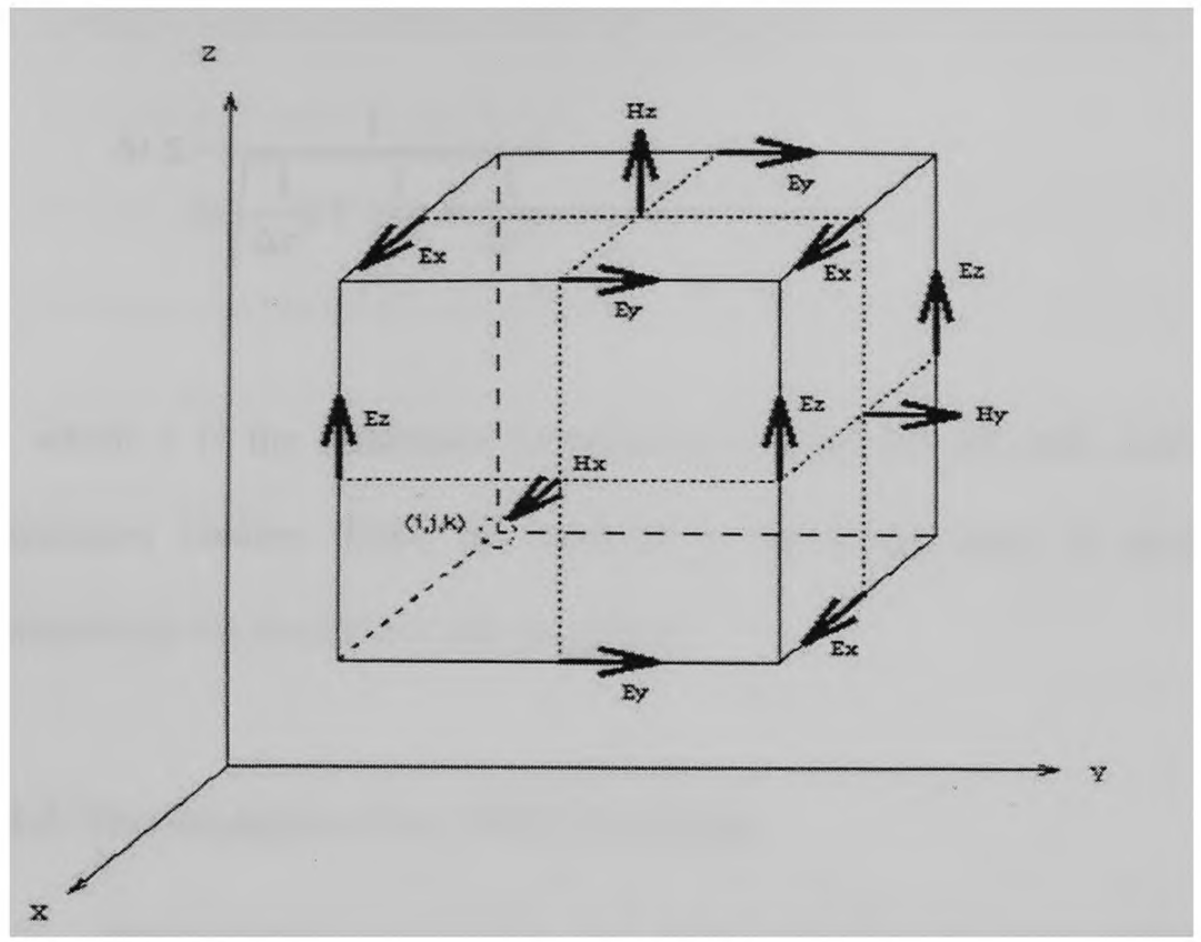

Fig.1 2-D Yee Cell [2]

Only a few representative fields have been labeled for the sake of clarity. The coordinate indexing scheme denotes cells in the $\mathrm{x}, \mathrm{y}$, and $\mathrm{z}$ directions as integer indices $\mathrm{i}$, $\mathrm{j}$, and $\mathrm{k}$ respectively. The cell dimensions are $\Delta \mathrm{x}^{*} \Delta \mathrm{y}^{*} \Delta \mathrm{z}$ which can vary as a function of $\mathrm{x}, \mathrm{y}$, and $\mathrm{z}$ to more closely conform to objects with curved edges or surfaces. For accurate simulations, cells with edges of length $\lambda_{\mathrm{m}} / 10$ or less is required with $\lambda_{\mathrm{m}} / 20$ as the recommended maximum size $\left(\lambda_{\mathrm{m}}\right.$ is the wavelength of an isotropic material contained within the cell of interest). This discretization allows a sufficient number of field samples as a function of spatial distance, to yield an accurate representation of the actual field. In addition, the time increment used for the simulation must be set below a maximum value to ensure numerical stability. The relation that must be satisfied is known as the courant stability condition [3], and is expressed as 


$$
\Delta t \leq \frac{1}{c \sqrt{\frac{1}{\Delta x^{2}}+\frac{1}{\Delta y^{2}}+\frac{1}{\Delta z^{2}}}}
$$

in which $\mathrm{c}$ is the minimum propagation velocity for all cells contained within the simulation volume. Thus, all materials in the model must be accounted for when determining the maximum time increment.

\subsubsection{The strengths of the FDTD Technique}

Every modeling technique has some strengths and some weaknesses [4]. Some types of models were a given technique will excel and some types of models were the same technique will have difficulty (if it is even possible to use) performing rapidly and accurately.

- FDTD is a very versatile modeling technique. It is a very intuitive technique, so users can easily understand how to use it, and know what to expect from a given model.

- FDTD is a time domain technique, and when a time-domain pulse (such as a Gaussian pulse) is used as the source pulse, then a wide frequency range is solved with only one simulation. This is extremely useful in applications where resonant frequencies are not known exactly or anytime that a broadband result is desired.

- Since FDTD is a time-domain technique, which finds the $\mathrm{E} / \mathrm{H}$ fields everywhere in the computational domain, it lends itself to providing animation displays (movies) of the E/H field movement throughout the model. This type of display is extremely 
useful to understanding exactly what is going on in the model, and to help insure that the model is working correctly.

- FDTD allows the user to specify the material at all points within the computational domain. All materials are possible and dielectrics, magnetic materials, etc. can be simply modeled without the need to resort to 'work arounds' or 'tricks' to model these materials.

- FDTD allows the effects of apertures to be determined directly. Shielding effects can be found, and the fields both inside and outside a structure can be found directly.

- FDTD provides the $\mathrm{E}$ and $\mathrm{H}$ fields directly. Since most EMLEMC modeling applications are interested in the E/H fields, it is best that no conversions must be made after the simulation has run to get these values.

- Since the computational domain must end at some point (or we would be modeling the entire universe!), a boundary must be established. FDTD has a number of very good absorbing boundary conditions to chose from (and some that are not quite so good). The absorbing boundary condition $(\mathrm{ABC})$ simulates the effect of free space beyond the boundary forever.

\subsubsection{The weaknesses of the FDTD Technique}

- Since FDTD requires that the entire computational domain be gridded, and these grids must be small compared to the smallest wavelength and smaller than the smallest feature in the model, very large computational domains can be developed, which result in very long solution times. Models with long, thin features, (like wires) 
are difficult to model in FDTD because of the excessively large computational domain required.

- FDTD finds the E/H fields directly everywhere in the computational domain. If the field values at some distance (like 10 meters away) are desired, it is likely that this distance will force the computational domain to be excessively large. Far field extensions are available for FDTD, but require some amount of post processing.

XFDTD is the professional version of program of FDTD by Remcom Inc. In general the steps of XFDTD calculation are

- Create geometry

- Set up the input simulation

- Start the simulation and do post processing including drawing conclusion For the input stimulus there are three broad types of input stimulus.

- Near zone sources

- Incident plane wave

- TEM excitation

The most commonly used are the near sources including current and voltage sources. Incident plane wave excitation is useful where scattering or absorption by the object are desired. TEM excitation mode is used with a special class of geometry and requires a suitable geometry for propagation. 
For every type of input stimulus the excitation for FDTD calculation may be a

- Gaussian pulse (provides broad band frequency response)

- Gaussian derivative pulse (same as Gaussian pulse except DC response removed)

- Modulated Gaussian pulse (for a specific frequency range response and other frequency ranges can destroy the results)

- User defined pulse (useful whenever only one frequency response is required)

\subsection{MoM Fundamentals}

The Method of Moments (MoM) has been in use for many years for a wide variety of applications. It is more computationally efficient method to FDTD algorithm for homogeneous objects. The reason is that the MoM technique discretizes only the surface of objects as opposed to a volumetric cell discretization of the entire simulation domain as in FDTD method. It is very commonly used to analyze antenna structures and a number of different applications. The MoM technique is a frequency domain technique. It will only analyze a single frequency at a time, although most popular software codes allow the solution to iterate over a number of frequencies [7].

\subsubsection{The MoM Procedure [7]}

Suppose that $\mathrm{L}$ is a linear operator and the following linear operator equation holds,

$$
\begin{gathered}
L(f)=g \\
g(x, y, z, \varpi), f(x, y, z, \varpi)
\end{gathered}
$$


Here,

$L$ is a linear operator (like integro-differential operator),

$G$ is the known function (like impressed field or voltage),

$F$ is the unknown (like distribution of electric current),

Now expanding $f$ as a series of functions, we have

$$
f=\sum_{n=1}^{N} \alpha_{n} f_{n}
$$

For approximate solutions equation (2.17) is a finite summation.

Since $L$ is a linear operator, substituting equation (2.17) in 2.16) gives us

$$
\sum_{n=1}^{N} \alpha_{n} L\left(f_{n}\right)=g
$$

The next step is to define a suitable linear product $<\mathrm{a}, \mathrm{b}>$.

$$
\langle a, b\rangle=\int_{s} a b d s
$$

The above integral is taken over the space S (e.g. the surface of the conducting body) Now we define a set of weighing (testing) functions $\mathrm{w}_{\mathrm{b}}$ in the range of $L$, and take the inner product of equation (2.18). So, we get

$$
\sum_{n=1}^{N} \alpha_{n}\left\langle w_{m}, L\left(f_{n}\right)\right\rangle=\left\langle w_{m}, g\right\rangle
$$

The problem is simplified to solve a set of linear equations, which can be written in matrix form,

$$
\left[l_{m n}\right]\left[\alpha_{n}\right]=\left[g_{m}\right]
$$

Where, $\left[\alpha_{n}\right]$ will be given by,

$$
\left.\left[\alpha_{n}\right]=\left[l_{n m}^{-1}\right] g_{m}\right]
$$


The solution for $f$ can be written as

$$
f=\left[\tilde{f}_{n}\right]\left[\alpha_{n}\right]=\left[\tilde{f}_{n}\right]\left[l_{n m}^{-1}\right]\left[\left[g_{m}\right]\right.
$$

Where, $\left[\tilde{f}_{n}\right]=\left[f_{1} f_{2} f_{3} \ldots \ldots ..\right]$

This solution may be exact or approximate depending upon the choice of $f_{n}$ and $w_{n}$. So, the choice of $f_{n}$ and $w_{n}$ is the main task in solving any problem. $f_{n}$ and $w_{n}$ should be linearly independent and chosen so that some superposition (eq. 2.17) can approximate $f$ reasonably well.

The particular choice of $w_{n}=f_{n}$ is known as Galerkin's method. This method is the basis of the MoM software used in this thesis. Existing numerical codes indicate that Galerkin's method yields numerical results more accurate than other MoM's under similar computational constraints. Examples include the analysis of rectangular plate structures in which Galerkin's method converges faster than point matching. In addition it is particular noteworthy that MoM solutions of waveguides, phased arrays, and periodic structures are predominantly of the Galerkin's type [7]. An advantage of the Galerkin's method is that when real-valued basis functions are used, both reciprocity and conservation of energy are preserved in the approximation in a Galerkin solution. Under certain assumptions, it can be shown that Galerkin's method lead to a solution approaching the exact solution [7].

A final advantage of the Galerkin's method, which has not been recognized in the mathematical literature, is the circumvention of source singularity inherent in MoM integral equations [7]. 


\subsubsection{The MoM Technique}

The MoM technique requires that the entire structure to be modeled be broken down into wires and/or metal plates. Each wire is subdivided to a number of wire segments, which must be small, compared to the frequency's wavelength (so that the assumption of a constant value of current across that wire segment is valid). Each metal plate is subdivided into a number of surface patches, which must be small compared to wavelength (again so the assumption of constant current is valid).

Once the model is defined, a source is imposed (a plane wave approaching, or a voltage source on one of the wire segments). The MoM technique is used to determine the current on every wire segment and surface patch due to the source and all other currents (or the other wire segments and surface patches). Once these currents are known, then the $\mathrm{E}$ field at any point in space is determined from the sum of all the contributions from all the wire segments and surface patches.

\subsubsection{The Strengths of MoM Technique}

- MoM is a very versatile modeling technique. It is also a very intuitive technique, so users can easily understand how to use it, and know what to expect from a given model. Users can picture the RF currents on a structure and understand how they would lead to an $\mathrm{E} / \mathrm{H}$ field.

- MoM models only the metal structure, and not the space around it. Therefore, long wires are easily modeled using MoM. 
- Since MoM is a frequency domain technique, it can solve problems very quickly if only one frequency is desired. If multiple frequencies are desired, then the simulation will take longer, but still solutions are often available is a short amount of time.

- MoM allows discrete components to be inserted into a model by simply defining the impedance desired on any given wire segment. This can be useful when analyzing the effect of filter location, etc.

\subsubsection{The weaknesses of MoM Technique}

- Although MoM is very easy to use for wires and metal plates, it is very difficult to use for dielectric and special magnetic materials. Special solution techniques do exist to allow dielectric in a MoM solution, but these are not widely implemented and care must be taken when they are used.

- MoM assumes the current on a wire segment, or on a surface patch to be the same throughout the conductor's depth. Therefore, using MoM to determine the effect of an aperture with fields both inside and outside is difficult.

- MoM is a frequency domain technique, therefore, if a wide frequency range is desired in the solution, the simulation must run a number of times. If the frequency step size is not sufficiently small, important effects (e.g. resonance) may be overlooked. 


\section{CHAPTER 3}

\section{PLANAR ANTENNA STRUCTURES}

As mentioned earlier, planar antenna structures offer many advantages over nonplanar structures. First, the uniplanar nature of these structures makes them much easier to fabricate, especially in large volumes. Passive antenna topologies can be constructed as simply and inexpensively as etching away metal on dielectric boards. In addition, transmission lines structures for planar antenna technology are generally well understood and easily employed in planar antenna designs.

In planar antenna technology, there are numerous antenna topologies to choose from. The choice of antenna depends upon the individual system specifications and criteria that need to be satisfied. In some cases, the choice will be dictated simply by the locations of the source and receiver. Antennas that radiate towards broadside have their main beam aligned along an axis that is perpendicular to the plane of antenna itself. On the other hand, antennas that radiate towards endfire have their main beam aligned along an axis that is parallel to the plane of antenna itself. Certain applications may require a broadband antenna, where the antenna must work over a specified frequency range. Here, strongly resonant antenna structures, which work only in a narrow frequency range, cannot be used. Due to these considerations it becomes important to be aware of the properties of various antenna topologies. 


\subsection{Microstrip Patch Antennas}

A microstrip antenna in its simplest configuration consists of a radiating patch on one side of the dielectric substrate $\left(\varepsilon_{\mathrm{r}}<=10\right)$, which has the ground plane on the other side [8]. The patch conductors normally of copper and gold can assume virtually any shape, but regular shapes are generally used to simplify analysis and performance prediction. Ideally the dielectric constant of the substrate should be low $\left(\varepsilon_{\mathrm{r}}<2.5\right)$. To enhance the fringe fields that account for radiation. However, other performance requirements may dictate the use of substrate materials whose dielectric constants can be greater than four.

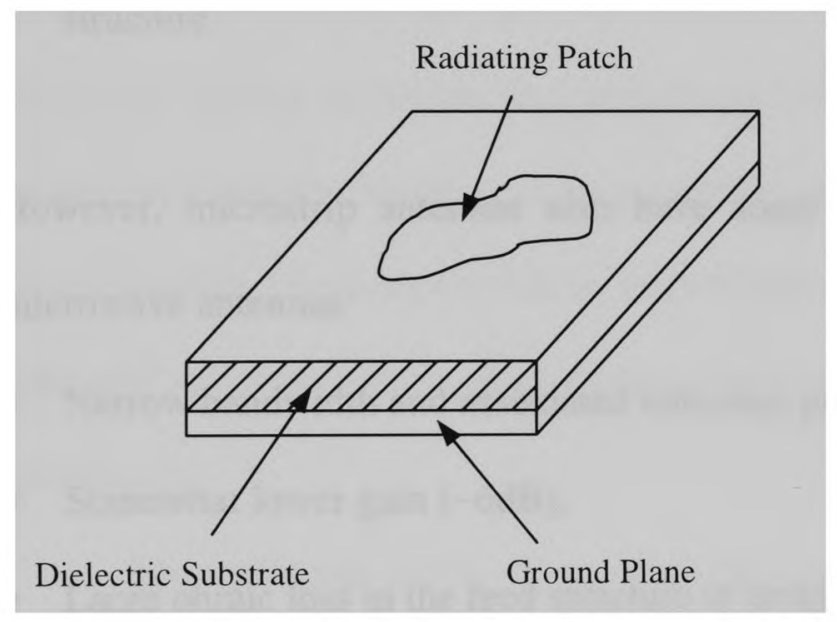

Fig.2 Microstrip Antenna Configuration

\subsubsection{Advantages and Limitations of Microstrip Antennas}

Microstrip antennas have several advantages compared to conventional microwave antennas, and therefore many applications cover the broad frequency range from $100 \mathrm{MHz}$ - $100 \mathrm{GHz}$. Some principal advantages of microstrip antennas compared to conventional microwave antennas are [8]: 
- Light weight, Low volume, and thin profile configurations, which can be made conformal;

- Low fabrication cost; readily amenable to mass production;

- Linear and circular polarization's are possible with simple feed;

- Dual-frequency and dual polarization antennas can be easily made;

- No cavity backing is required;

- Can be easily integrated with microwave integrated circuits;

- Feed lines and matching networks can be fabricated simultaneously with the antenna structure.

However, microstrip antennas also have some limitations compared to conventional microwave antennas:

- Narrow bandwidth and associated tolerance problems;

- Somewhat lower gain ( 6dB);

- Large ohmic loss in the feed structure of arrays;

- Most microstrip antennas radiate into half space;

- Complex feed structures required for high performance arrays;

- Polarization purity is difficult to achieve;

- Poor end-fire radiator. Except tapered slot antennas;

- Extraneous radiation from feeds and junctions;

- Lower power handling capability ( 100W); 
- Reduced gain and efficiency as well as unacceptably high levels of cross- polarization and mutual coupling within an array environment at high frequencies;

- Excitation of surface waves;

- Microstrip antennas fabricated on a substrate with high dielectric constant are strongly preferred for easy integration with MMIC RF front-end circuitry. However use of high dielectric constant substrate leads to poor efficiency and narrow bandwidth.

There are ways to minimize the effect of some of these limitations. For example, bandwidth can be increased to more than $60 \%$ by using special techniques like suitable choice of feeding technique and impedance matching network; lower gain and lower power handling limitations can be overcome through an array configuration. Surface wave-associated limitations such as poor efficiency, increased mutual coupling, reduced gain and radiation pattern degradations can be overcome by the use of photonic gap structures.

The radiating patch of a microstrip antenna can be shaped in a variety of configurations including rectangular, circular, elliptical and triangular. The rectangular patch antenna is the most commonly used of those mentioned.

Different feeding methods also give rise to differences in microstrip performance. The four commonly used feed techniques are, edge-fed, coaxial or probe fed, proximity coupled fed and aperture coupled fed. 


\subsubsection{Methods of Analysis}

Microstrip patch antennas have been analyzed using a variety of techniques. Three well-known methods are transmission line model, cavity model and full wave model.

\section{(A) Transmission Line Model}

The transmission line model is the simplest of the three techniques and, as a result, is the least accurate [9]. Since the transmission-line model accounts for the fringing effects at the edges of the patch, it provides a good characterization of the resonant frequency. It also models the input impedance of the antenna fairly accurately. However, it does not account for the affects of a truncated dielectric substrate or a finite ground plane nor does it provide insight into the radiation patterns of the antenna. Additionally, the model breaks down, as the dielectric substrate becomes a significant portion of the wavelength.

(B) Cavity Model

In order to gain insight into the radiating mechanism of an antenna, we need to first understand the near-field quantities that are present on the structure. The cavity model aids in this pursuit since it provides a mathematical solution for the electric and magnetic fields of a microstrip antenna. It does so by using a dielectrically loaded cavity to represent antenna. Although the cavity model is quite adept at modeling the radiating mechanism for a microstrip antenna, it does have some limitations [9]. First the cavity 
model does not model the feed effects. Nor does it model the adverse effects introduced by a finite substrate and ground plane. One way to circumvent these limitations is to employ numerical techniques.

(C) Full-Wave Numerical Models

In some instances, we may need to understand how the behavior of an antenna is affected by its surroundings, like a feed structure, a finite ground plane, or a case enclosure. For problems such as these, the techniques described above become highly impractical. For problems like these numerical analysis techniques like the method of moments (MoM), the finite-element method (FEM), and the FDTD method need to be used. The details of each technique are quite intricate, and Chapter 2 was entirely devoted to these numerical techniques in Electromagnetics. 


\subsubsection{Coax Fed Microstrip Patch Antenna}
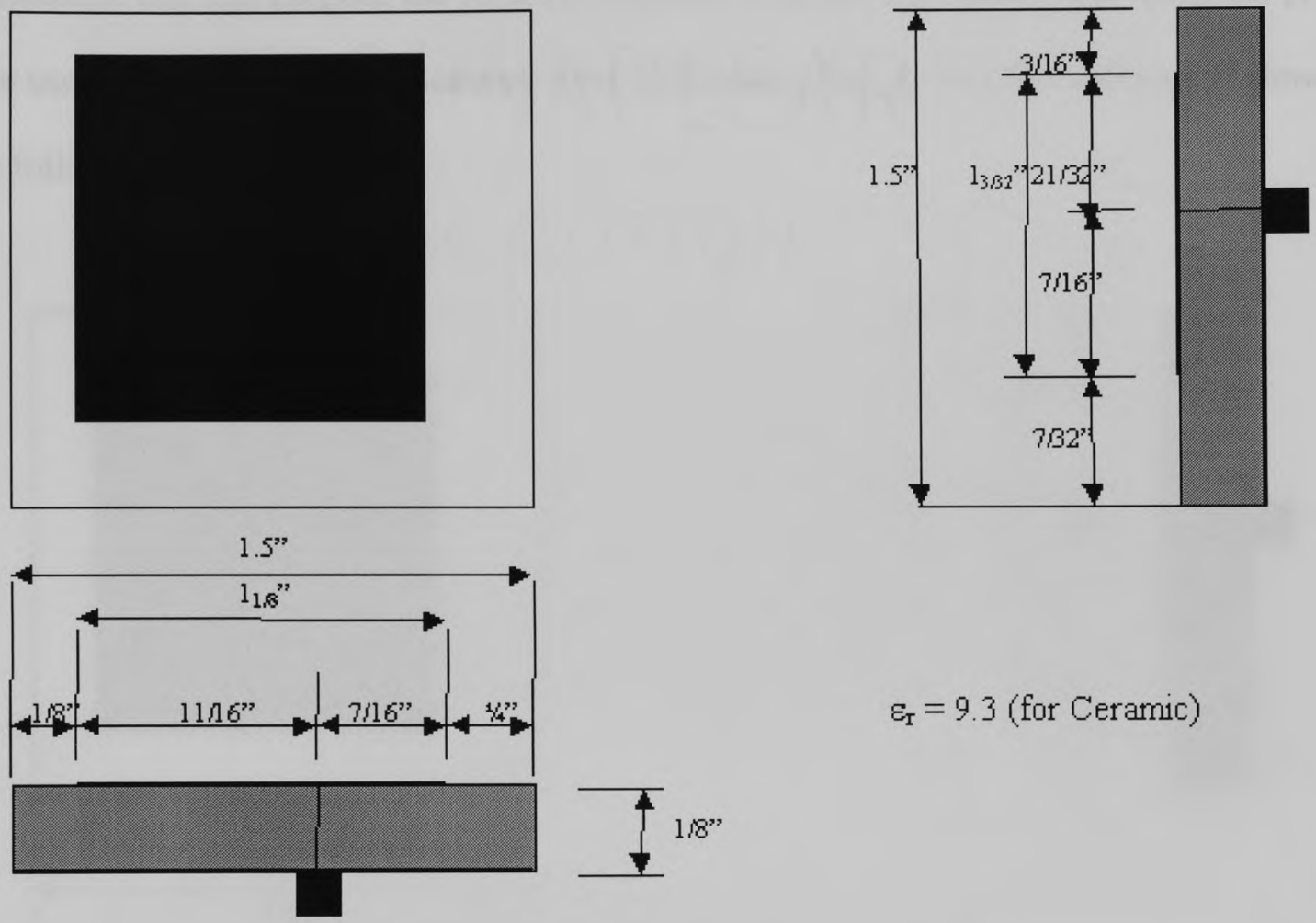

$\varepsilon_{\mathrm{T}}=9.3$ (for Ceramic)

Fig. 3 Geometry of Coaxial line fed Microstrip Patch Antenna [16] 
The above antenna is analyzed using both the FDTD method and Method of Moments. For this purpose the XFDTD software [10] and the MultiSTRIP program [11] are used respectively. The geometry used for creating files in XFDTD software is shown as follows.

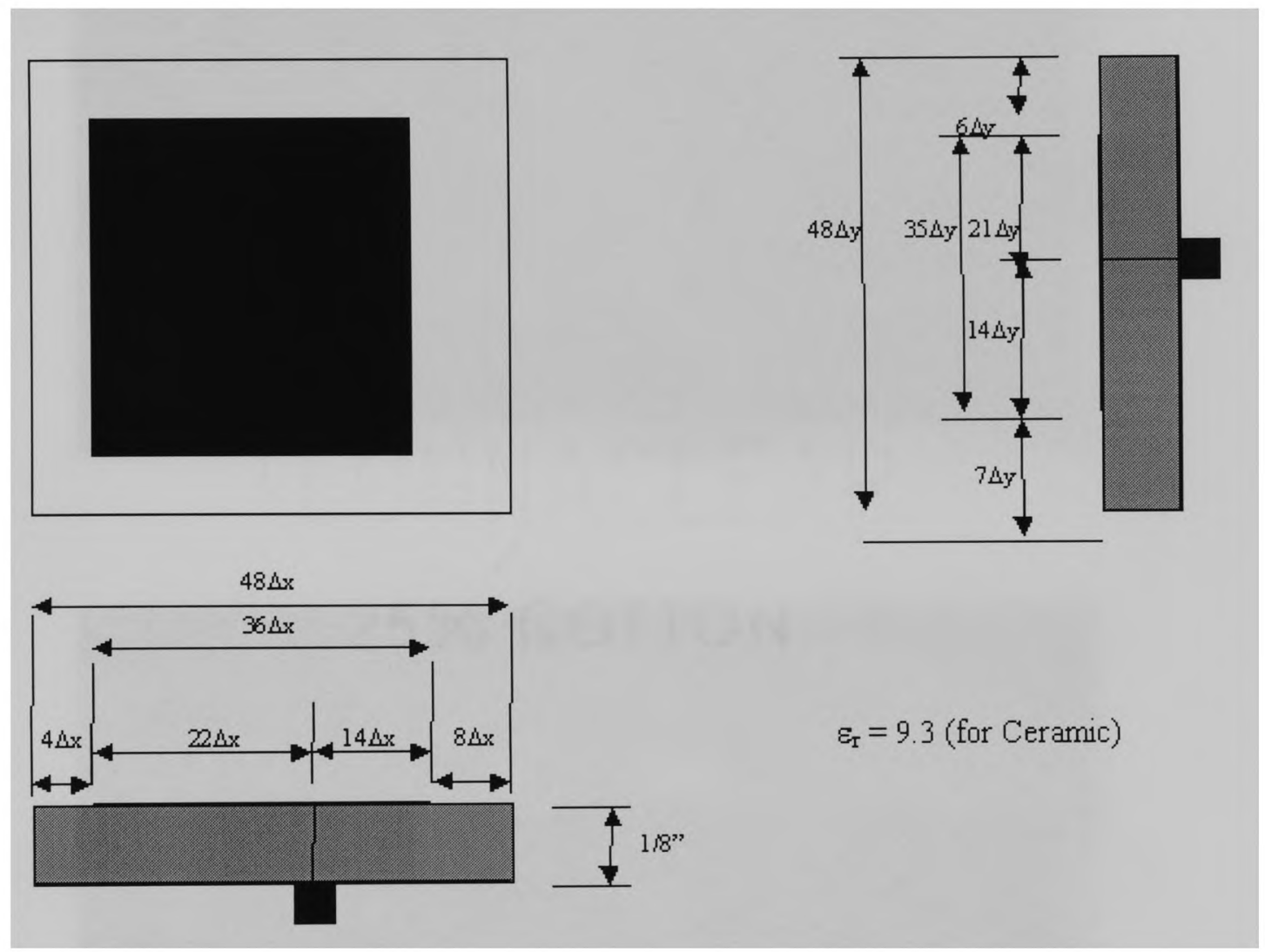

Fig.4 Geometry of Coaxial line fed Microstrip Patch Antenna for XFDTD Simulation

Using the above geometry as the basis, geometry is created in XFDTD, which is used for actual simulation.

The geometry file created in XFDTD is shown in Figure 5. A modulated Gaussian pulse is used for excitation, and the frequency is specified as $1.63 \mathrm{GHz}$. 

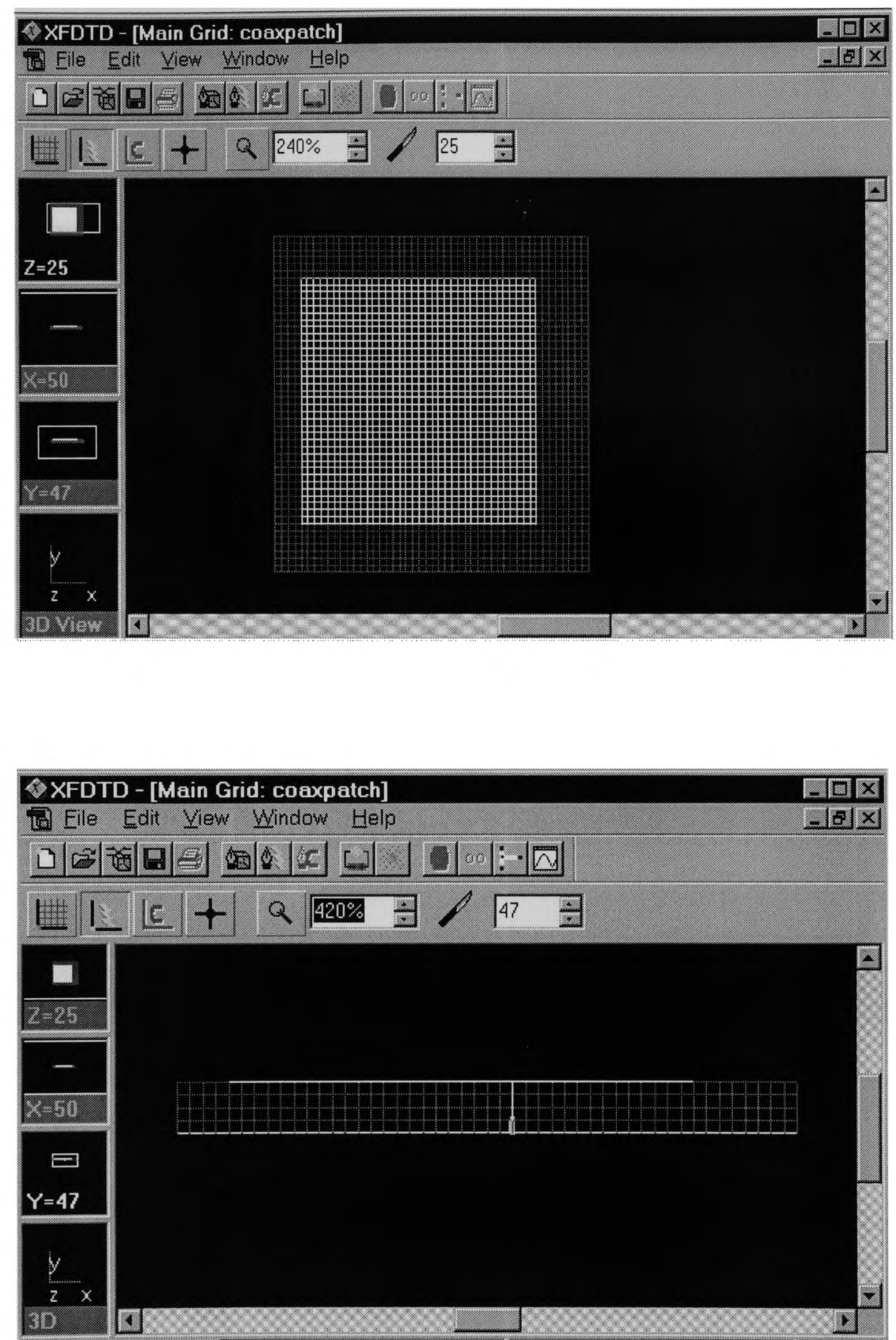

Fig.5 X-Y plane (Top), X-Z plane (Bottom) 
The following Figures 6 and 7 show the results of the simulations performed using the XFDTD software for the antenna with the geometry shown above. Figure 6 shows that the antenna is resonant at about $1.6 \mathrm{GHz}$.

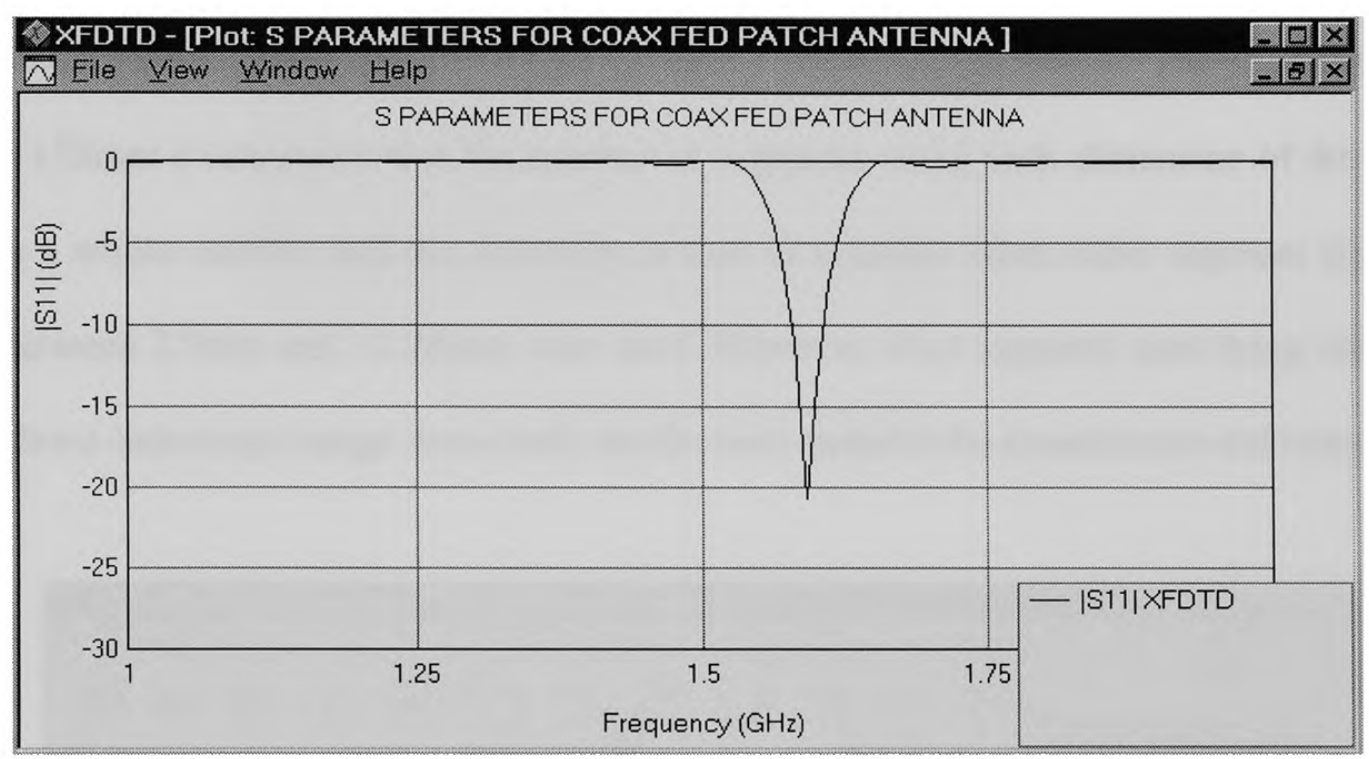

Fig.6 IS11I Vs Frequency for Single Coax fed Patch Antenna

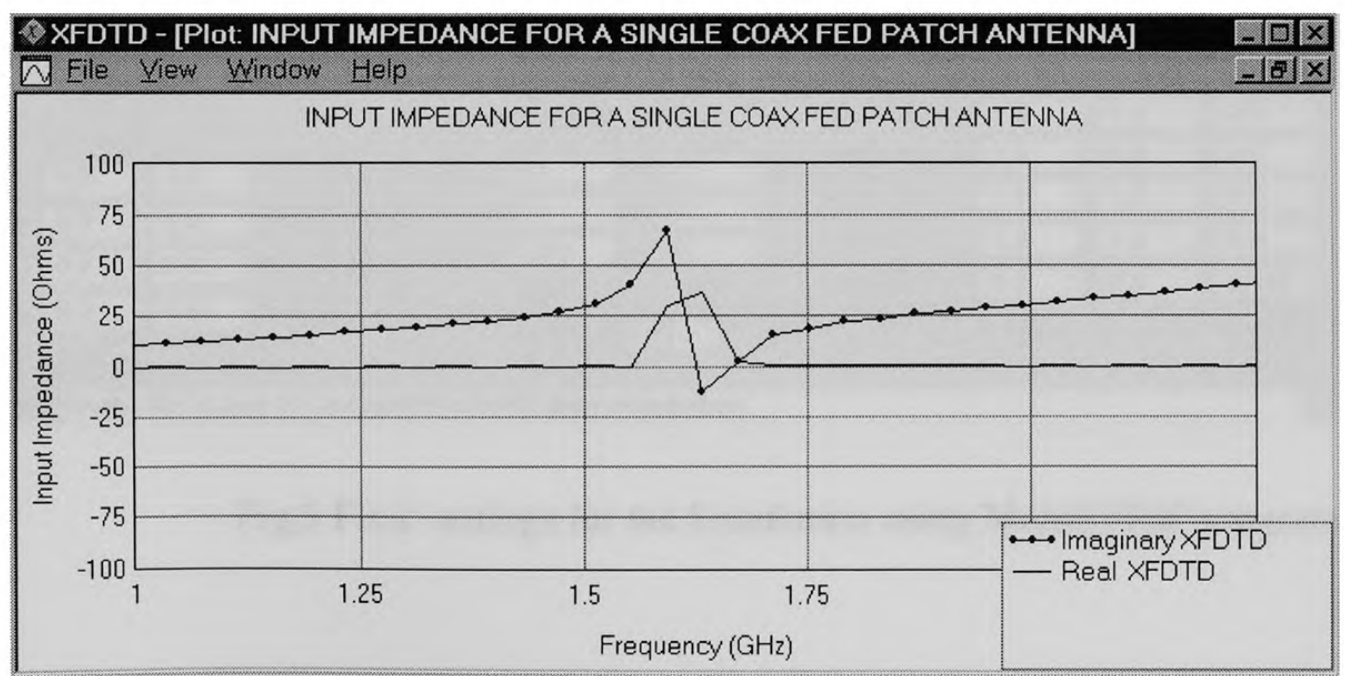

Fig.7 Input Impedance Vs Frequency for Single Coax fed Patch antenna 
Now the simulations are repeated using the MultiSTRIP program. Here, the segment size for both $\mathrm{x}$ and $\mathrm{y}$ directions are chosen as $3.175 \mathrm{~mm}$. For this particular software, for the results to be accurate, the segment size should lie between $1 / 5$ and $1 / 20$ of the wavelength in the dielectric. Here the wavelength in the dielectric is $181.81 \mathrm{~mm}$ and so the segment size should lie between $2.9 \mathrm{~mm}$ and $11.98 \mathrm{~mm}$. The segment size of $3.175 \mathrm{~mm}$ is chosen so that the number of segments along each dimension of the antenna is a whole number and the geometry is thus as accurate when other segment sizes lying between $2.9 \mathrm{~mm}$ and $11.98 \mathrm{~mm}$ were used. However when segment sizes lying outside the above-mentioned range were used, results were found to be inconsistent and inaccurate.

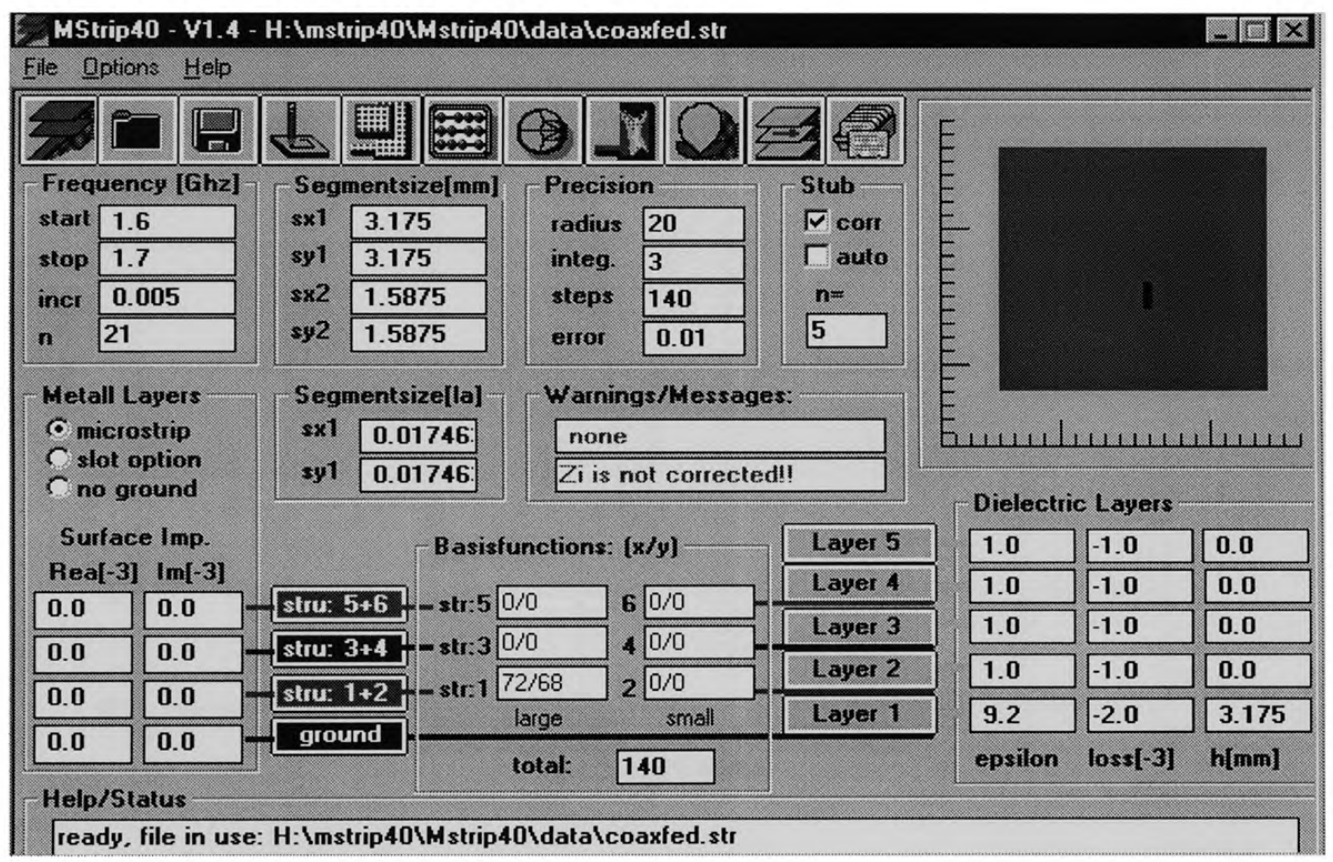

Fig.8 Final settings for the Simulation using MultiSTRIP program 


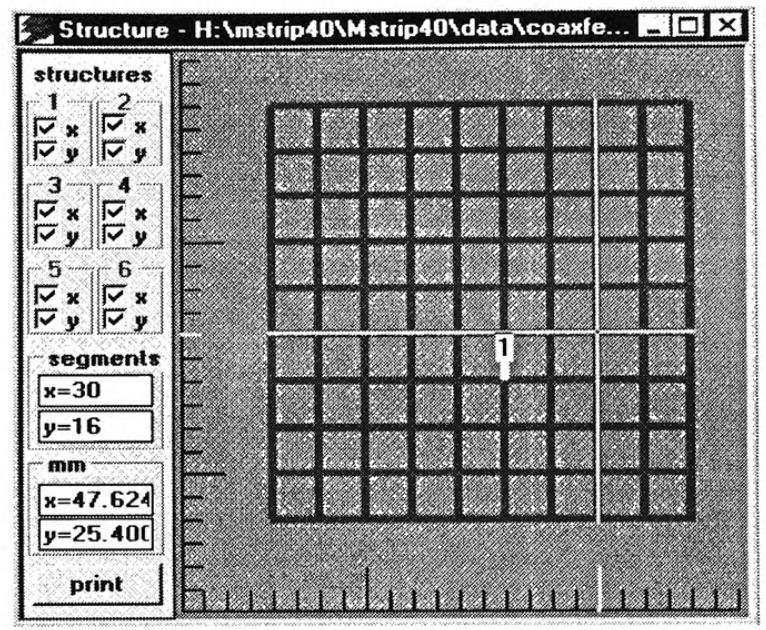

Fig.9 Details of the Geometry

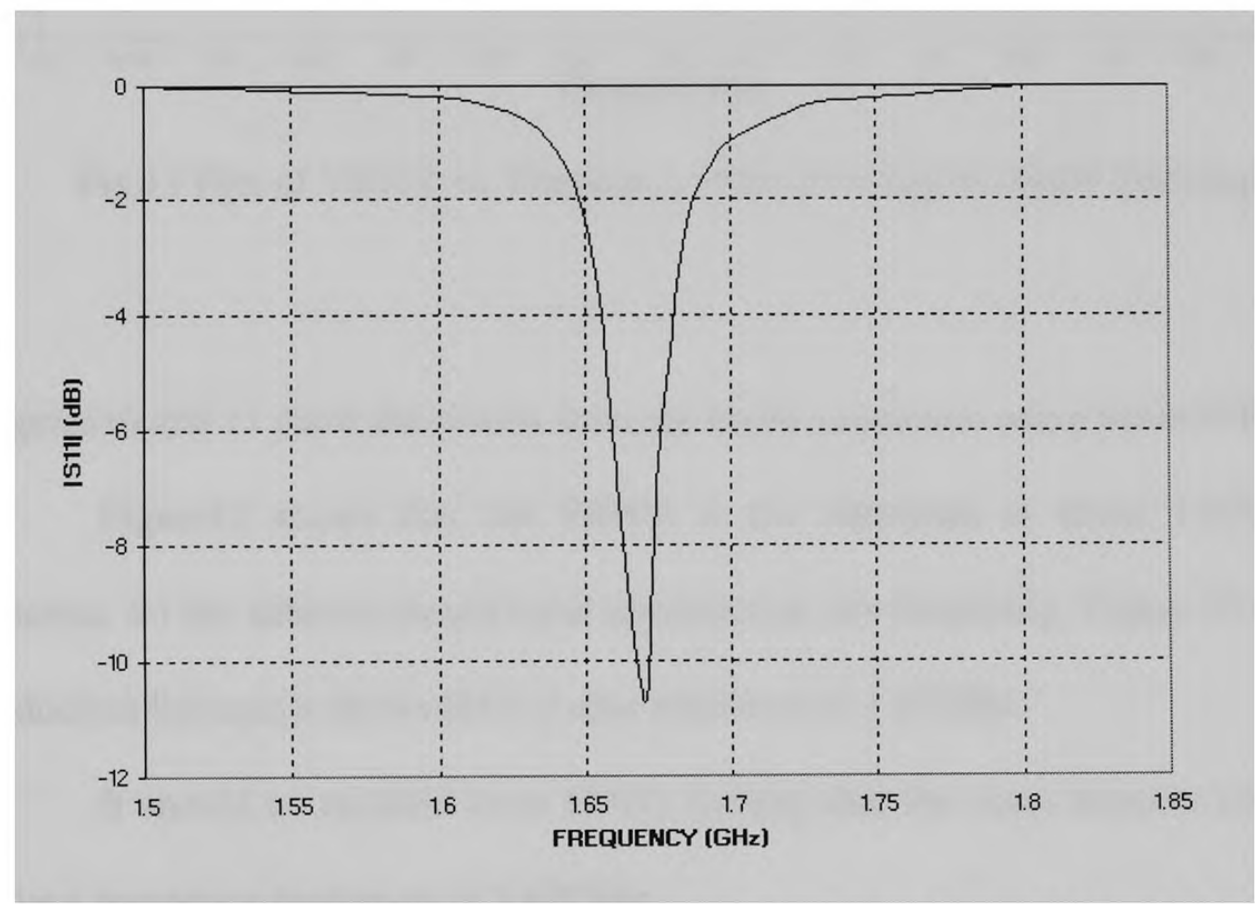

Fig.10 IS11| Vs. Frequency for Coax-fed microstrip patch from MoM 


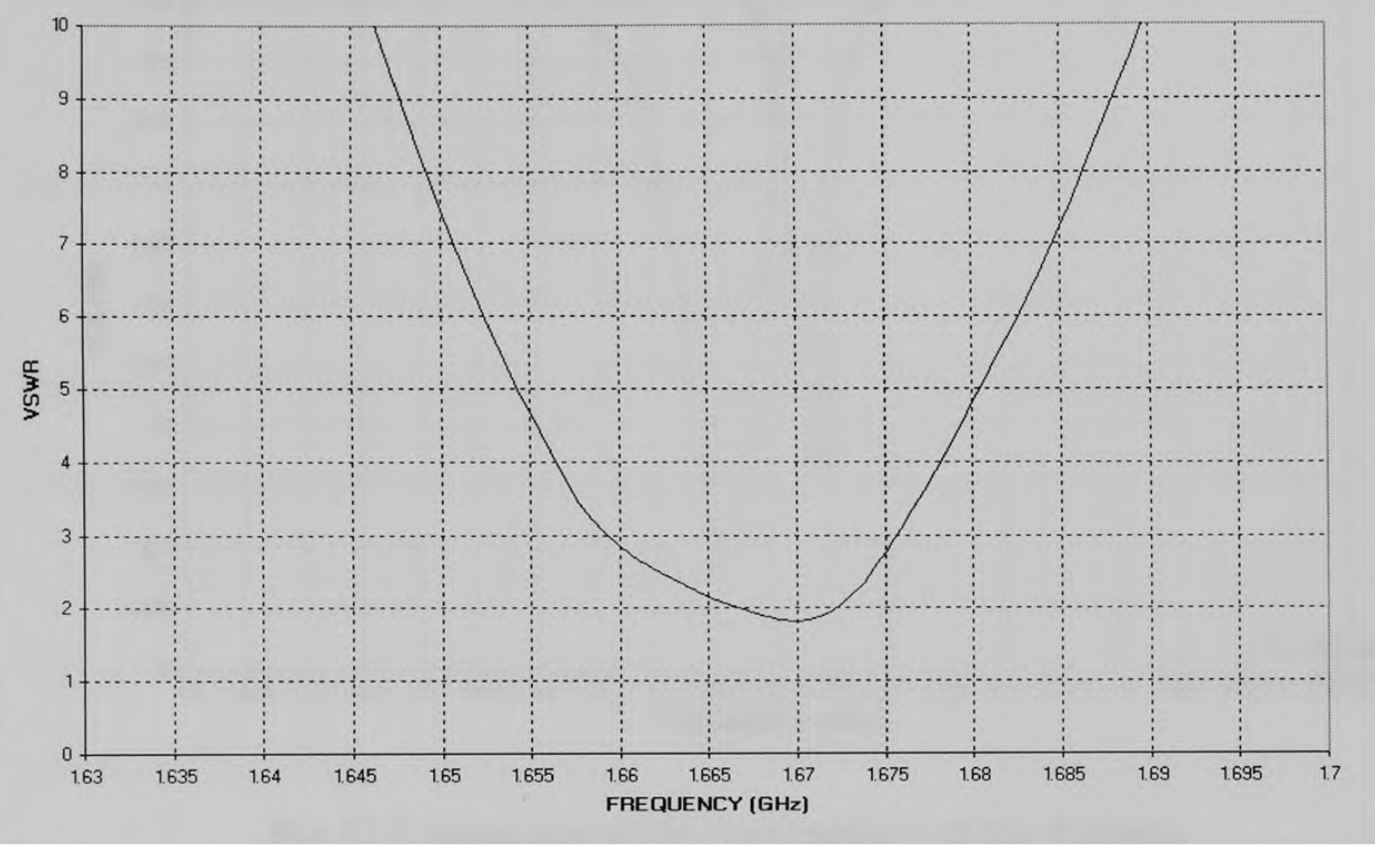

Fig.11 Plot of VSWR vs. Frequency obtained using the MoM Technique

Figures 10 and 11 show the results from the MoM simulation using MultiSTRIP program.

Figure11 shows that the VSWR is the minimum at about $1.67 \mathrm{GHz}$ for this antenna. So the antenna should have resonance at this frequency. Figure 10 confirms this deduction because it shows IS11I is also minimum at $1.67 \mathrm{GHz}$.

It should be recalled from FDTD method that the same antenna was deduced to have a resonance frequency of $1.63 \mathrm{GHz}$. 


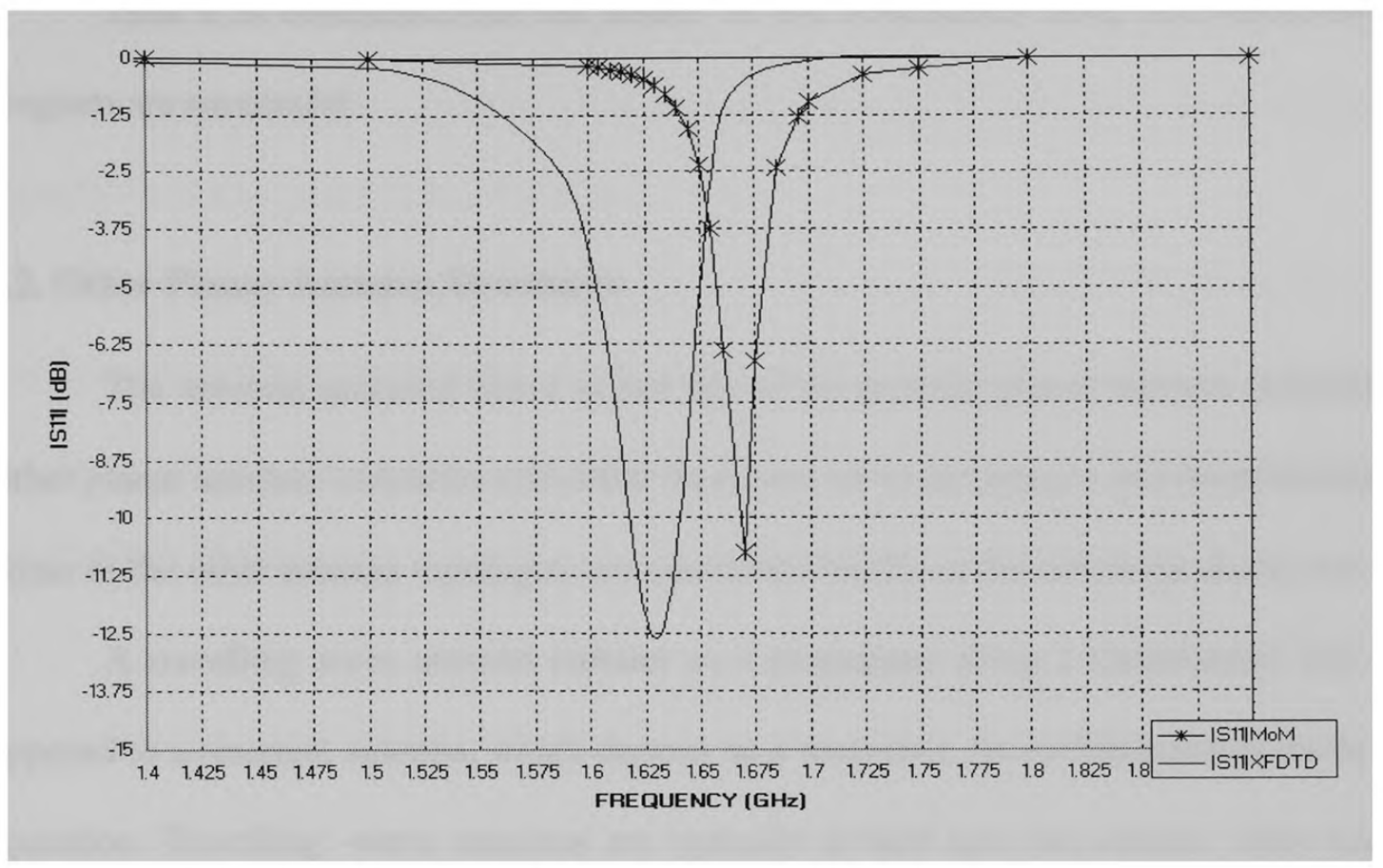

Fig.12 Comparison of the S-parameters of the Antenna

Figure 12 compares the S-Parameters of the antenna obtained using XFDTD software, MultiSTRIP program.

The results from MoM technique are shifted slightly to the right and according to the results from this method; the antenna resonates at $1.67 \mathrm{GHz}$. In fact, when the antenna is analyzed by the MoM technique using the MultiSTRIP program, the finite ground plane (and hence the shape of the substrate) is not modeled. This is a limitation of the software used and causes some discrepancy in the results. For the several antenna structures analyzed using this software, the limitation did not seriously impair the accuracy of the results. So, despite this limitation, the software is found to be fairly accurate, very fast and very useful for preliminary analysis of antenna structures. 
Thus it is concluded that the results of the simulations using the MultiSTRIP program are successful.

\subsection{Other Planar Antenna Structures}

The antenna analyzed above is just one of the popular planar antenna structures. Other planar antenna structures each offer their own set of advantages and disadvantages. Some of the other antenna topologies are mentioned briefly in the following discussion.

A travelling wave antenna radiates as it propagates along a transmission line as opposed to a resonant antenna, which depend on a resonance for its fundamental mode of operation. Travelling -wave antennas are typically divided into two classes: leaky-wave and surface-wave types. The leaky-wave antenna radiates continuously as the wave propagates while the surface-wave antenna radiates at points in the structure where discontinuities disrupt the propagating surface-wave. Leaky-wave antennas are considered to have moderate bandwidth.

The linearly tapered slot antenna (LTSA) offers broad bandwidth, is completely uniplanar, and can be designed to have high gain. However, LTSAs are usually built on substrates with low permittivity to ensure good radiation patterns and to maintain good radiation efficiency, making LTSAs electrically larger in size than patch antenna structures.

Other topologies have their own inherent shortcomings. Spiral antennas offer even wider bandwidth than LTSAs, but radiate bi-directionally just like slot antennas. 
Log periodic dipole antennas (LPDA) are two-layered structures requiring a balun to appropriately feed the antenna. Printed bowtie antennas require the use of absorber material to ensure good radiation patterns.

Another type of antenna of interest is the slot antenna. Although slot antennas also exhibit moderate bandwidth, they can be modified for broadband operation. An example is a Coaxial fed $U$-slot Rectangular Patch antenna (Figure 13), which will be analyzed in detail in this thesis. 


\section{CHAPTER 4}

\section{COAXIALLY FED U-SLOT RECTANGULAR PATCH ANTENNA}

During the last decade, a great deal of research has been devoted to bandwidthwidening techniques of microstrip antenna [12]. A popular method is the use of parasitic patches, either in another layer (stacked geometry) or in the same layer (coplanar geometry). However the stacked geometry has a disadvantage of increasing the thickness of the antenna. Recently, Huynh and Lee showed that a coaxially fed rectangular patch with a U-shaped slot could attain over $20 \%$ bandwidth, with good pattern characteristics.

In this thesis, the FDTD method is applied to analyze the coaxially fed U-slot rectangular patch antenna. This method has been applied to microstrip, CPW and Coaxial structures in earlier researches [14][15]. The variation of bandwidth through different antenna dimensions is also explored.

\subsection{Coaxial fed U-slot Rectangular patch Antenna Geometry}

The following geometry shows the structure and dimensions of the antenna that is under analysis [13]. As shown in Figure 13, the substrate is $5 \mathrm{~mm}$ thick with a dielectric constant of 2.33. All the Parameters involved in the construction of the geometry are listed below. The characteristic impedance of coaxial feed is taken as $50 \Omega$. 


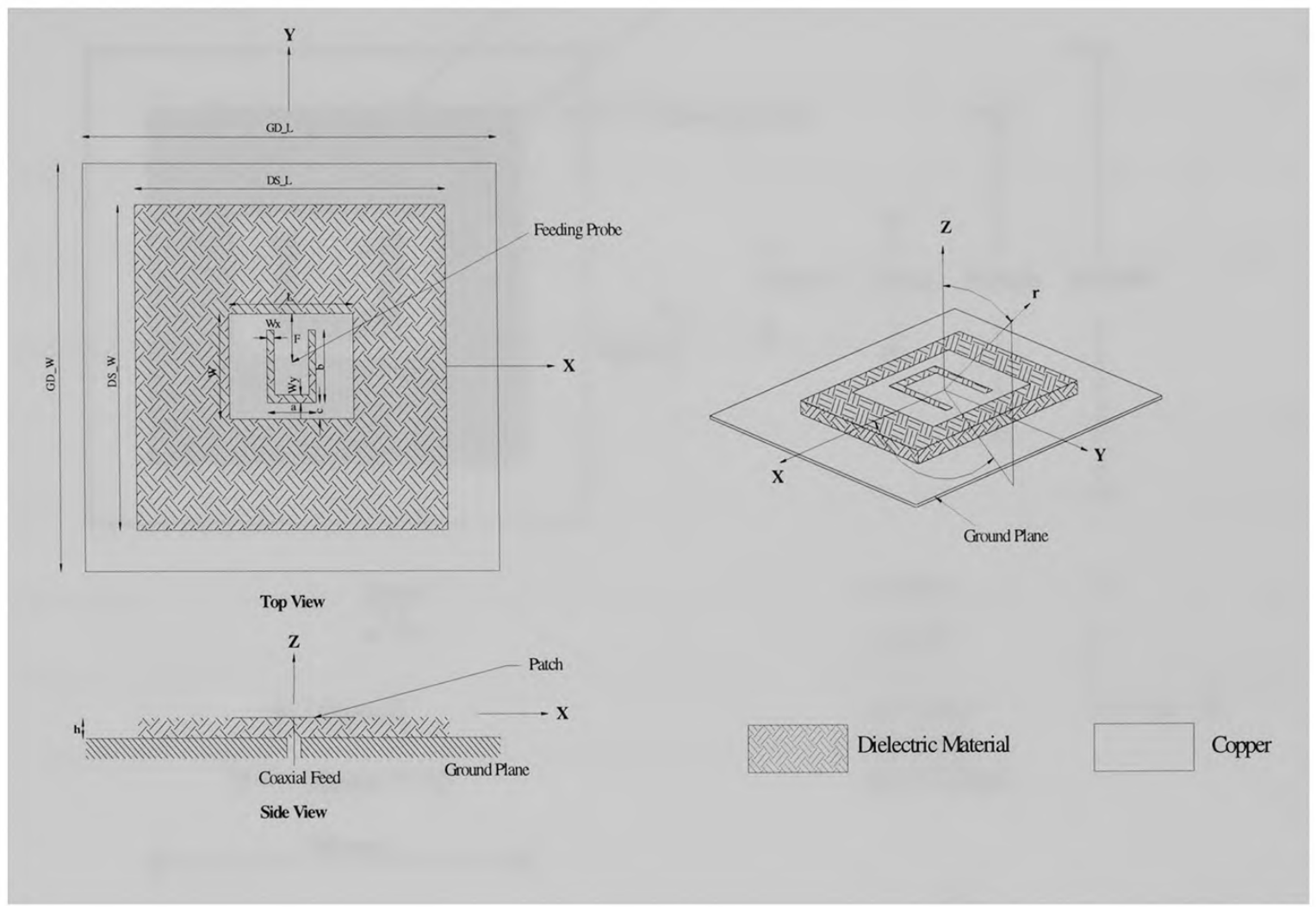

Fig.13 Geometry of Coaxial fed U- Slot Rectangular Patch Antenna [13]

Dimensions of Antenna in Millimeters

$\begin{array}{ccccccccccccrr}\text { GD_L } & \text { GD_W } & \text { DS_L } & \text { DS_W } & \varepsilon_{\mathrm{r}} & \text { L } & \text { W } & \text { a } & \text { b } & \text { c } & \text { h } & \text { F } & \text { Wx } & \text { Wy } \\ 120 & 100 & 90 & 80 & 2.33 & 36 & 26 & 14 & 18 & 4 & 5 & 13 & 2 & 2\end{array}$




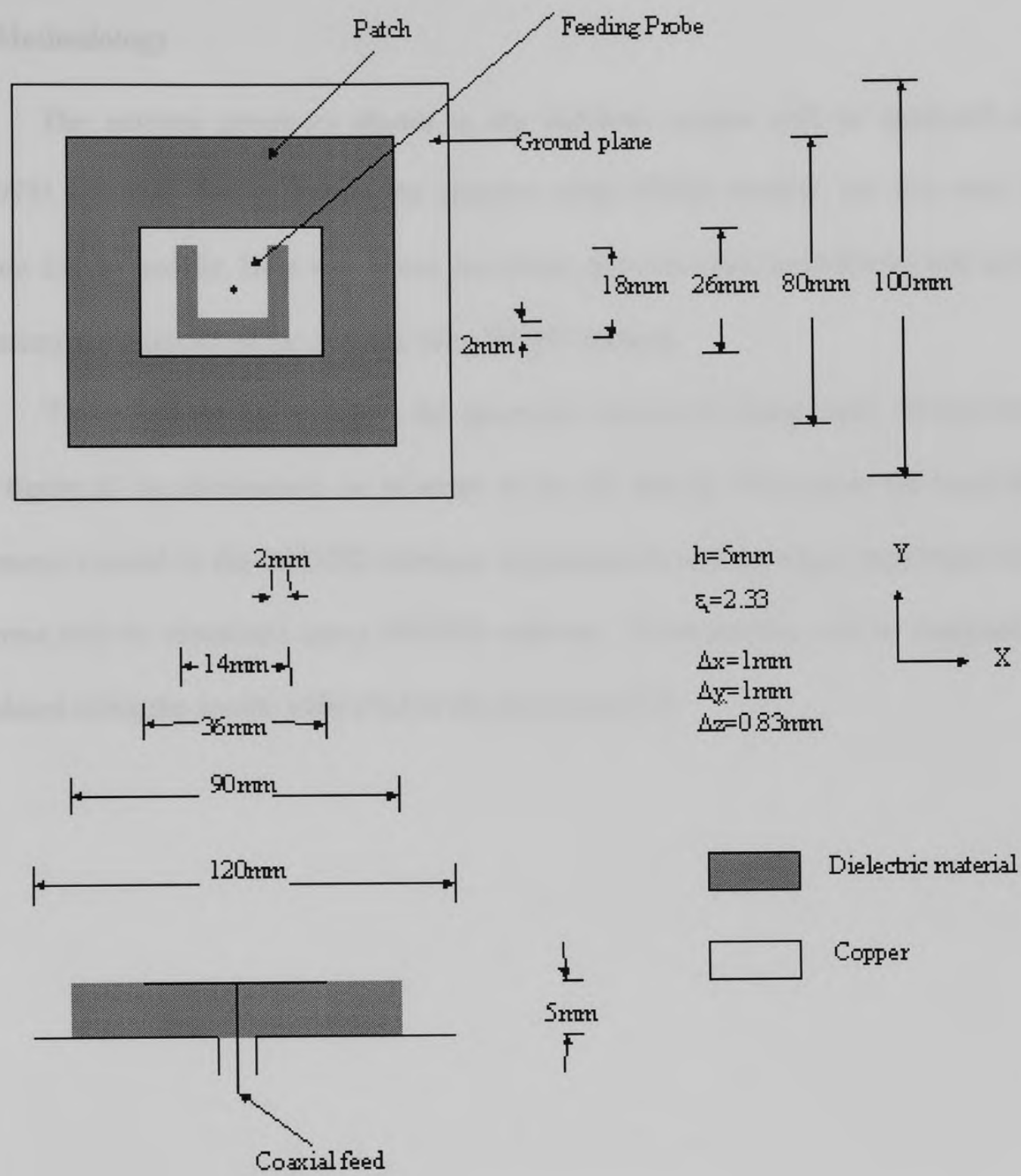

Fig. 14 Geometry of coaxial fed U-slot antenna under study [13] 


\subsection{Methodology}

The antenna geometry shown in the previous section will be analyzed using XFDTD software. For analyzing the antenna using FDTD method, the first step is to decide $\Delta x, \Delta y$ and $\Delta \mathrm{z}$. Here we choose $\Delta \mathrm{x}=1 \mathrm{~mm}, \Delta \mathrm{y}=1 \mathrm{~mm}$ and $\Delta \mathrm{z}=0.83 \mathrm{~mm}$ and create a geometry for analysis of the antenna using FDTD method.

The following figure shows the geometry created by using these dimensions. In this figure all the dimensions are in terms of $\Delta x, \Delta y$ and $\Delta z$. This forms the basis of the geometry created in the XFDTD software. S-parameters and the input impedance of this antenna will be simulated using XFDTD software. These results will be analyzed and validated using the results published in the reference [12]. 


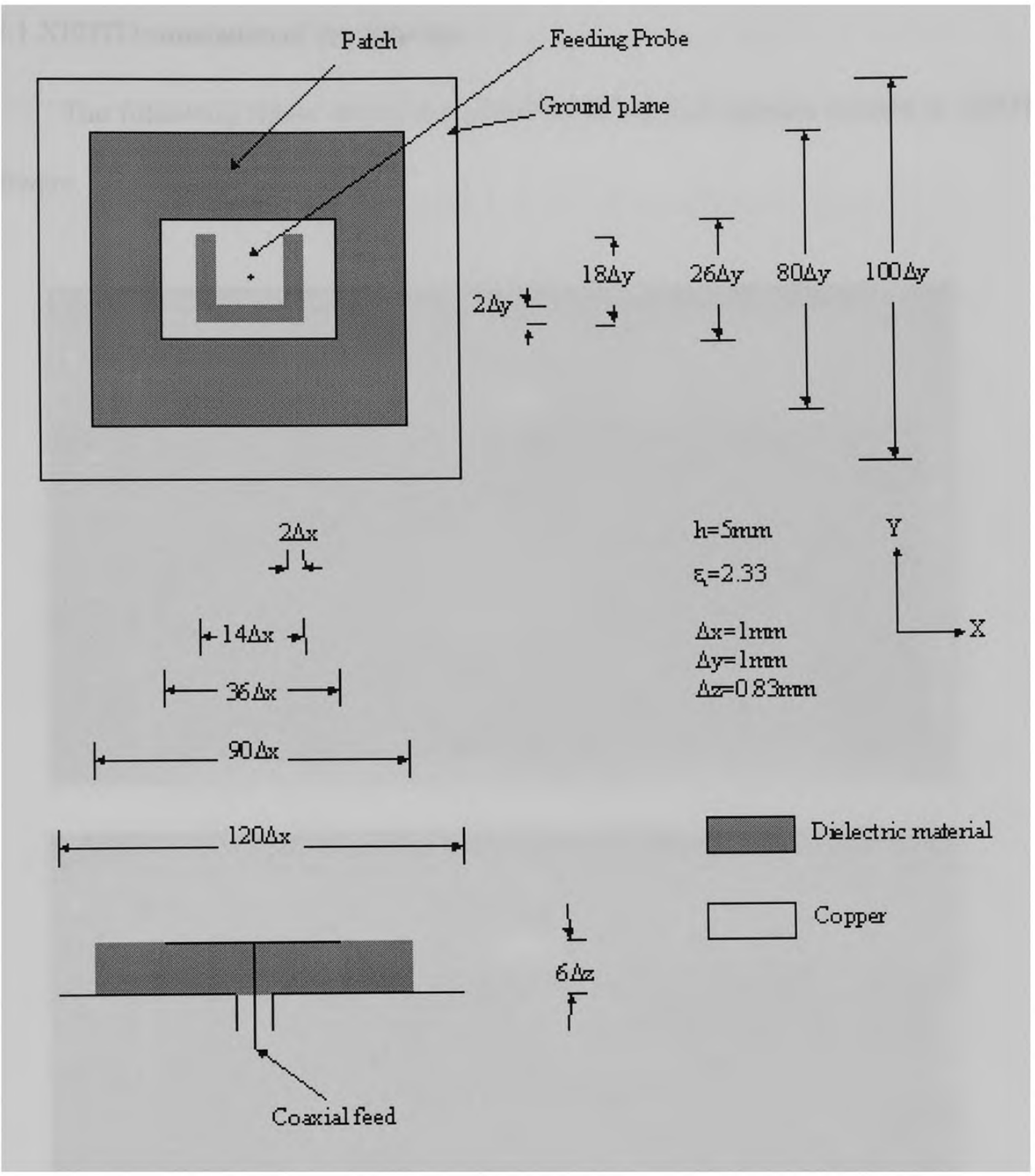

Fig.15 FDTD Geometry of Coaxial fed U-slot Antenna Under Study 
The following figure shows the geometry of the full antenna created in XFDTD software.
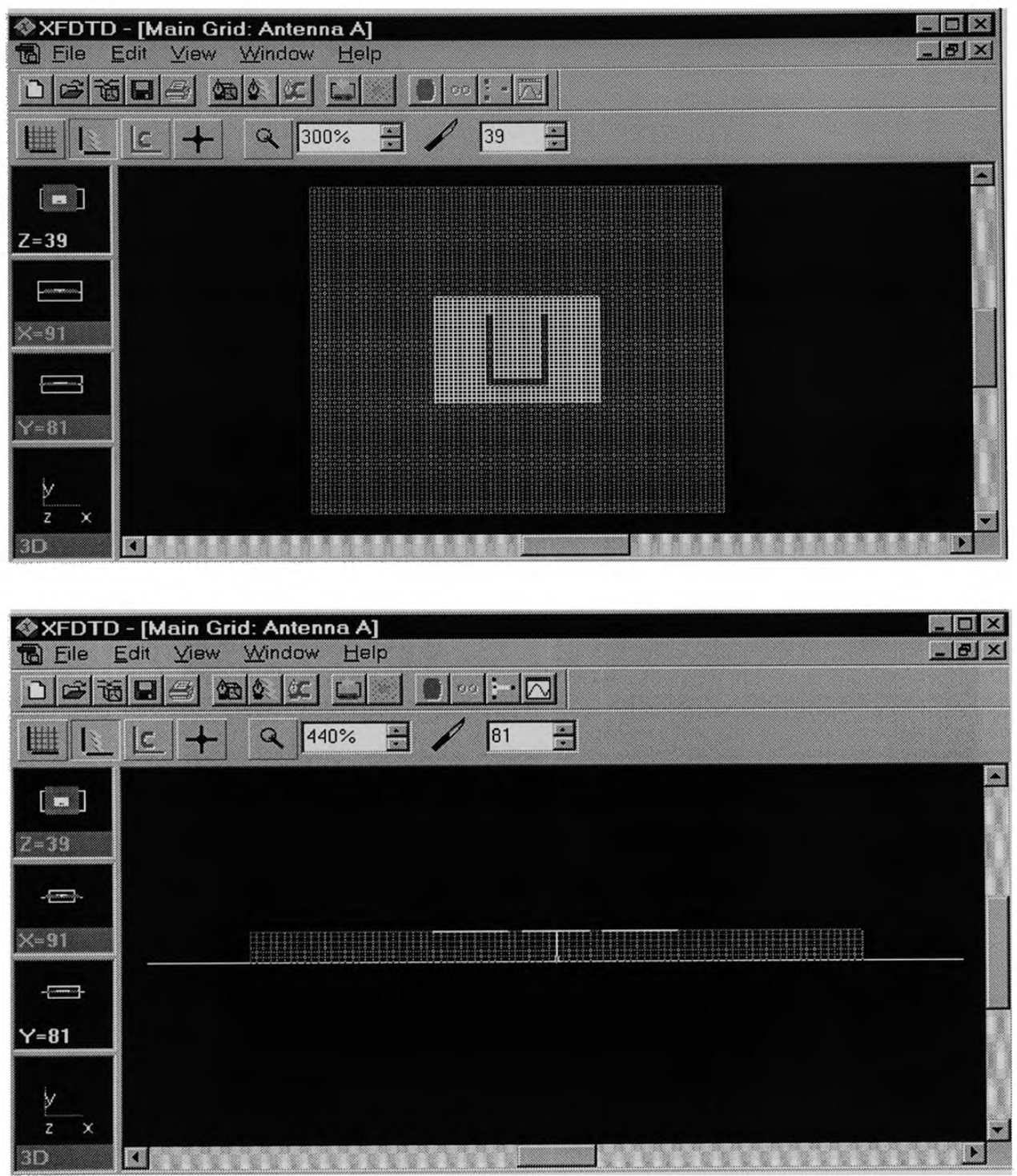

Fig.16 XFTD geometry, X-Y plane view (Top) \& X-Z plane view (Bottom) 
After creating the geometry, the stimulus to the antenna and the boundary conditions for the simulation are set. The following figures illustrate the same.

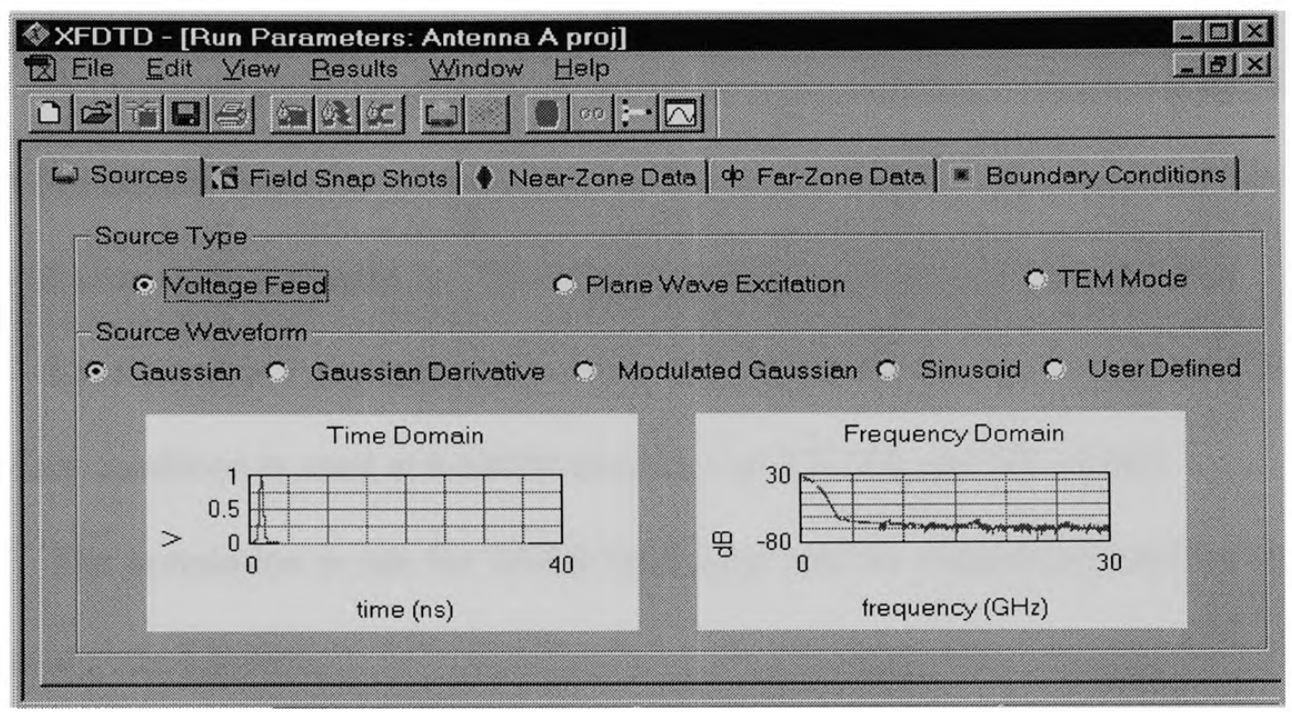

Fig.17 Stimulus setting for coaxial Fed U-slot Patch Antenna

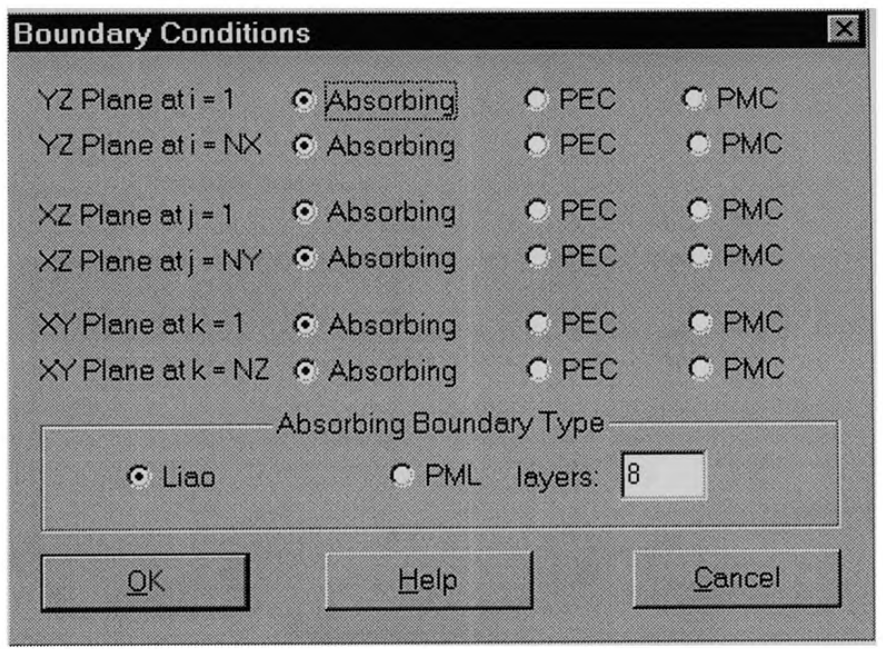

Fig.18 Boundary conditions for coaxial fed U-slot Patch Antenna 
The total grid dimensions for this geometry of coaxial fed U-slot antenna created in XFDTD software are $180 \times 160 \times 66$ in $\mathrm{X}, \mathrm{Y}$ and $\mathrm{Z}$ directions respectively. The substrate thickness is modeled as $6 \Delta \mathrm{z}$.

A Gaussian pulse is used as the stimulus to the antenna because we are interested in the broadband response of the antenna. The pulse width of the Gaussian stimulus in terms of time steps is chosen as 789 in keeping with courant stability condition.

Liao boundary condition is used as the absorbing boundary type and absorbing boundary condition is used at both the extremes of $\mathrm{YZ}, \mathrm{XZ}$ and $\mathrm{XY}$ planes.

The simulation is run for 20000 time steps and the simulation time for this run is approximately 6 hours.

The following figure shows the results for the S-parameters of the antenna.

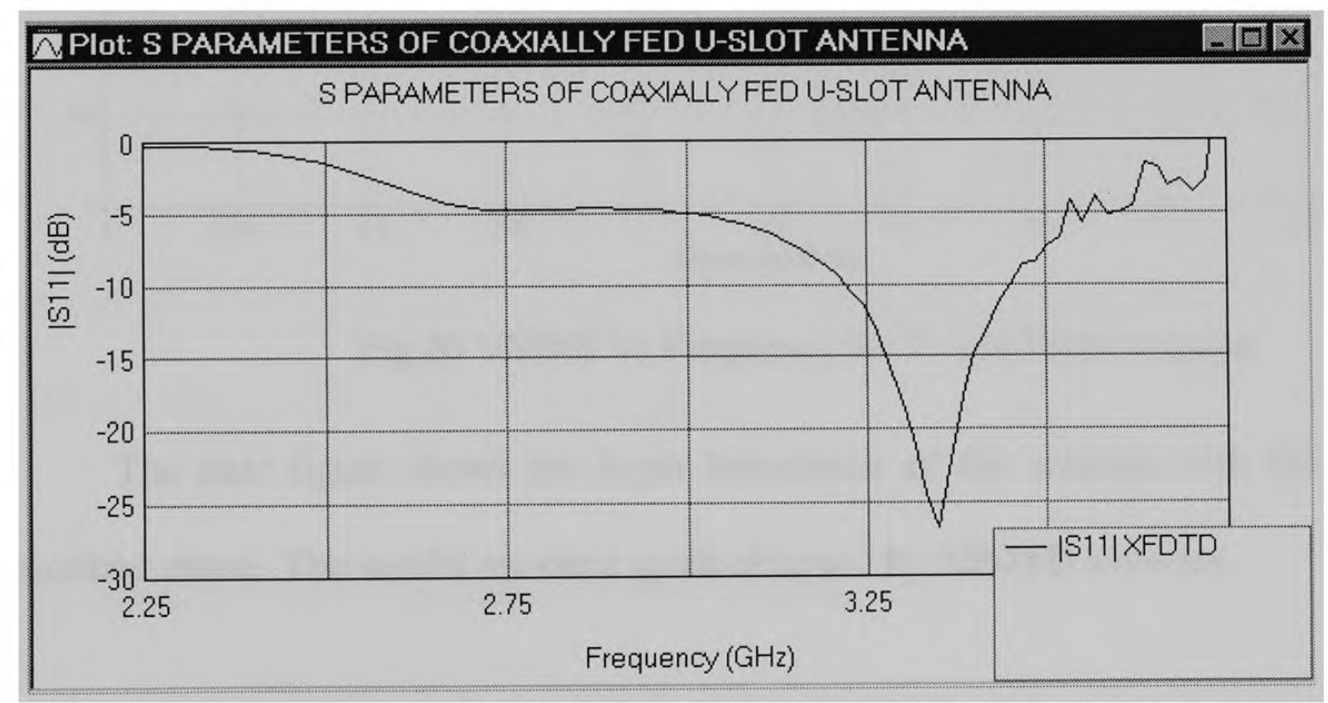

Fig.19 IS11| vs. Frequency for Coaxial fed U-slot Antenna

The antenna shows required resonance at the operating frequency of $3.4 \mathrm{GHz}$. 
Using the values of the S-parameters of the antenna obtained using the XFDTD simulation; the VSWR curve for the antenna is plotted.

The Figure 20 shows that VSWR of the antenna under consideration for the frequency range of interest. For a VSWR of 2:1, the plot below indicates that bandwidth of the antenna is $(3.5-3.25) / 3.40=0.0735$, i.e., about $7.35 \%$.

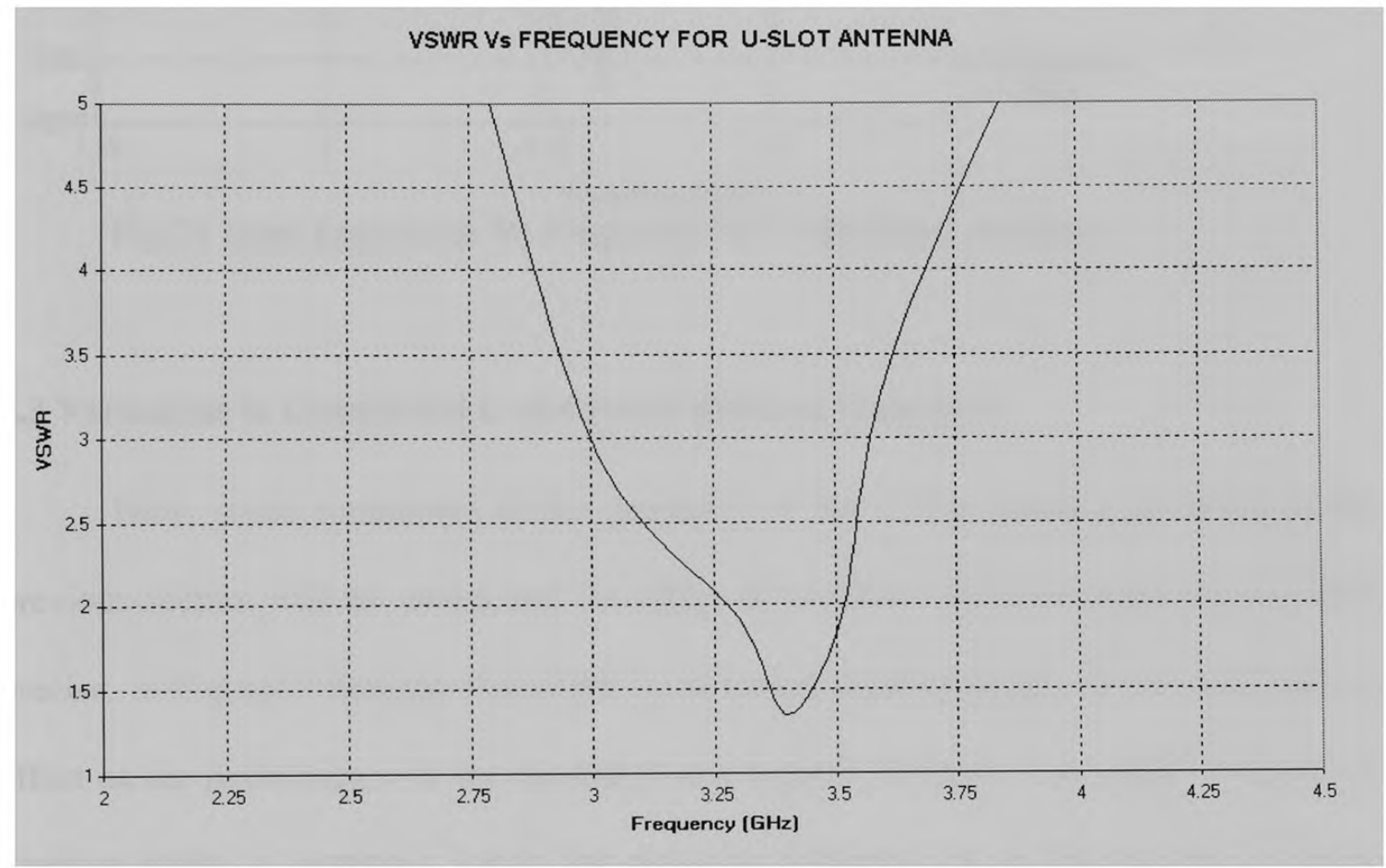

Fig.20 VSWR Vs Frequency for U-slot Patch antenna

The next figure shows the Input Impedance of the antenna with the geometry described above. The results are once again obtained by XFDTD software. 


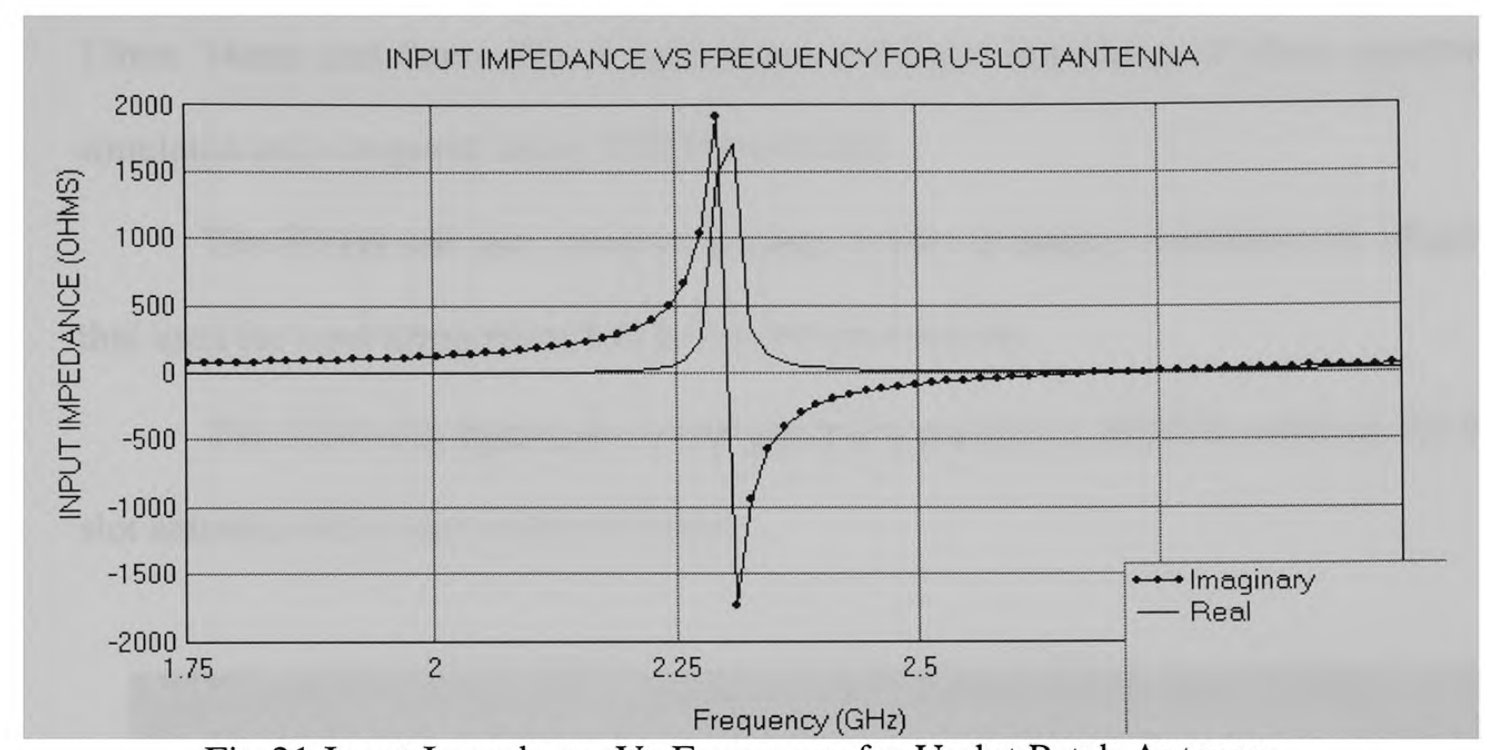

Fig.21 Input Impedance Vs Frequency for U-slot Patch Antenna

\subsection{Variations in Coaxial fed U-slot Patch Antenna Geometry}

Now, some parameters of the geometry of the U-slot antenna discussed in the previous section will be varied and the effect of variation will be studied. To be more precise, in Figure13 first the slot width ' $a$ ' is varied keeping length ' $b$ ' constant and its effect on the performance of the antenna is investigated. Next the slot length ' $b$ ' is varied keeping width ' $a$ ' constant. Lastly the substrate thickness ' $h$ ' of the antenna is varied keeping width 'a' and length 'b' constant.

4.3.1 Variations in the slot width 'a' of the antenna

Now we will analyze a Coaxial fed U-slot antenna that has all the dimensions identical to the antenna shown in Figure 14 except the slot width ' $a$ ' is varied keeping length ' $b$ ' constant at $20 \mathrm{~mm}$. We shall consider 4 cases where the slot width is $10 \mathrm{~mm}$, 
$12 \mathrm{~mm} 14 \mathrm{~mm}$ and $8 \mathrm{~mm}$. The S parameters and Input Impedance of these antennas are simulated and compared using XFDTD software.

The FDTD cell size, stimulus settings and the boundary conditions are identical to that used for simulation described in the previous section.

The following figure shows the geometry created in XFDTD software for the Uslot antenna with a slot width of $10 \mathrm{~mm}$.

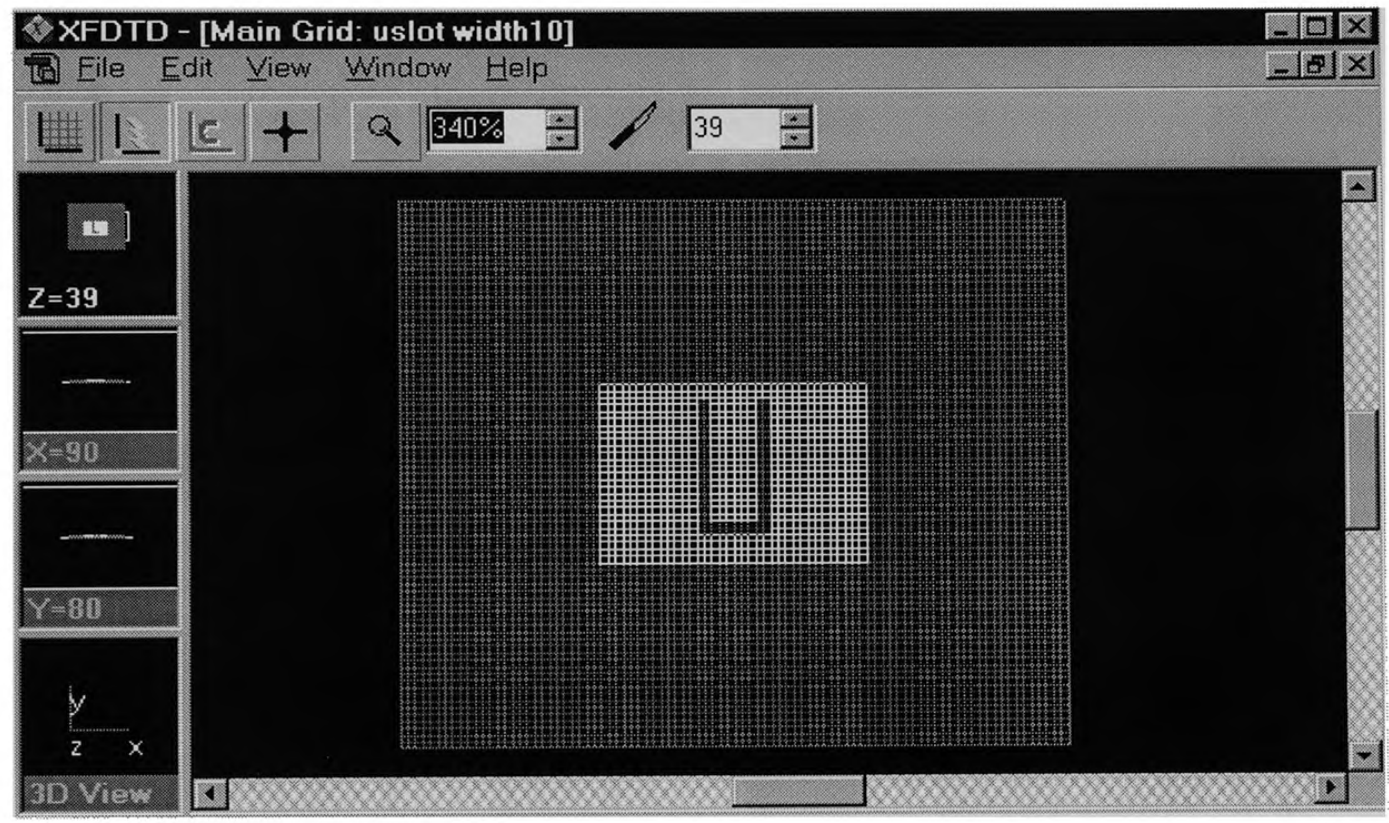

Fig.22 XFDTD geometry of Coaxial fed U-slot antenna with slot width of $10 \mathrm{~mm}$ 


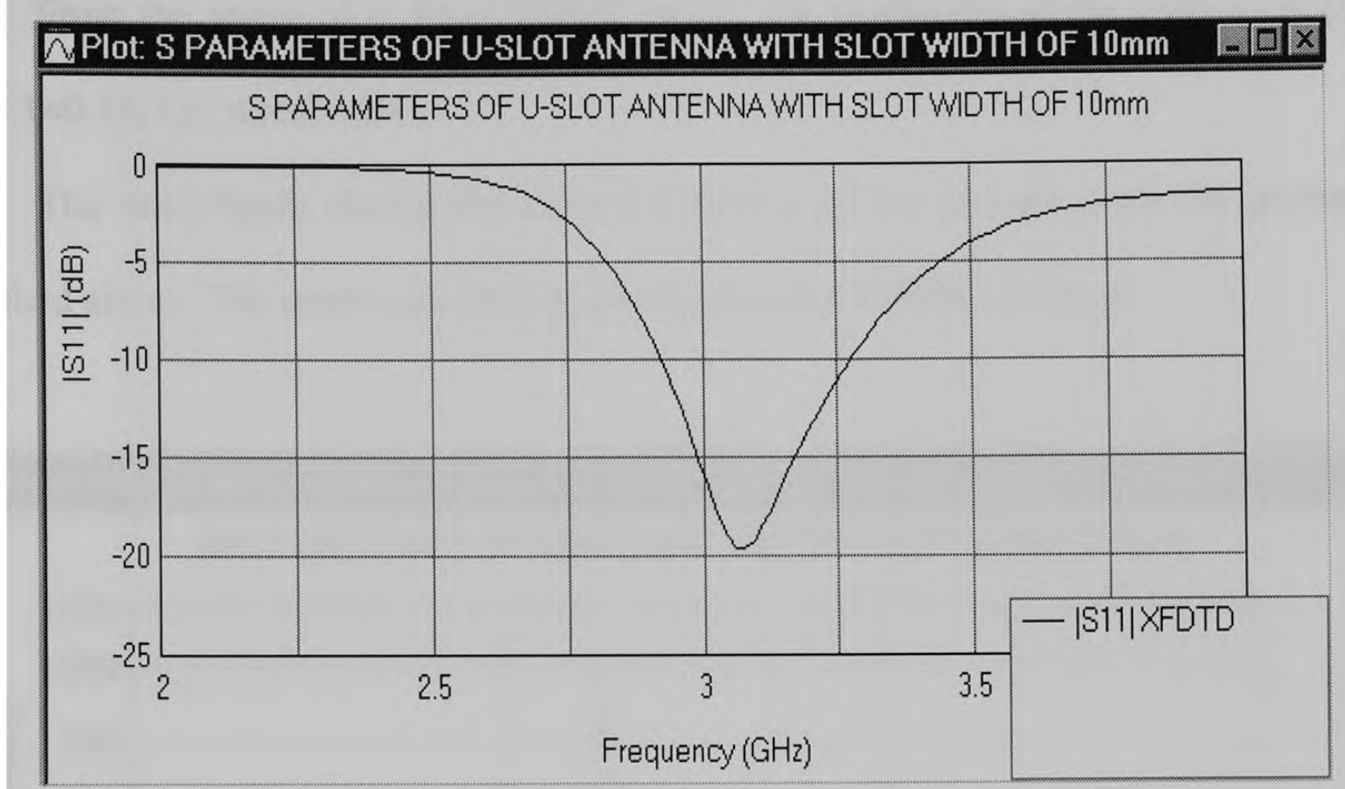

Fig.23 IS11| vs. Frequency for Coaxial fed U-slot antenna with a slot width of $10 \mathrm{~mm}$

Using the data for S-parameters obtained above, VSWR for the antenna under consideration is deduced and plotted as shown in the following figure.

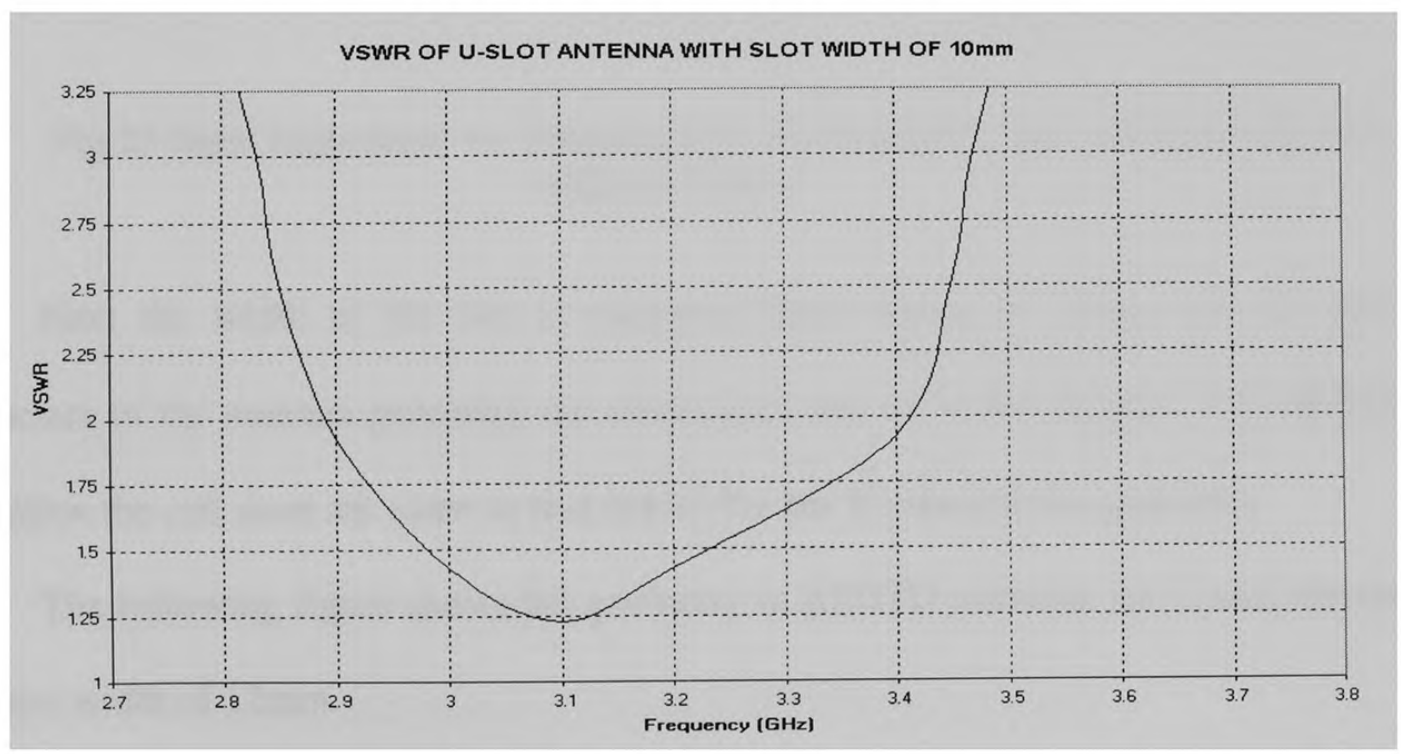

Fig.24 VSWR vs. Frequency for Coaxial fed U-slot antenna with a slot width of $10 \mathrm{~mm}$ 
From the above plot, for a VSWR of 2:1, the bandwidth of the antenna is (3.4$2.9) / 3.1=0.16$, i.e., about $16 \%$.

The next figure shows the Input Impedance of the antenna with the geometry described above. The results are once again obtained by XFDTD software.

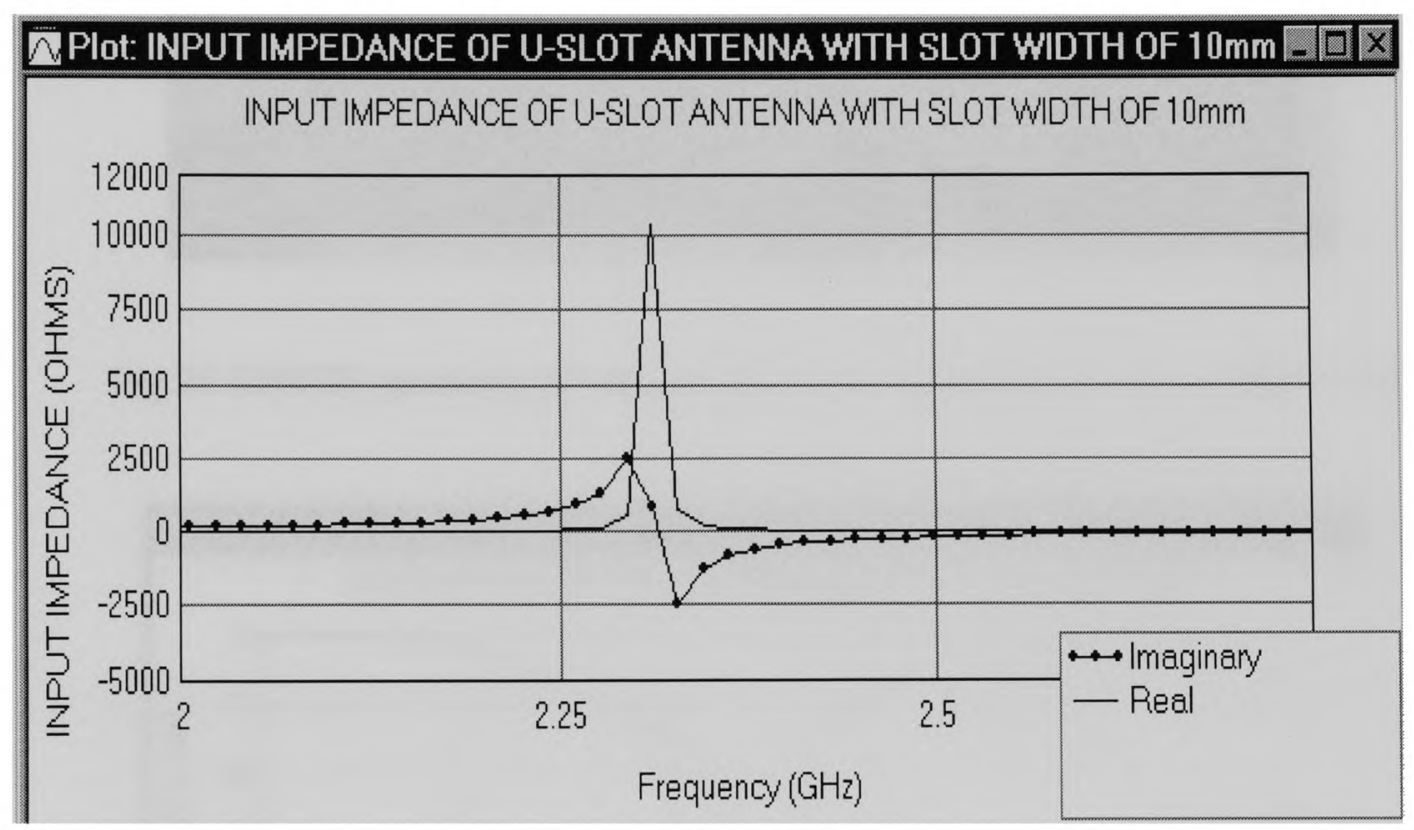

Fig.25 Input Impedance vs. Frequency for Coaxial fed U-slot antenna with a slot width of $10 \mathrm{~mm}$

Next the width of the slot is increases from $10 \mathrm{~mm}$ to $12 \mathrm{~mm}$. All the other parameters of the antenna geometry are identical to that of U-slot antenna. For XFDTD simulation the cell sizes are same as that chosen for the U-slot antenna geometry.

The following figure shows the geometry in XFDTD software for U-slot antenna with slot width of $12 \mathrm{~mm}$. 


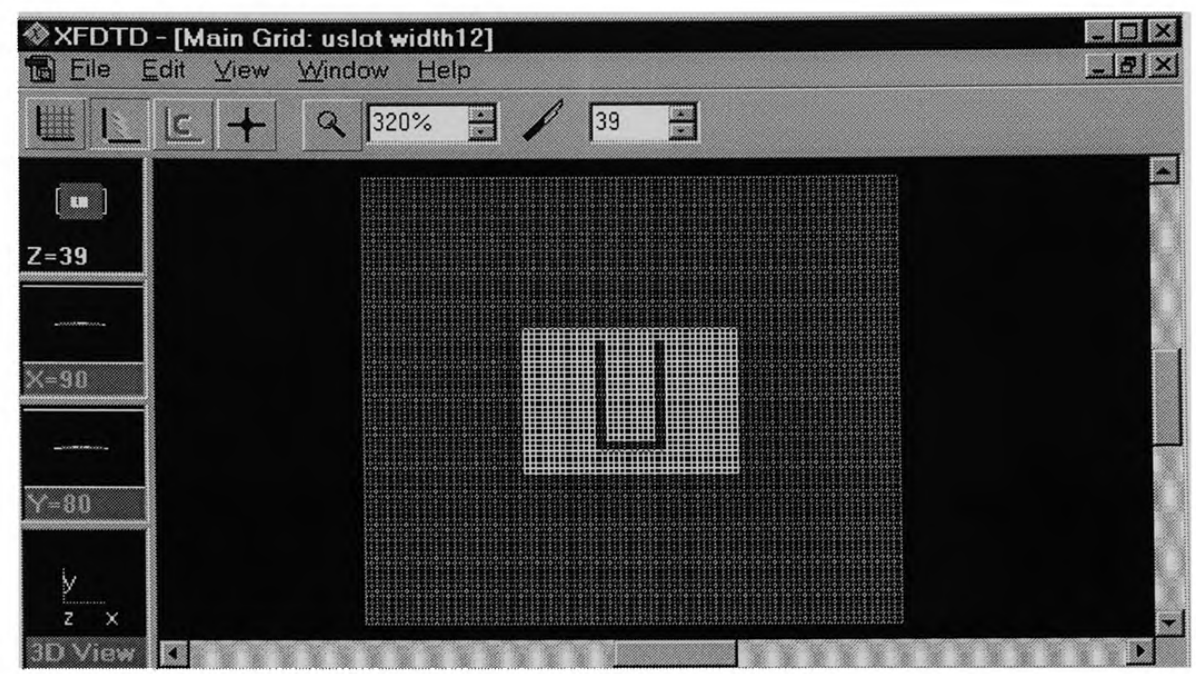

Fig.26 XFDTD geometry of coaxial fed U-slot antenna with slot width of $12 \mathrm{~mm}$

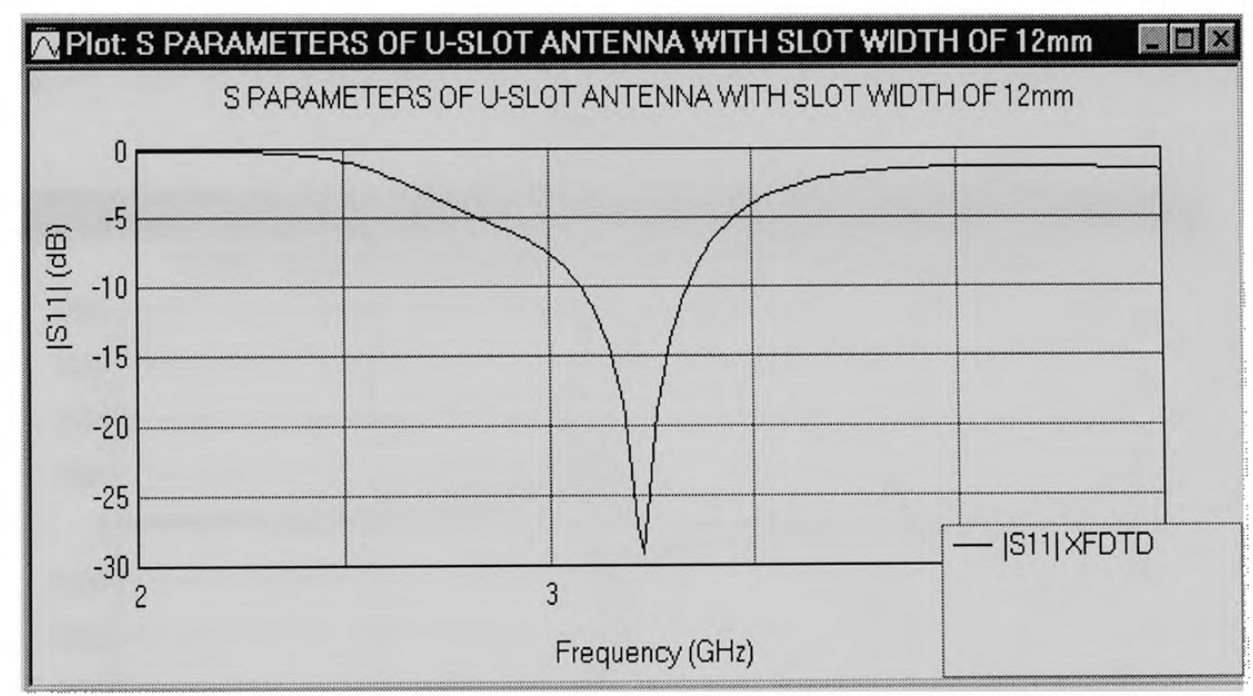

Fig.27 IS11I vs. Frequency for Coaxial fed U-slot antenna with a slot width of $12 \mathrm{~mm}$

Using the data for S-parameters obtained above; VSWR for the antenna under consideration is deduced and plotted as shown in the following figure. 
From the plot below, for a VSWR of $2: 1$, the bandwidth of the antenna is (3.53$3.07) / 3.24=0.1419$ i.e., about $14.2 \%$.

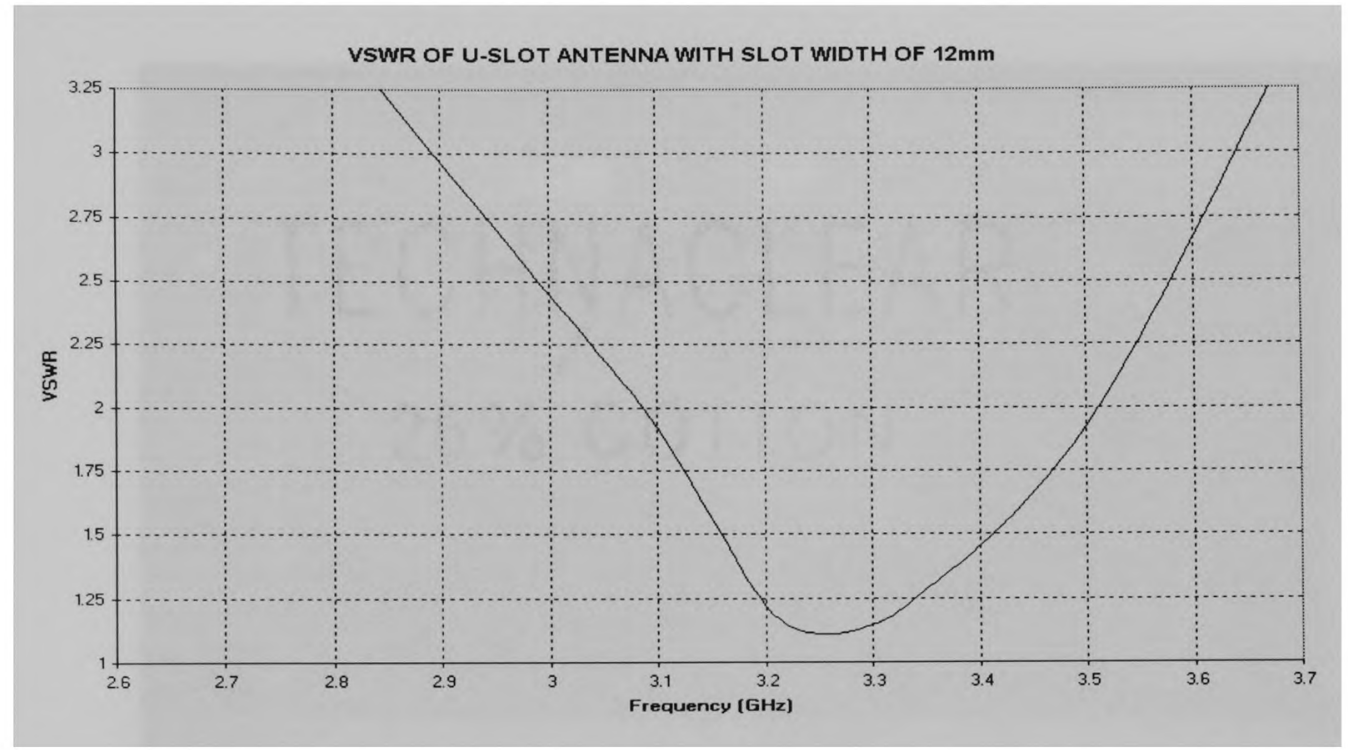

Fig.28 VSWR vs. Frequency for Coaxial fed U-slot antenna with a slot width of $12 \mathrm{~mm}$

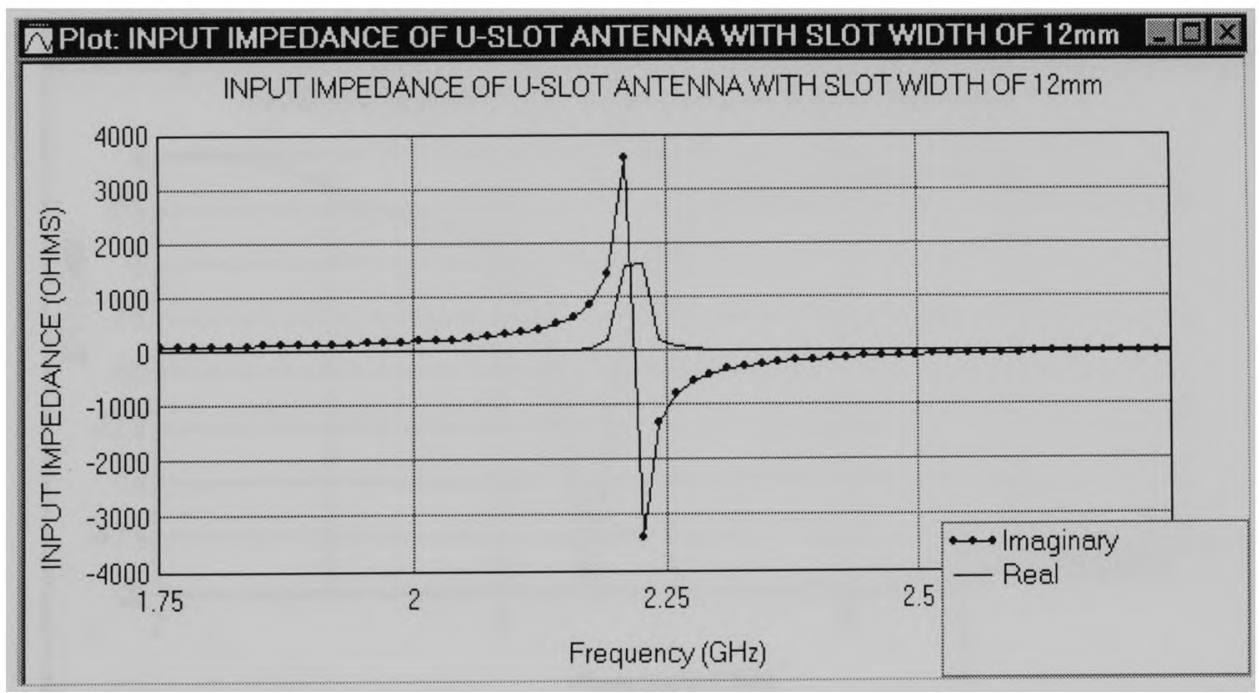

Fig.29 Input Impedance vs. Frequency for Coaxial fed U-slot antenna with a slot width of $12 \mathrm{~mm}$

Next the slot width is increased from $12 \mathrm{~mm}$ to $14 \mathrm{~mm}$. All the other parameters of the antenna geometry are identical chosen for the U-slot antenna geometry. The 
following figure shows the geometry in XFDTD software for U-slot antenna with slot width of $14 \mathrm{~mm}$.

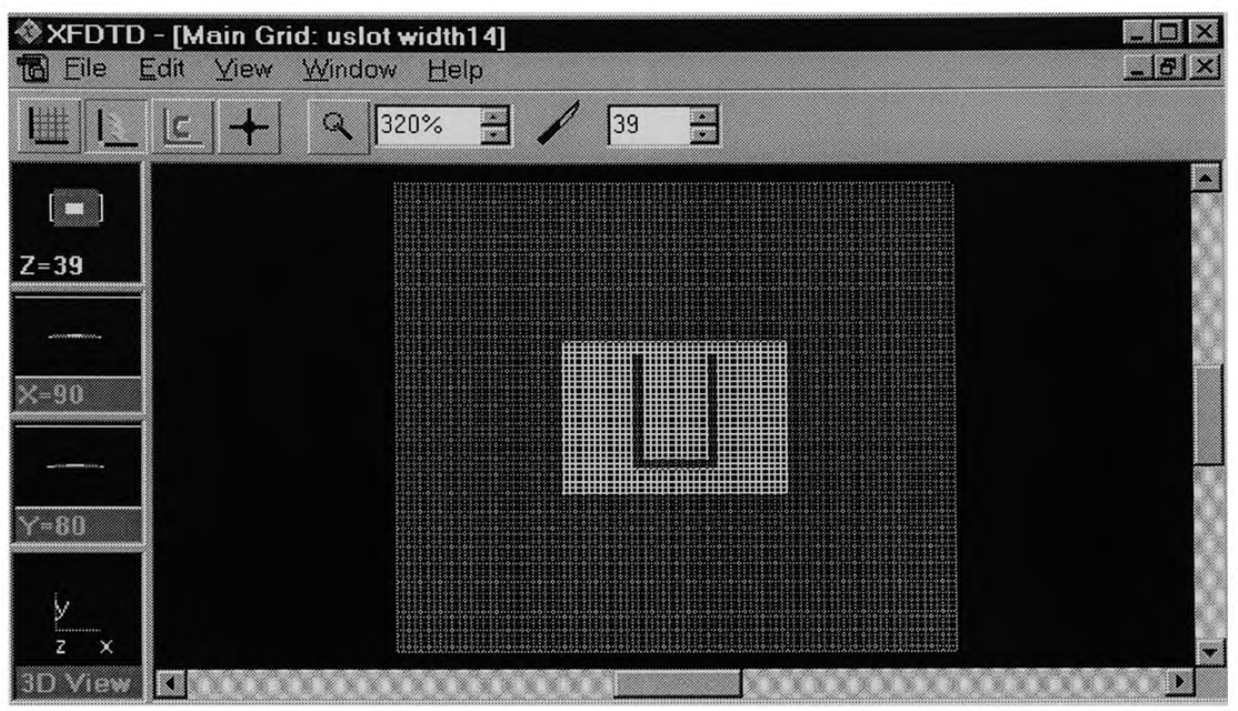

Fig.30 XFDTD geometry of coaxial fed U-slot antenna with slot width of $14 \mathrm{~mm}$

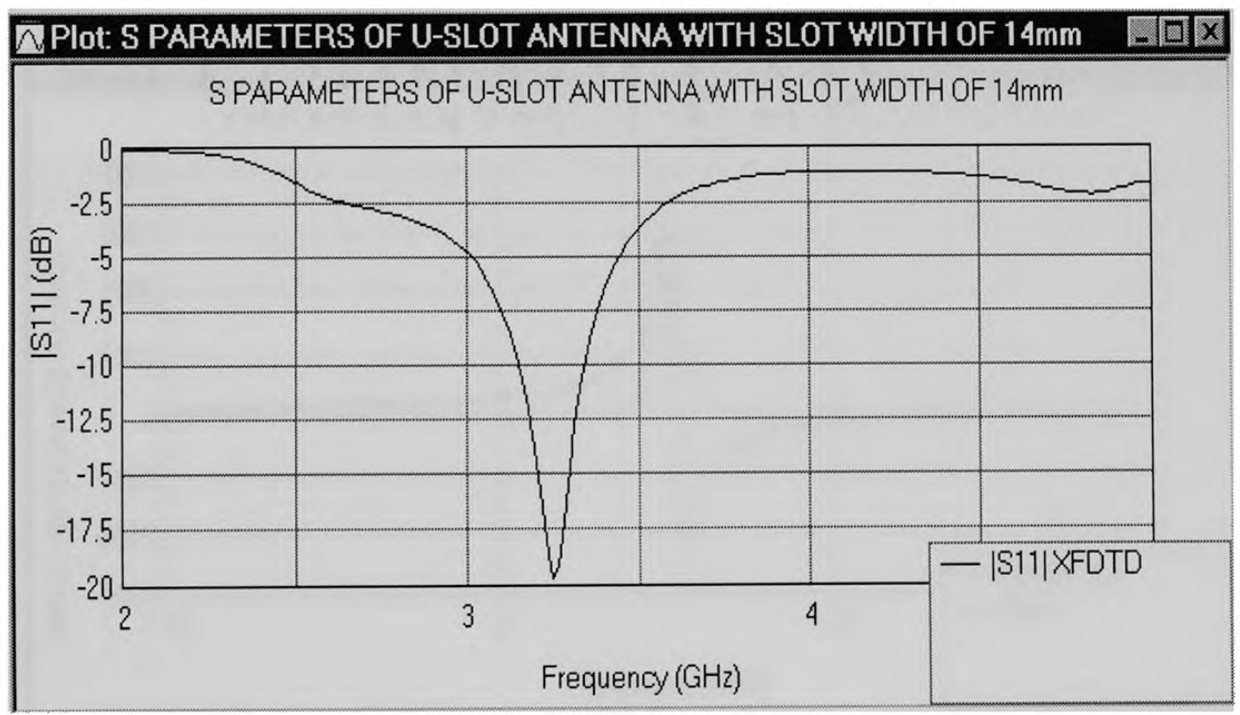

Fig.31 IS11I vs. Frequency for Coaxial fed U-slot antenna with a slot width of $14 \mathrm{~mm}$

Using the data for S-parameters obtained above; VSWR for the antenna under consideration is deduced and plotted as shown in the following figure. 
From the plot below, for a VSWR of 2:1, the bandwidth of the antenna is (3.4$3.15) / 3.25=0.075$ i.e., about $7.5 \%$.

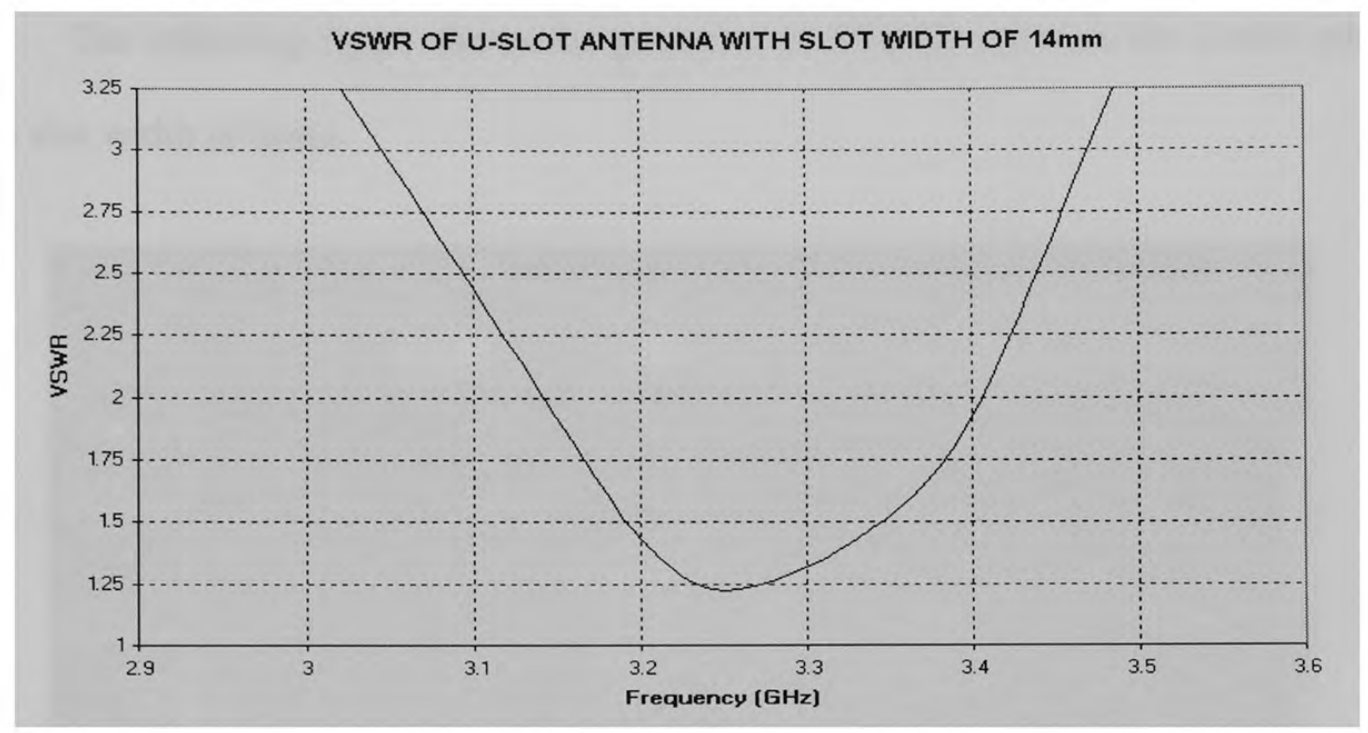

Fig.32 VSWR vs. Frequency for Coaxial fed U-slot antenna with a slot width of $14 \mathrm{~mm}$

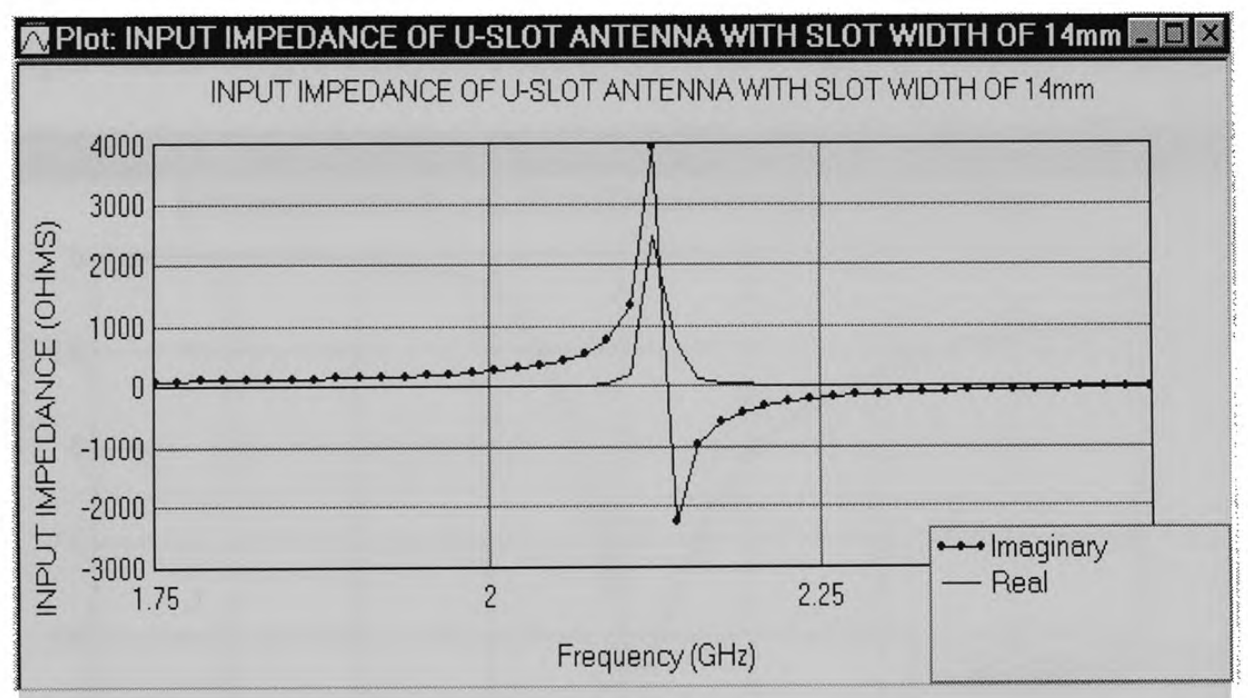

Fig.33 Input Impedance vs. Frequency for Coaxial fed U-slot antenna with a slot width of $14 \mathrm{~mm}$ 
Next the slot width is taken as $8 \mathrm{~mm}$. All the other parameters of the antenna geometry are identical chosen for the U-slot antenna geometry.

The following figure shows the geometry in XFDTD software for U-slot antenna with slot width of $8 \mathrm{~mm}$.

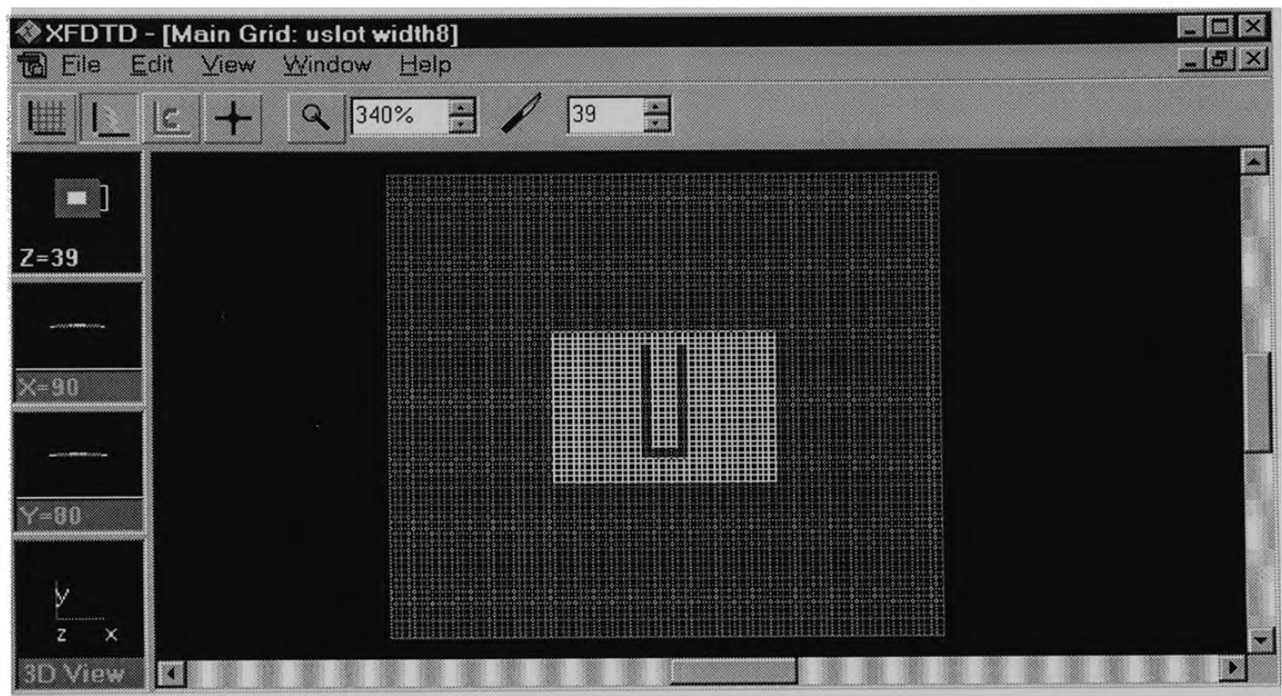

Fig.34 XFDTD geometry of coaxial fed U-slot antenna with slot width of 8mm

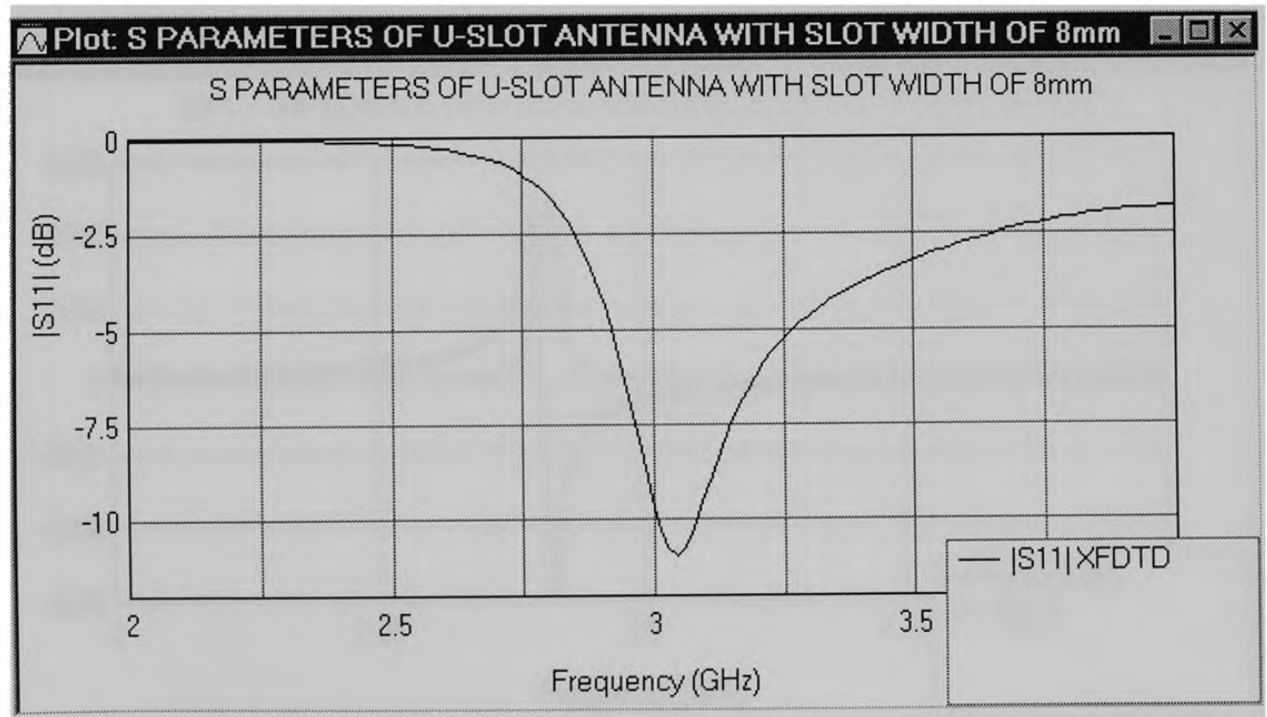

Fig.35 IS11I vs. Frequency for Coaxial fed U-slot antenna with a slot width of $8 \mathrm{~mm}$ 
From the plot below, for a VSWR of 2:1, the bandwidth of the antenna is (3.23)/3.1=0.064 i.e., about $6.4 \%$.

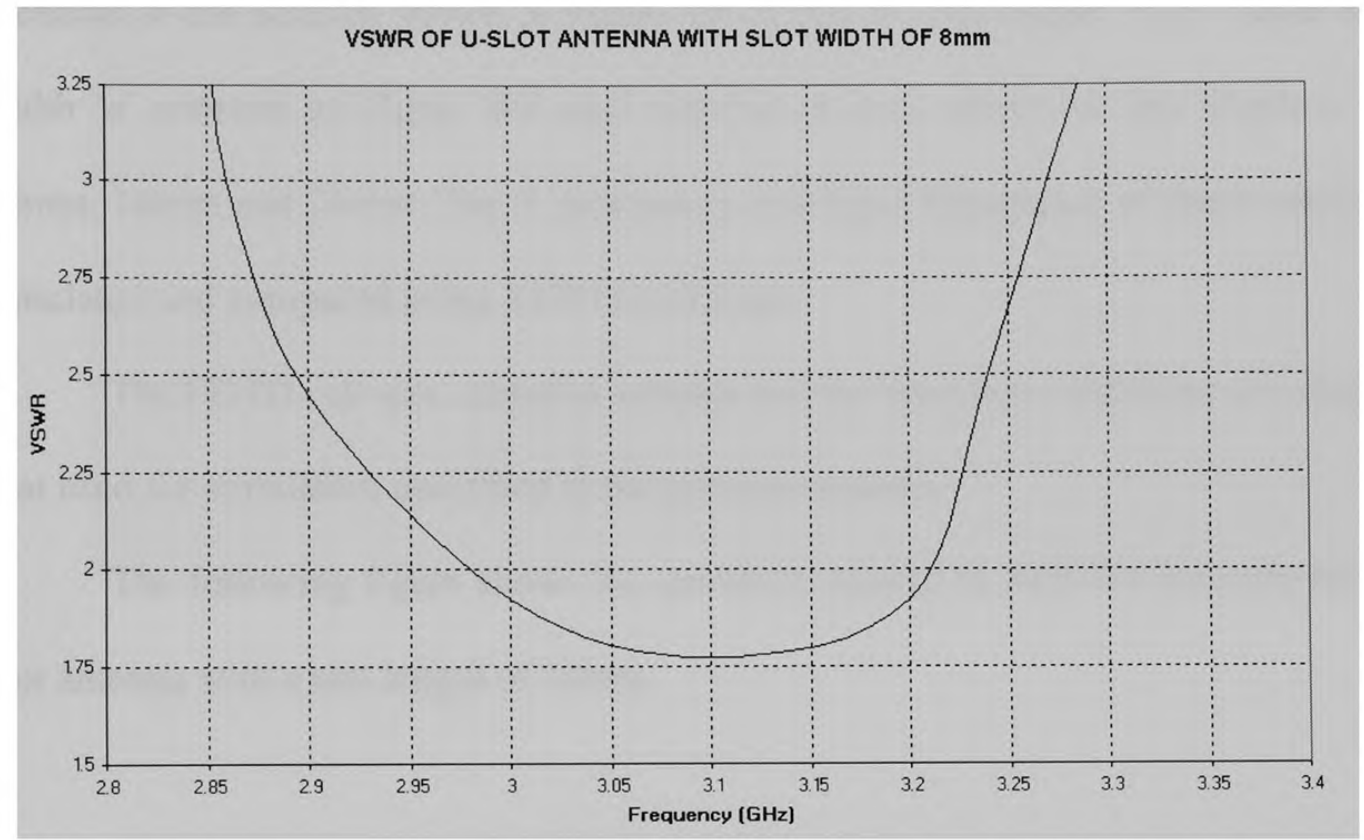

Fig.36 VSWR vs. Frequency for Coaxial fed U-slot antenna with a slot width of $8 \mathrm{~mm}$

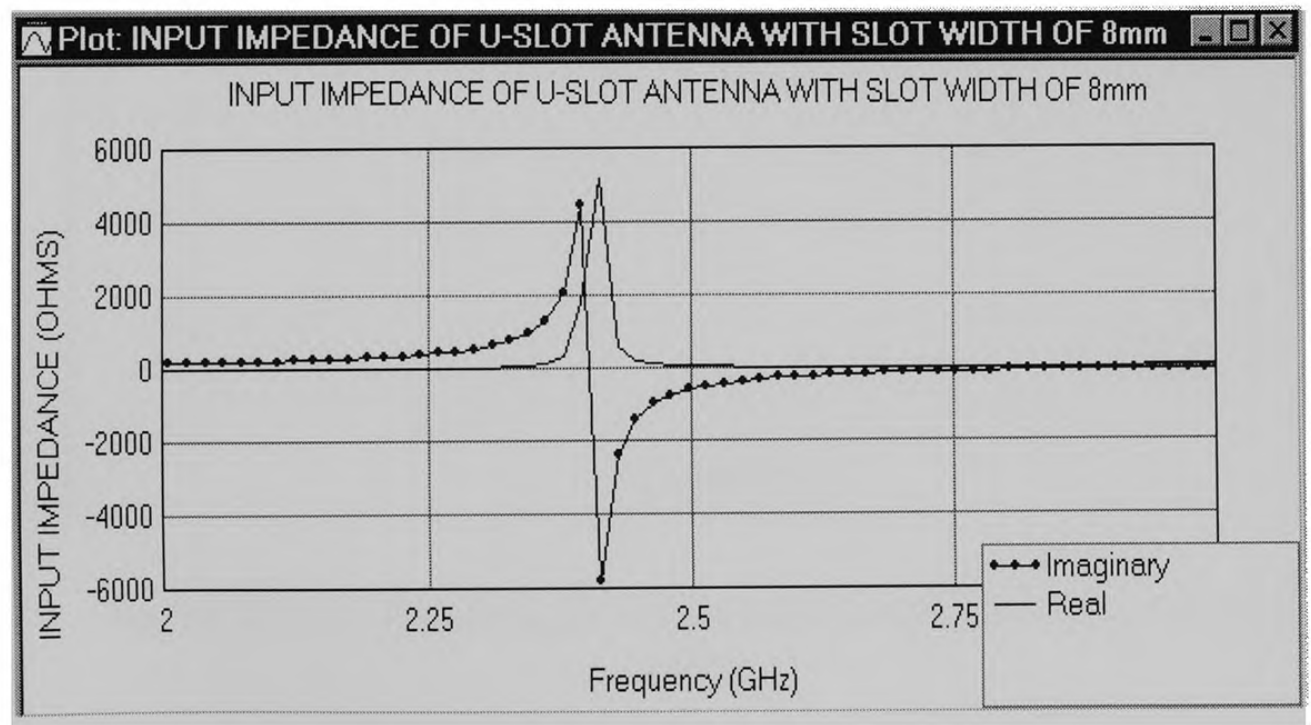

Fig.37 Input Impedance vs. Frequency for Coaxial fed U-slot antenna with a slot width of $8 \mathrm{~mm}$ 
4.3.2 Variations in the slot length ' $\mathrm{b}$ ' of the antenna

Now we will analyze a Coaxial fed U-slot antenna that has all the dimensions identical to the antenna shown in Figure 14 except the slot length ' $b$ ' is varied keeping width ' $\mathrm{a}$ ' constant at $12 \mathrm{~mm}$. We shall consider 4 cases where the slot length is $14 \mathrm{~mm}$, $16 \mathrm{~mm}, 18 \mathrm{~mm}$ and $20 \mathrm{~mm}$. The S parameters and Input Impedance of these antennas are simulated and compared using XFDTD software.

The FDTD cell size, stimulus settings and the boundary conditions are identical to that used for simulation described in the previous section.

The following figure shows the geometry created in XFDTD software for the Uslot antenna with a slot length of $14 \mathrm{~mm}$. 


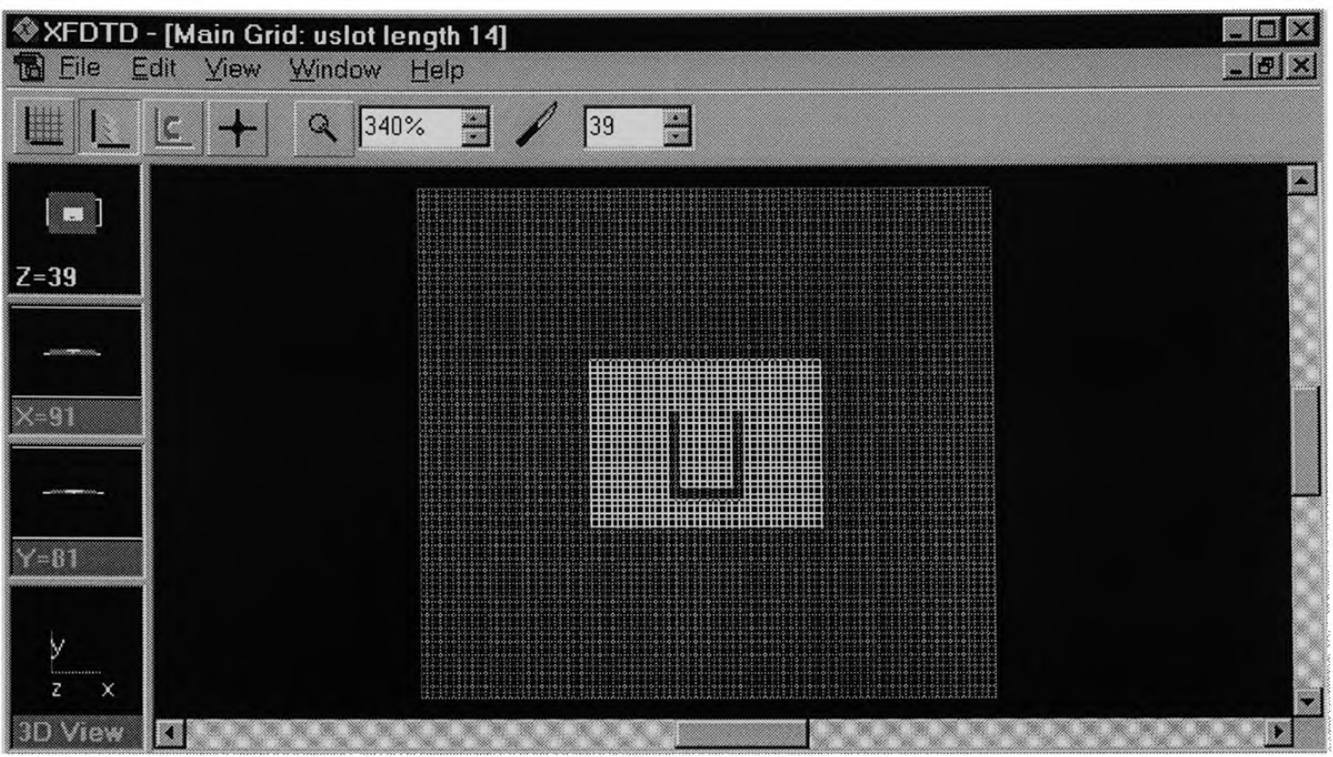

Fig. 38 XFDTD geometry of coaxial fed U-slot antenna with slot length of $14 \mathrm{~mm}$

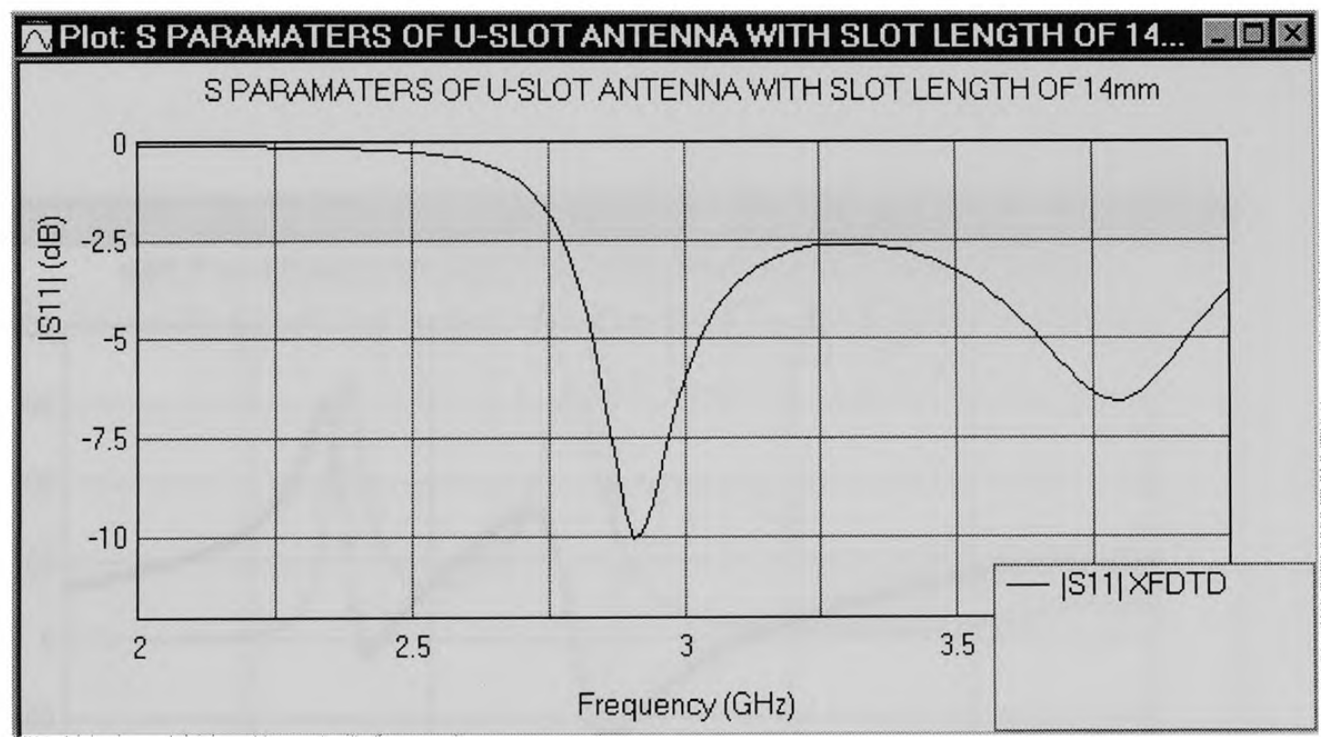

Fig.39 IS11I vs. Frequency for coaxial fed U-slot antenna with a slot length of $14 \mathrm{~mm}$

From the plot below, for a VSWR of $2: 1$, the bandwidth of the antenna is (2.872.93)/2.9=0.02 i.e., about $2 \%$. 


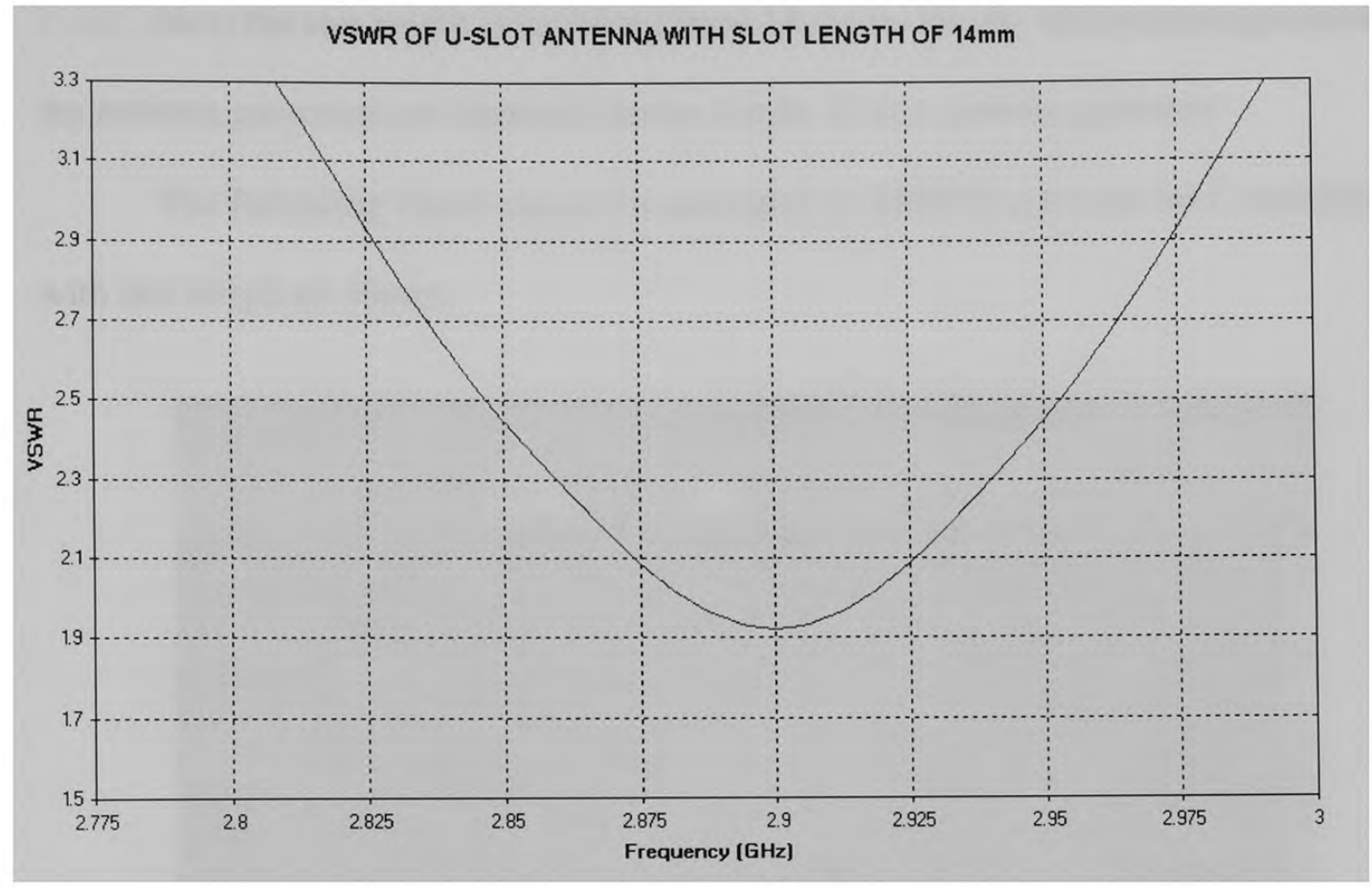

Fig.40 VSWR vs. Frequency for Coaxial fed U-slot antenna with a slot length of $14 \mathrm{~mm}$

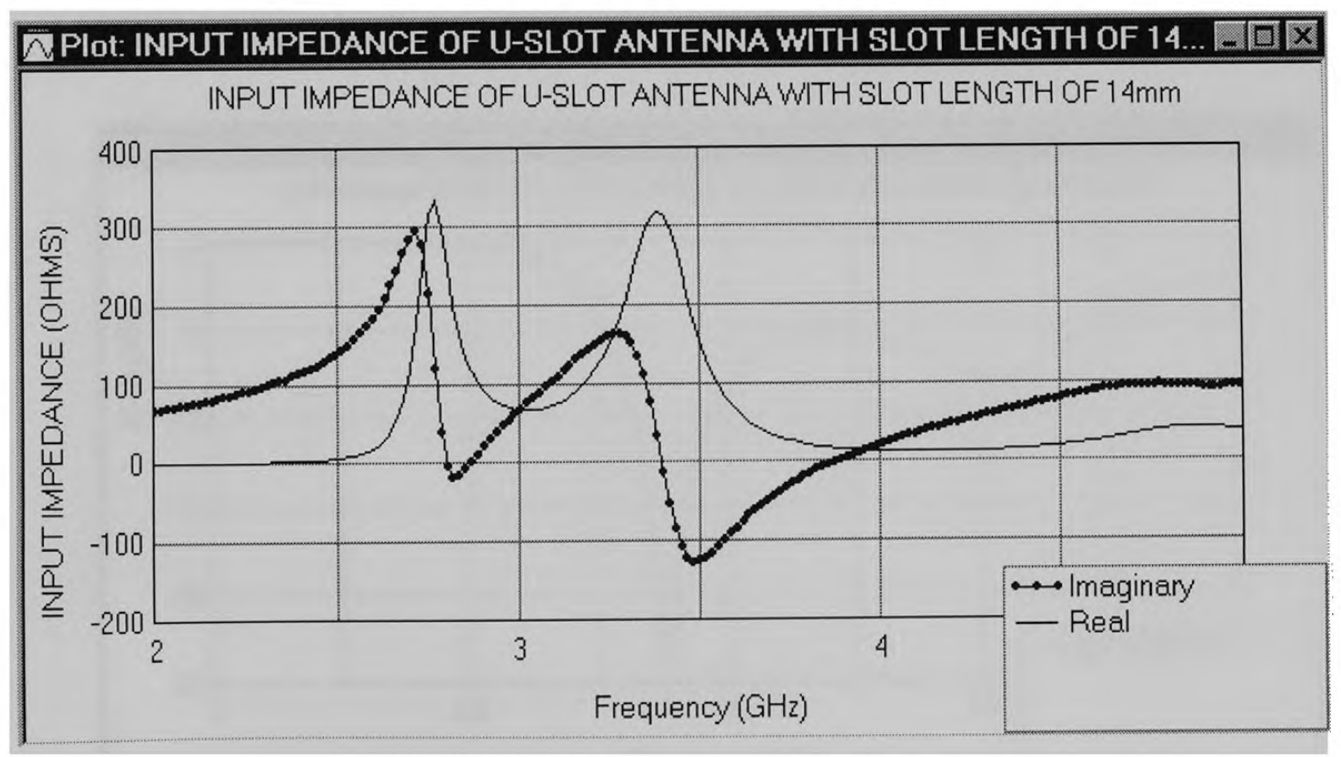

Fig.41 Input Impedance vs. Frequency for Coaxial fed U-slot antenna with a slot length of $14 \mathrm{~mm}$ 
Next the slot length is increased from $14 \mathrm{~mm}$ to $16 \mathrm{~mm}$. All the other parameters of the antenna geometry are identical chosen for the U-slot antenna geometry.

The following figure shows the geometry in XFDTD software for U-slot antenna with slot length of $16 \mathrm{~mm}$.

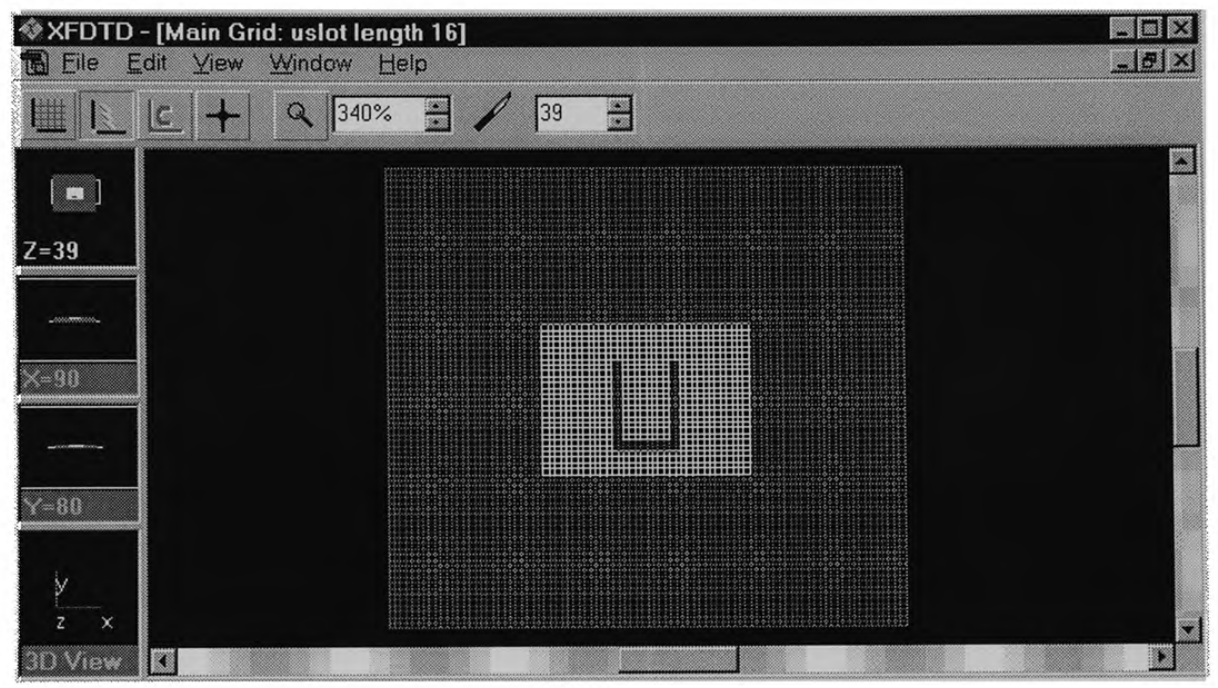

Fig.42 XFDTD geometry of coaxial fed U-slot antenna with slot length of $16 \mathrm{~mm}$

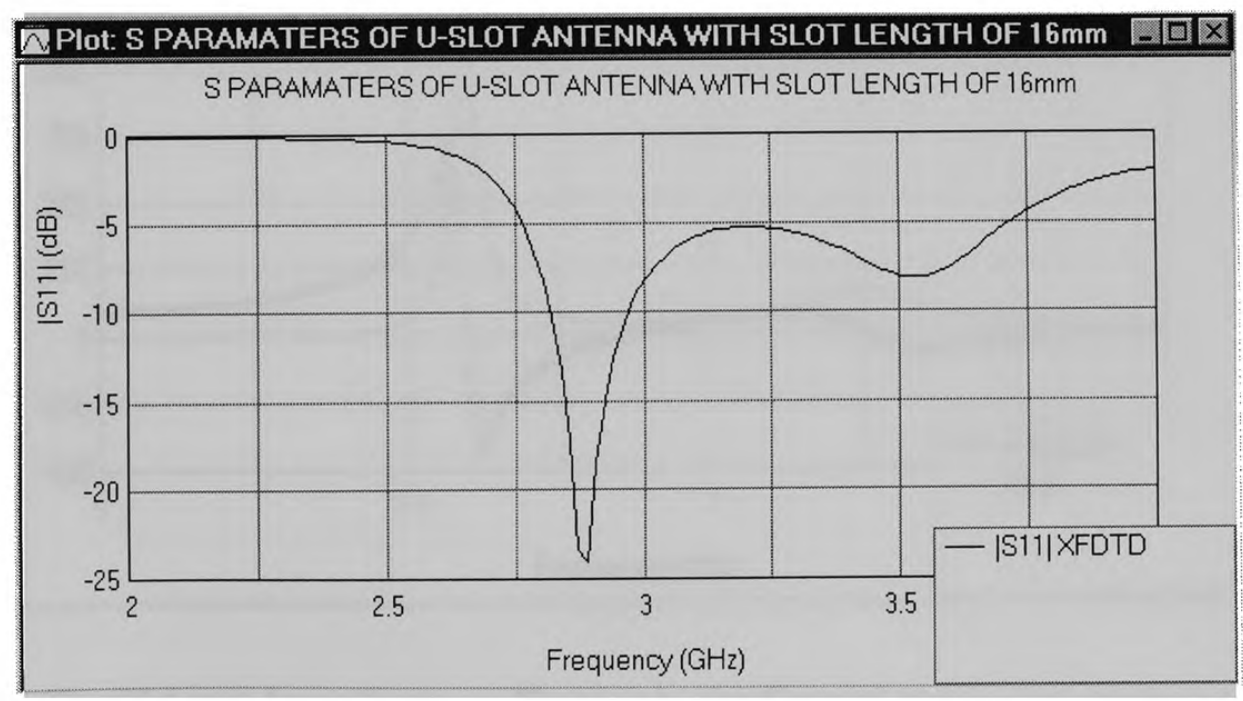

Fig.43 IS11I vs. Frequency for Coaxial fed U-slot antenna with a slot length of $16 \mathrm{~mm}$ 
From the plot below, for a VSWR of 2:1, the bandwidth of the antenna is (3.05$2.75) / 2.9=0.10$ i.e., about $10 \%$.

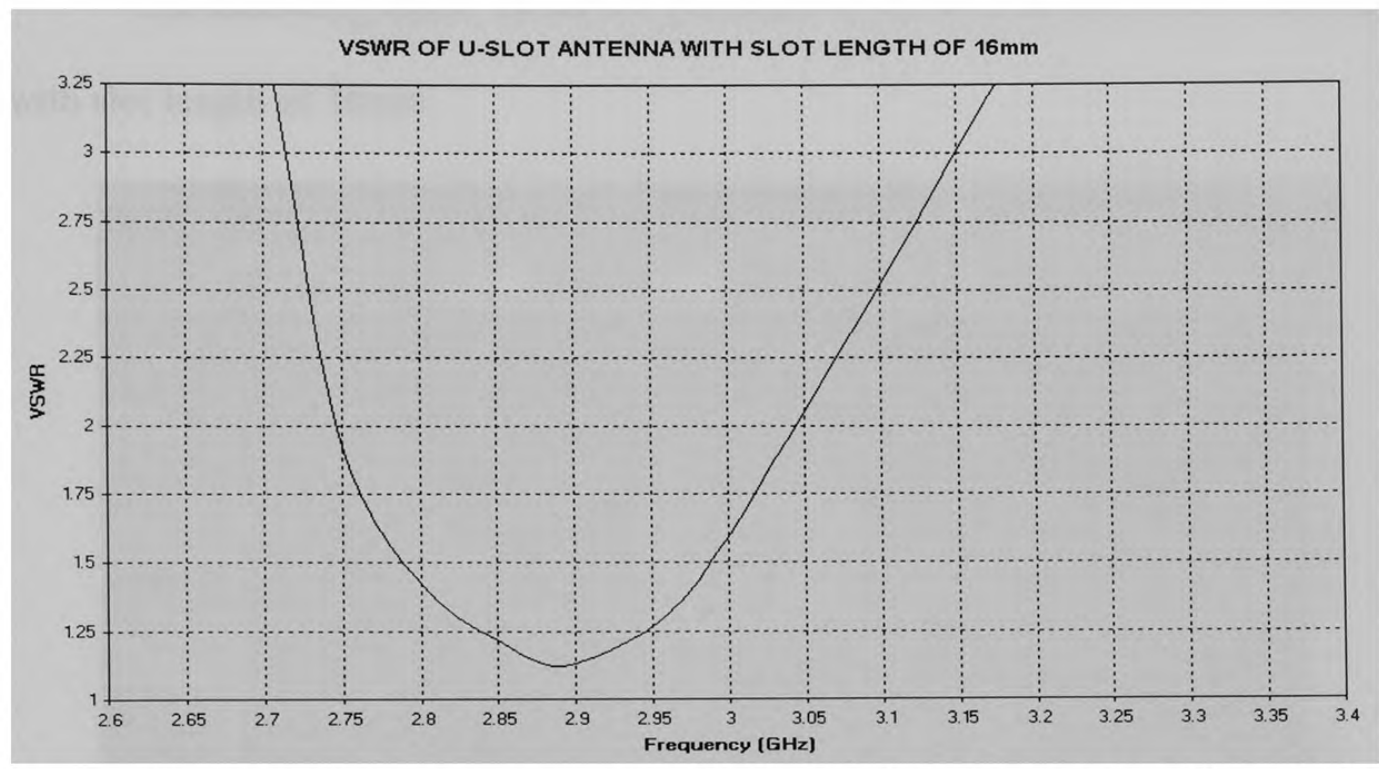

Fig.44 VSWR vs. Frequency for Coaxial fed U-slot antenna with a slot length of $16 \mathrm{~mm}$

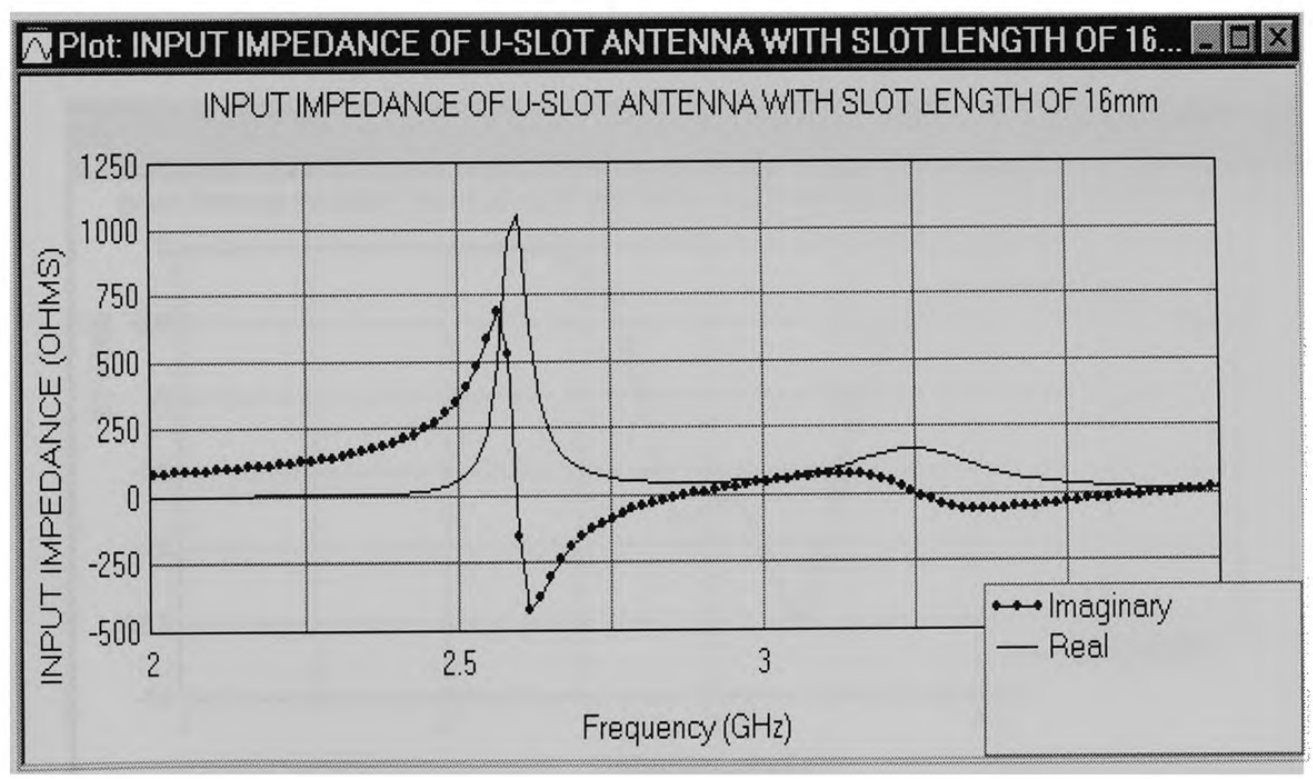

Fig.45 Input Impedance vs. Frequency for Coaxial fed U-slot antenna with a slot length of $16 \mathrm{~mm}$ 
Next the slot length is increased from $16 \mathrm{~mm}$ to $18 \mathrm{~mm}$. All the other parameters of the antenna geometry are identical chosen for the U-slot antenna geometry.

The following figure shows the geometry in XFDTD software for U-slot antenna with slot length of $18 \mathrm{~mm}$.

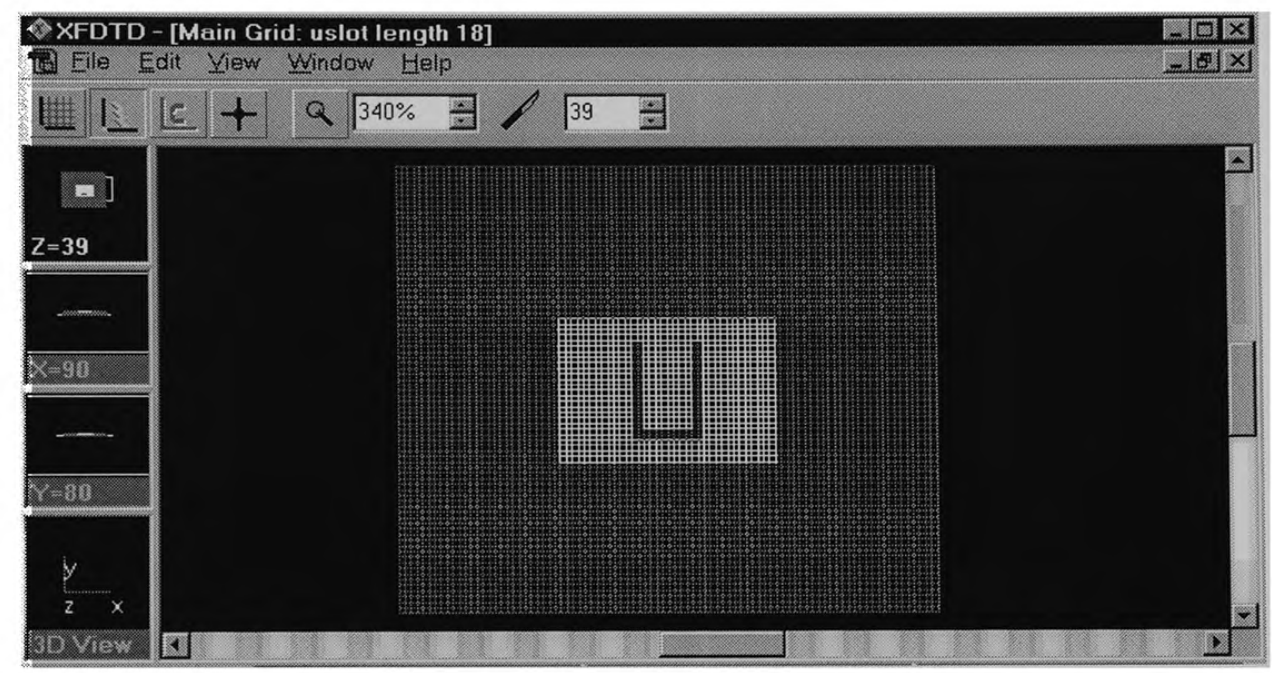

Fig.46 XFDTD geometry of coaxial fed U-slot antenna with slot length of $18 \mathrm{~mm}$

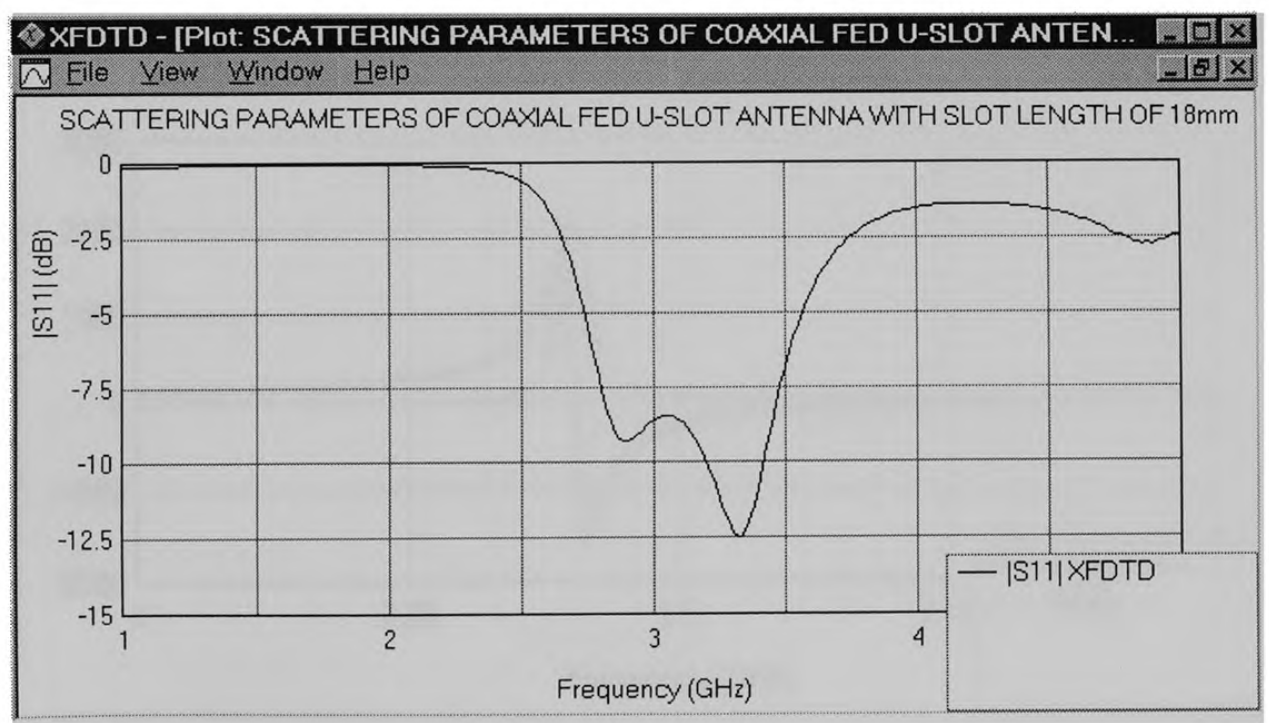

Fig.47 IS11I vs. Frequency for Coaxial fed U-slot antenna with a slot length of $18 \mathrm{~mm}$ 
From the plot below, for a VSWR of $2: 1$, the bandwidth of the antenna is (3.5$3.25) / 3.35=0.074$ i.e., about $7.4 \%$.

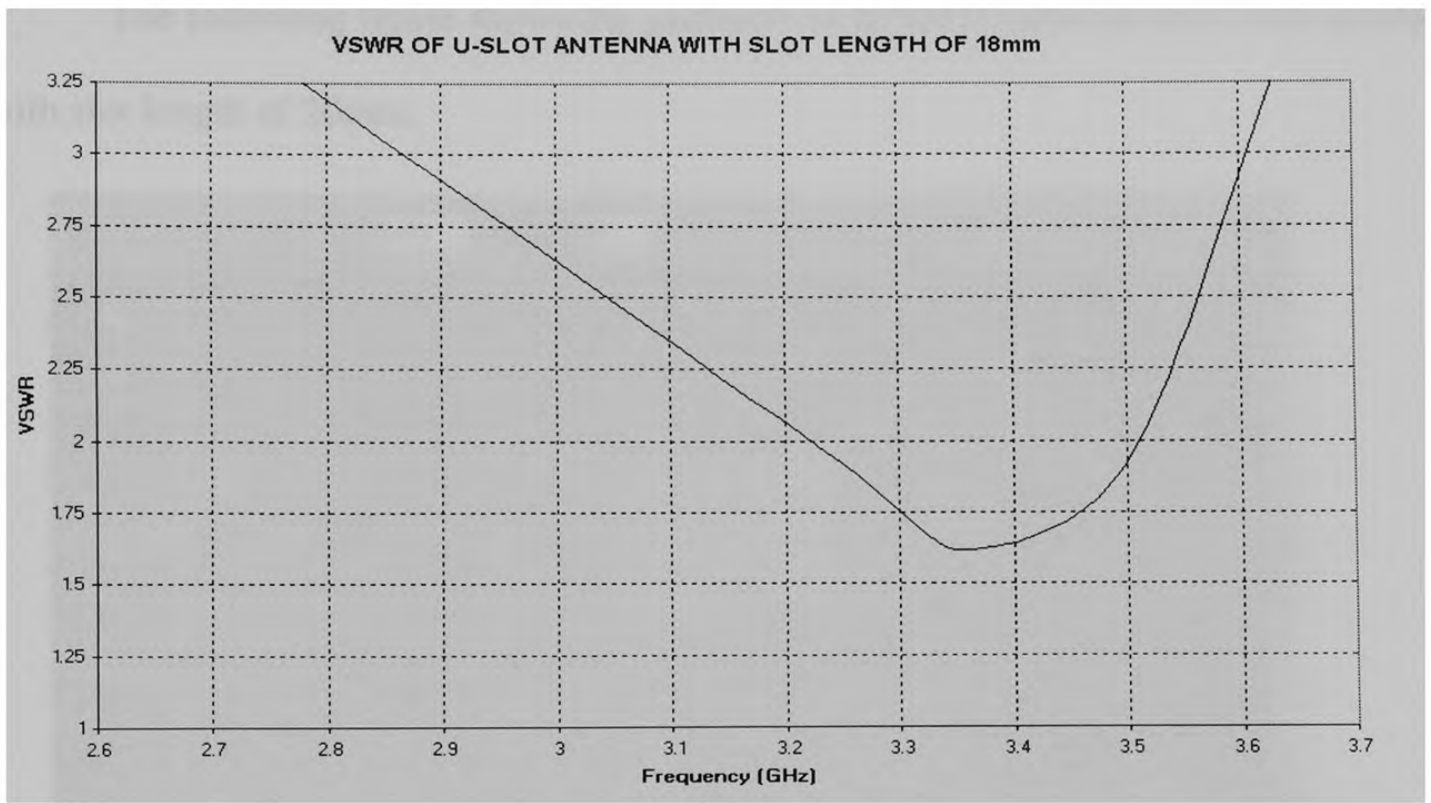

Fig.48 VSWR vs. Frequency for Coaxial fed U-slot antenna with a slot length of $18 \mathrm{~mm}$

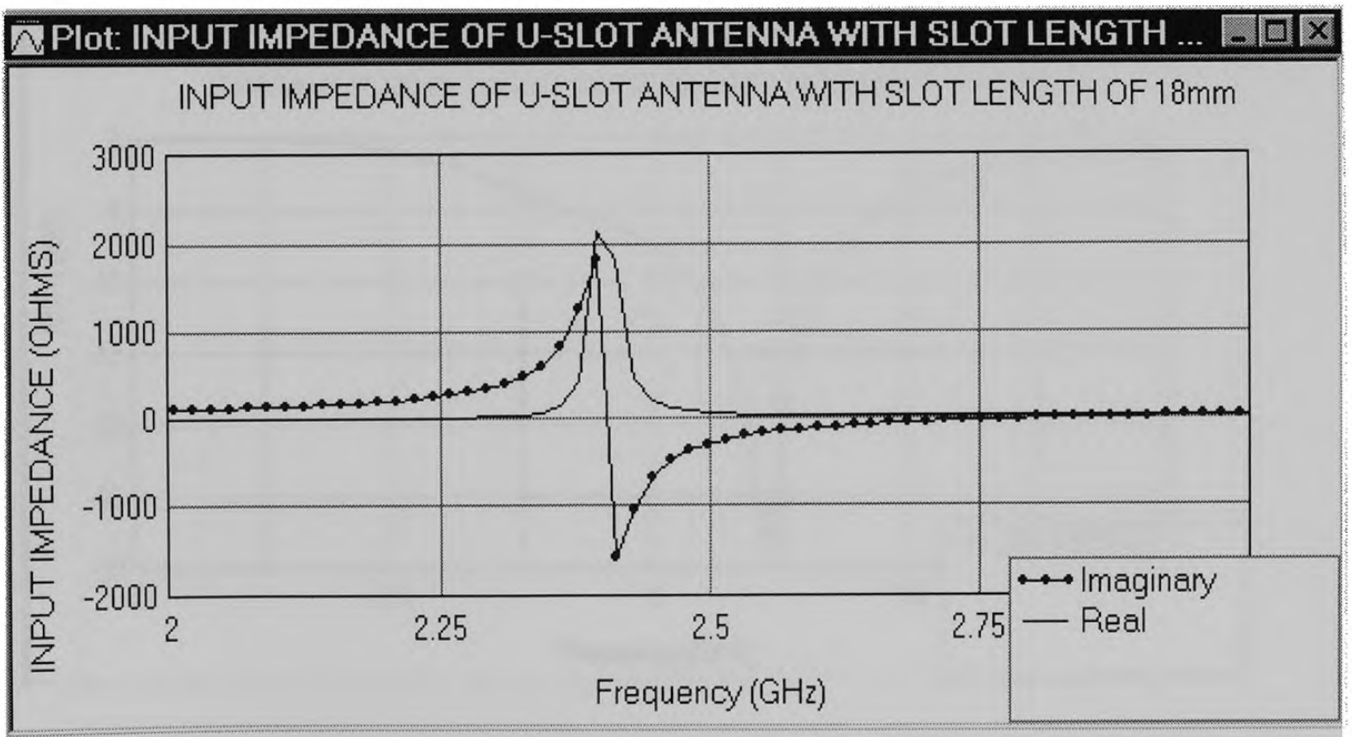

Fig.49 Input Impedance vs. Frequency for Coaxial fed U-slot antenna with a slot length of $18 \mathrm{~mm}$ 
Next the slot length is increased from $18 \mathrm{~mm}$ to $20 \mathrm{~mm}$. All the other parameters of the antenna geometry are identical chosen for the U-slot antenna geometry.

The following figure shows the geometry in XFDTD software for U-slot antenna with slot length of $20 \mathrm{~mm}$.

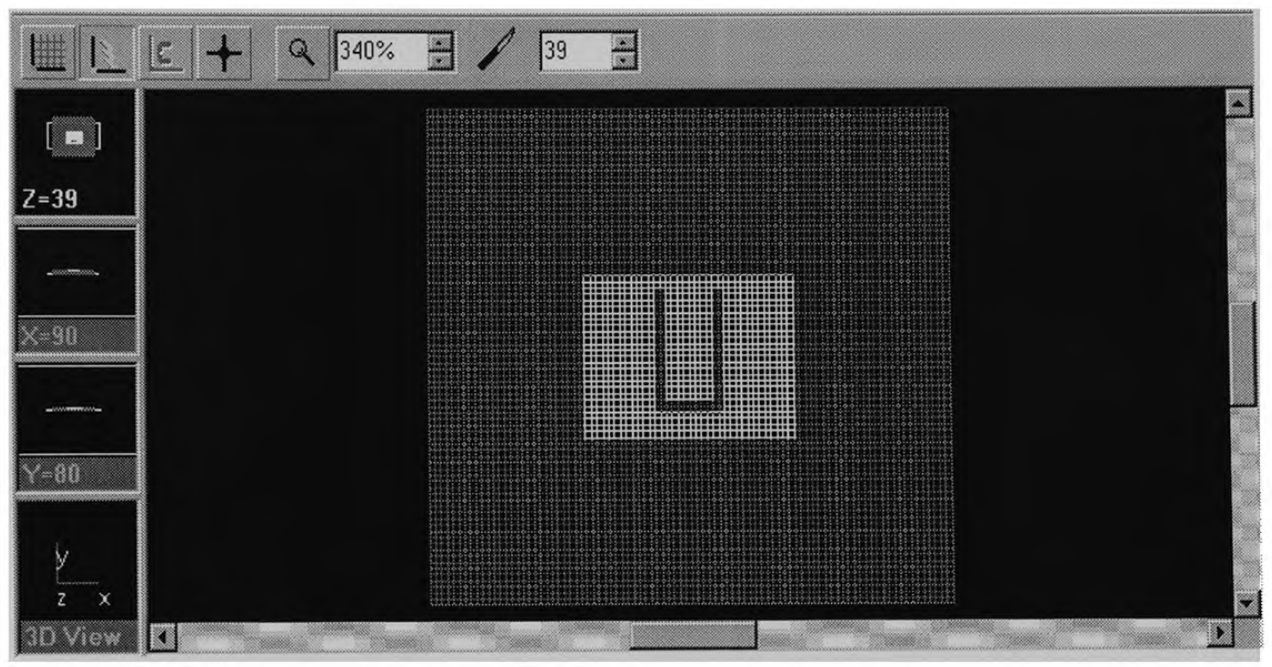

Fig.50 XFDTD geometry of coaxial fed U-slot antenna with slot length of $20 \mathrm{~mm}$

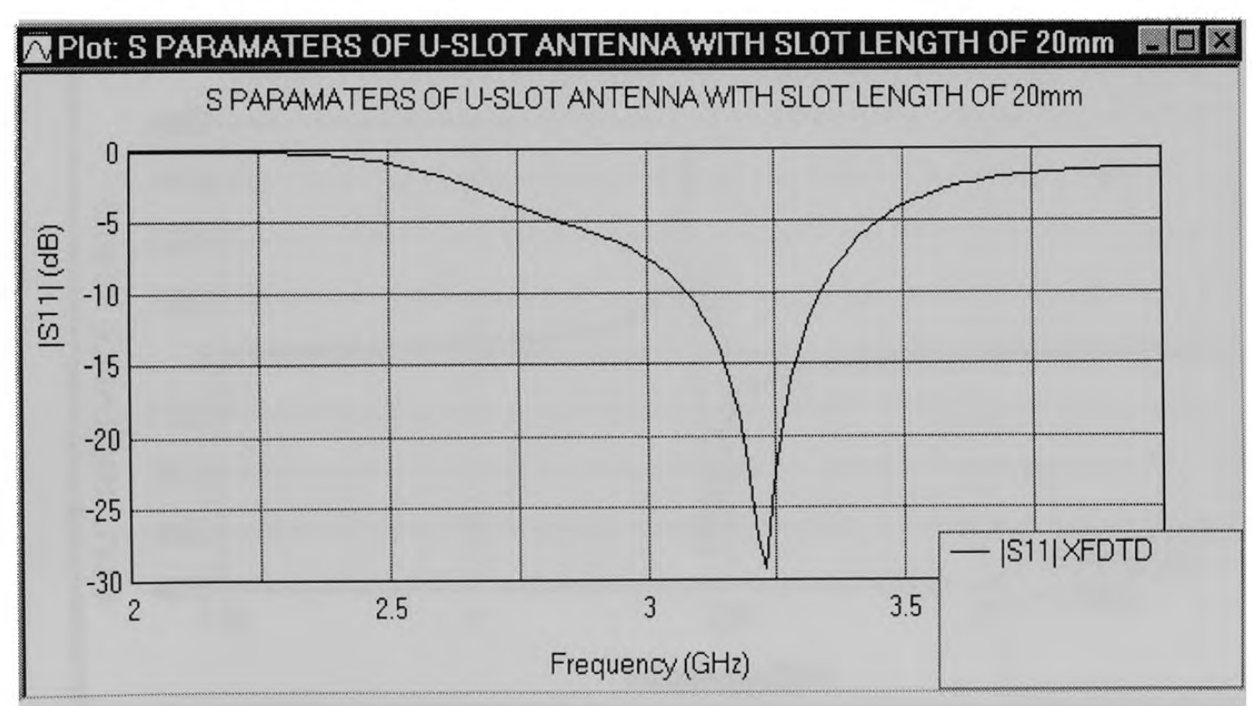

Fig.51 IS11I vs. Frequency for Coaxial fed U-slot antenna with a slot length of $20 \mathrm{~mm}$ 
From the plot below, for a VSWR of 2:1, the bandwidth of the antenna is (3.533.07)/3.24=0.1419 i.e., about $14.2 \%$.

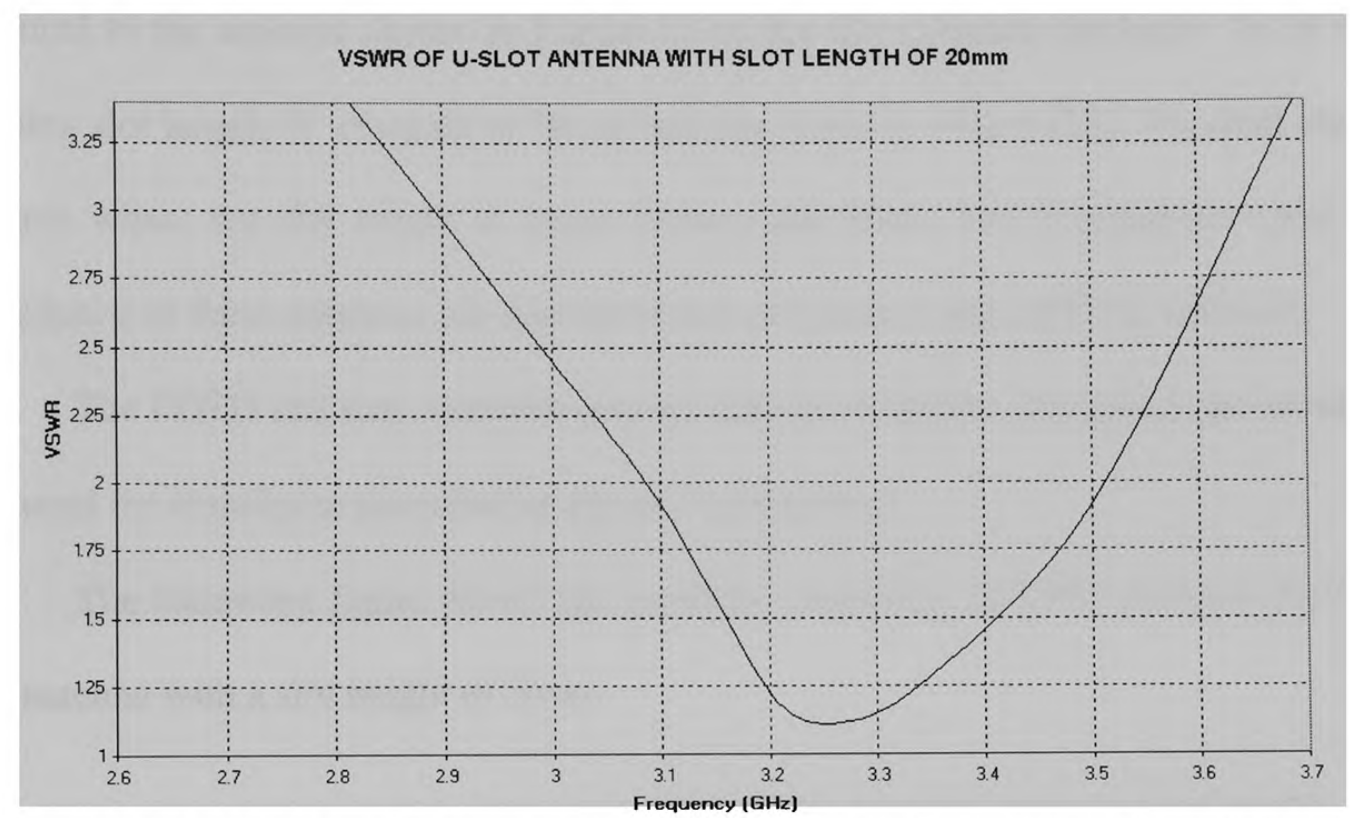

Fig.52 VSWR vs. Frequency for Coaxial fed U-slot antenna with a slot length of $20 \mathrm{~mm}$

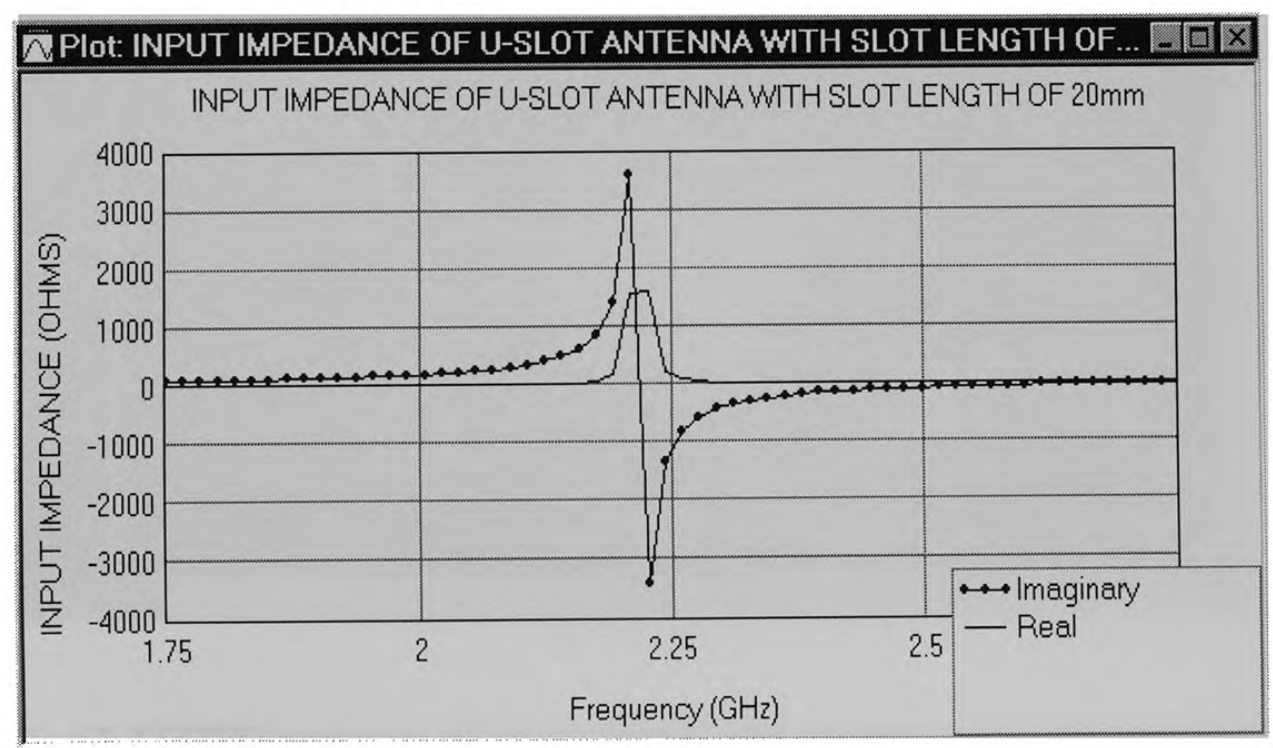

Fig.53 Input Impedance vs. Frequency for Coaxial fed U-slot antenna with a slot length of $20 \mathrm{~mm}$ 
Now we will analyze a Coaxial fed U-slot antenna that has all the dimensions identical to the antenna shown in Figure 14 except the substrate thickness ' $h$ ' is varied keeping slot length 'b' constant at $18 \mathrm{~mm}$ and slot width at $14 \mathrm{~mm}$ [13]. We shall consider 3 cases where the slot height is $5 \mathrm{~mm}, 6.4 \mathrm{~mm}$ and $8 \mathrm{~mm}$. The S parameters and Input Impedance of these antennas are simulated and compared using XFDTD software.

The FDTD cell size, stimulus settings and the boundary conditions are identical to that used for simulation described in the previous section.

The following figure shows the geometry created in XFDTD software for the Uslot antenna with a slot height of $5 \mathrm{~mm}$.

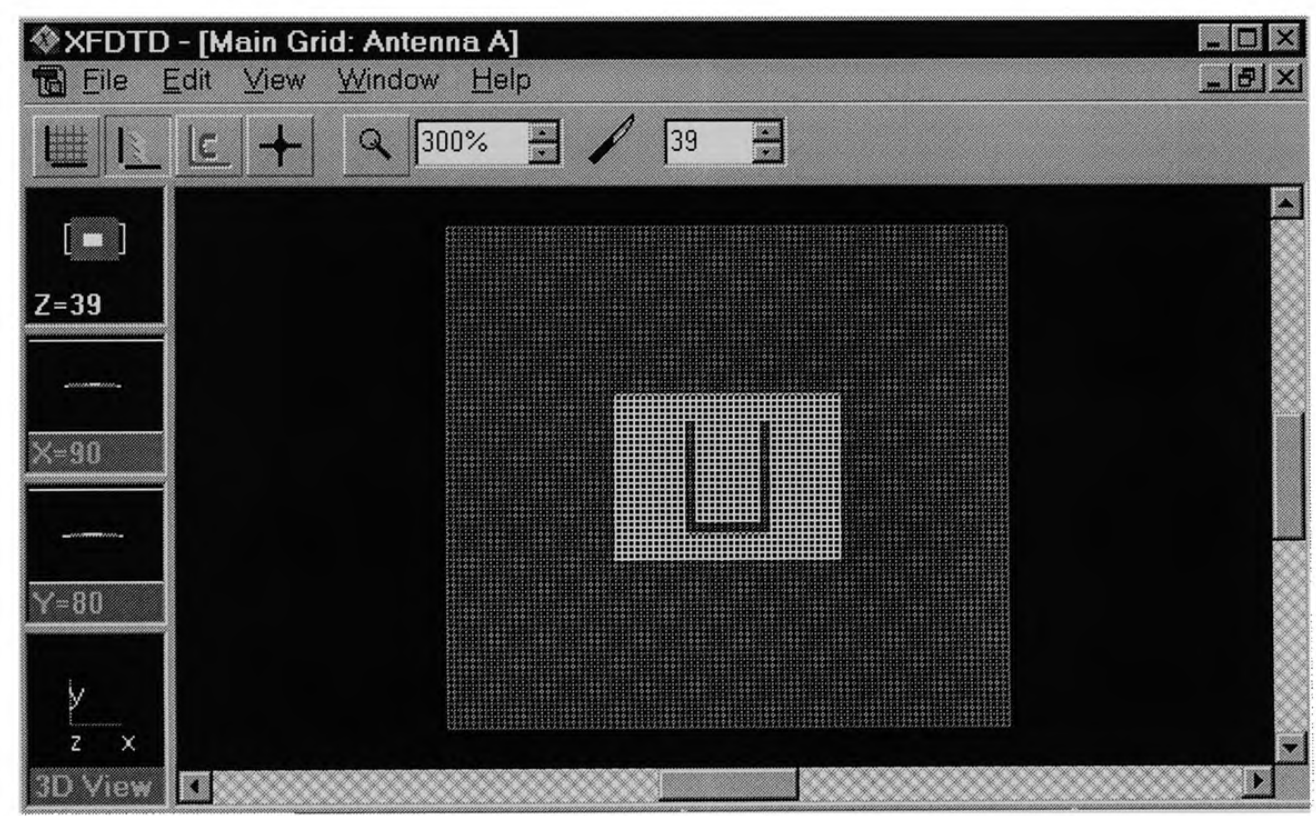

Fig.54 XFDTD geometry of coaxial fed U-slot antenna with substrate thickness of $5 \mathrm{~mm} X-Y$ plane view 


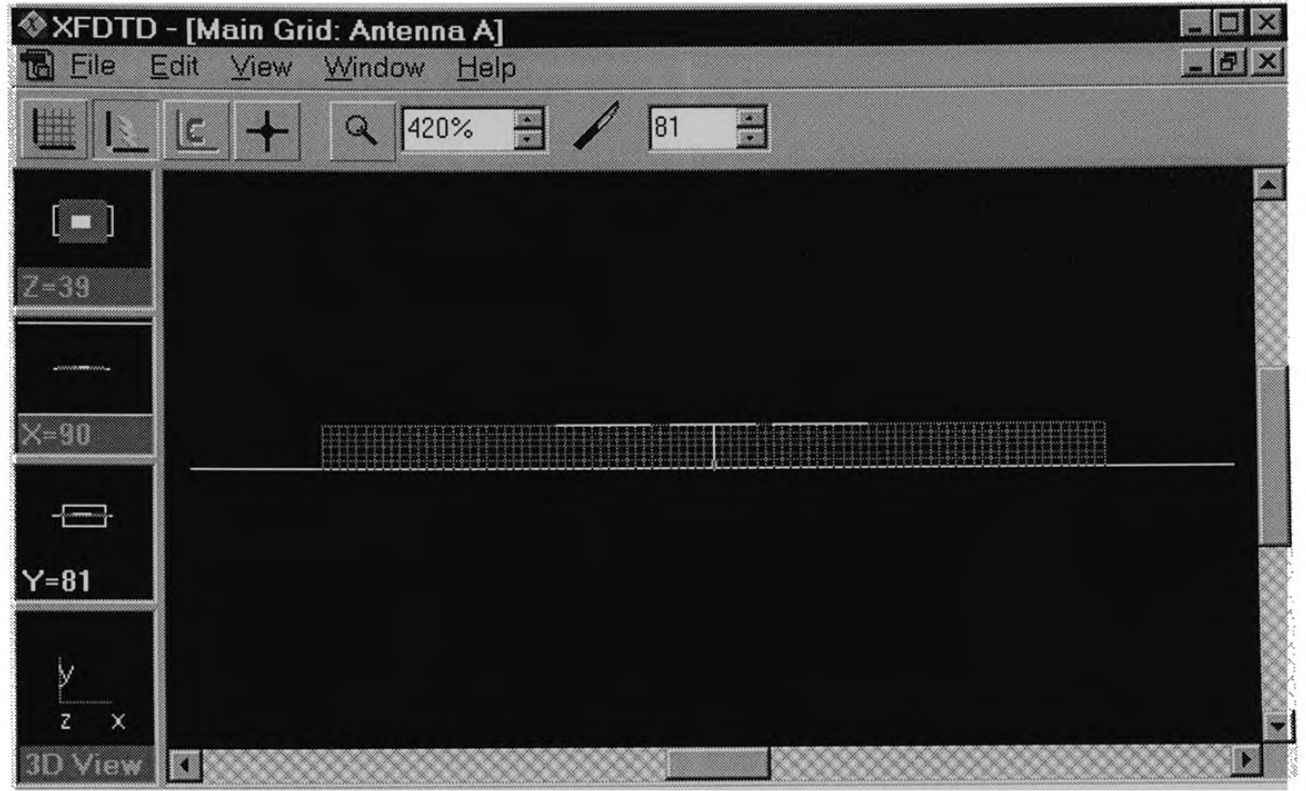

Fig.55 XFDTD geometry of coaxial fed U-slot antenna with substrate thickness of $5 \mathrm{~mm} X-Z$ plane view

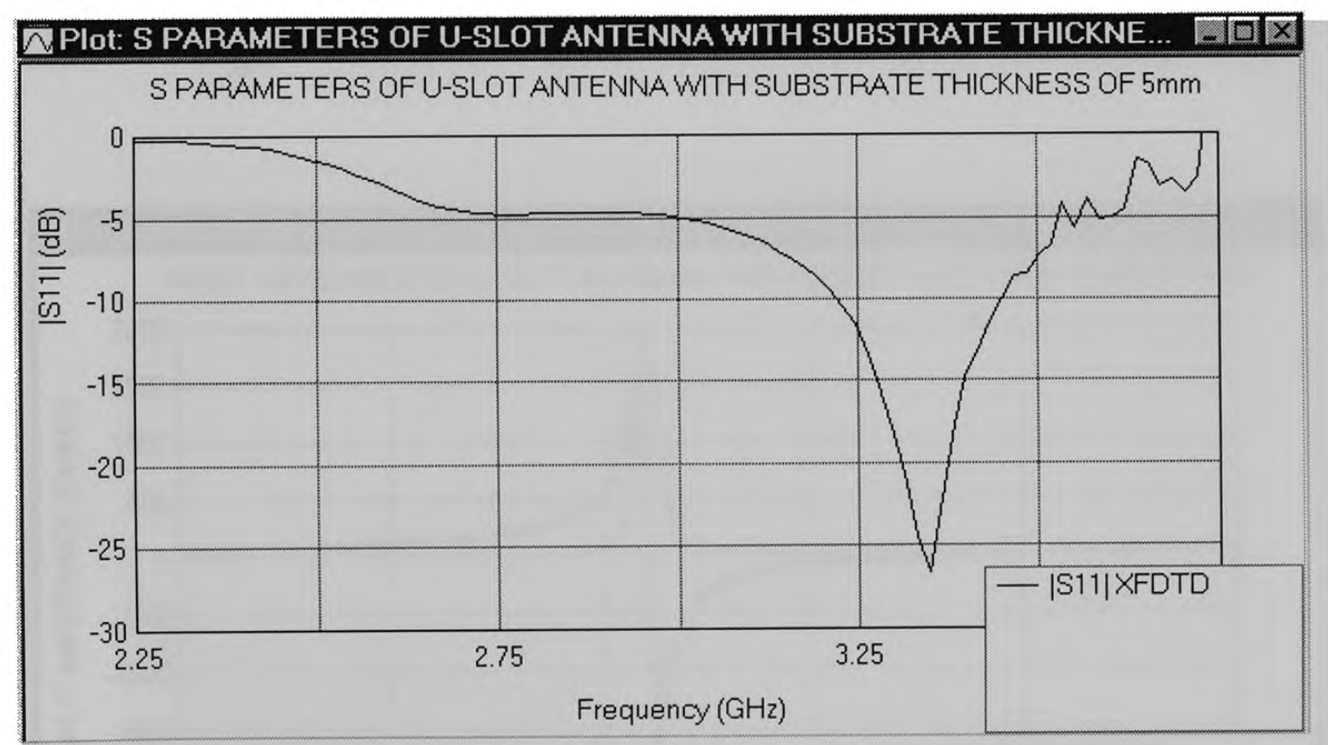

Fig.56 IS 11 I Vs Frequency of U-slot antenna with substrate thickness of $5 \mathrm{~mm}$ 
Using the data for S-parameters obtained above; VSWR for the antenna under consideration is deduced and plotted as shown in the following figure.

From the plot below, for a VSWR of $2: 1$, the bandwidth of the antenna is (3.513.3)/3.4=0.061 i.e., about $6.1 \%$.

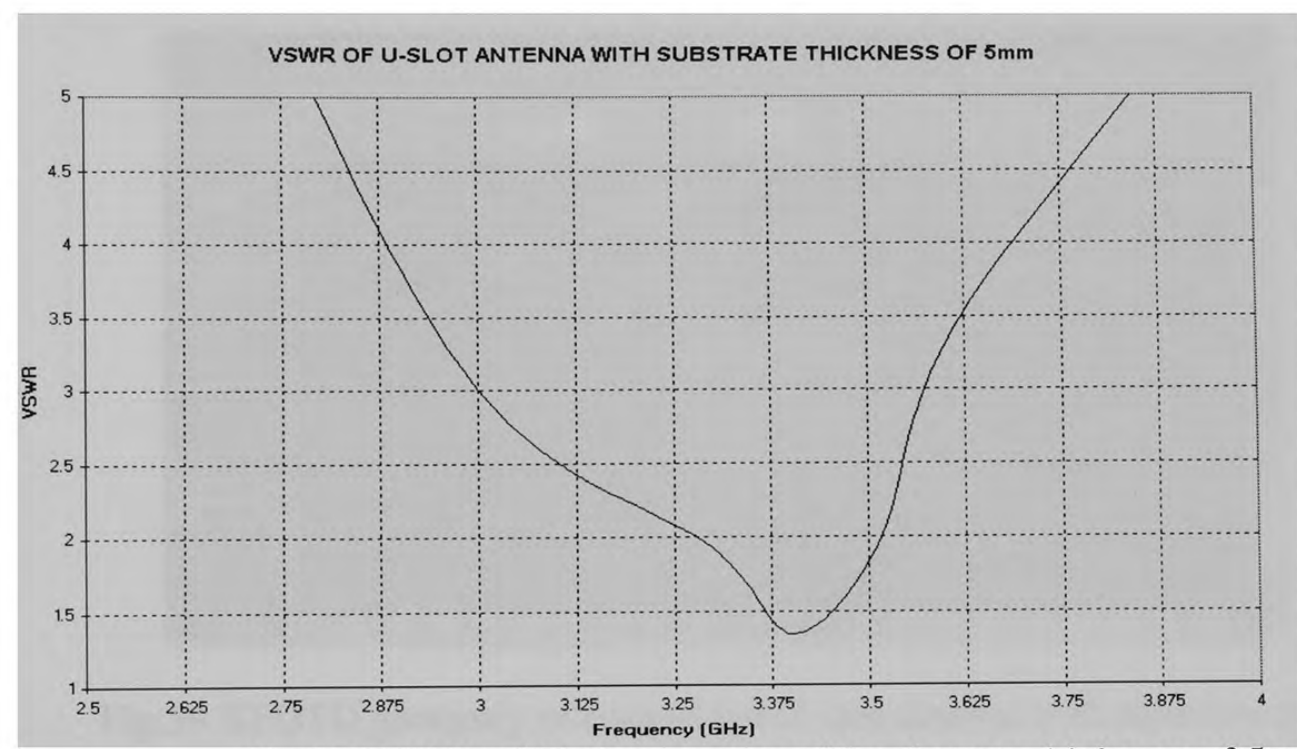

Fig.57 VSWR of U-slot antenna with substrate thickness of $5 \mathrm{~mm}$

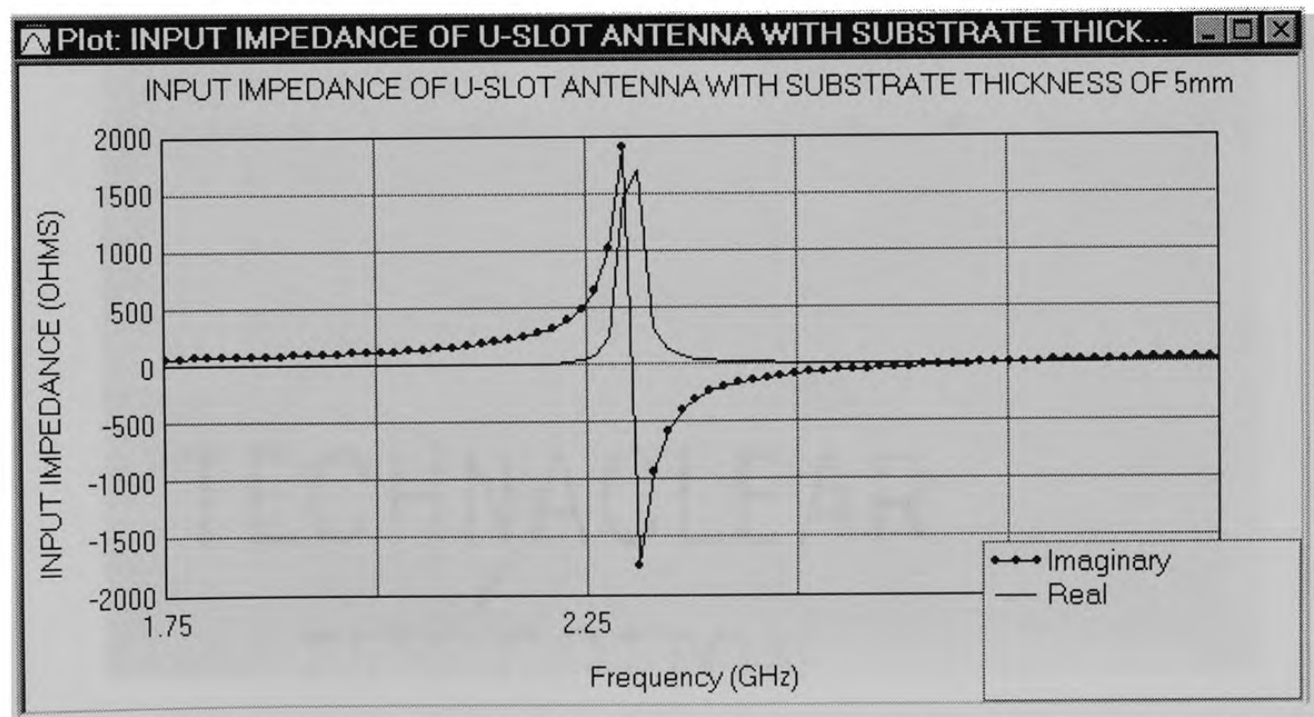

Fig.58 Input Impedance of U-slot antenna with substrate thickness of $5 \mathrm{~mm}$ 
Next the substrate thickness is increased from $5 \mathrm{~mm}$ to $6.4 \mathrm{~mm}$. All the other parameters of the antenna geometry are identical chosen for the U-slot antenna geometry.

The following figure shows the geometry in XFDTD software for U-slot antenna with substrate thickness of $6.4 \mathrm{~mm}$.

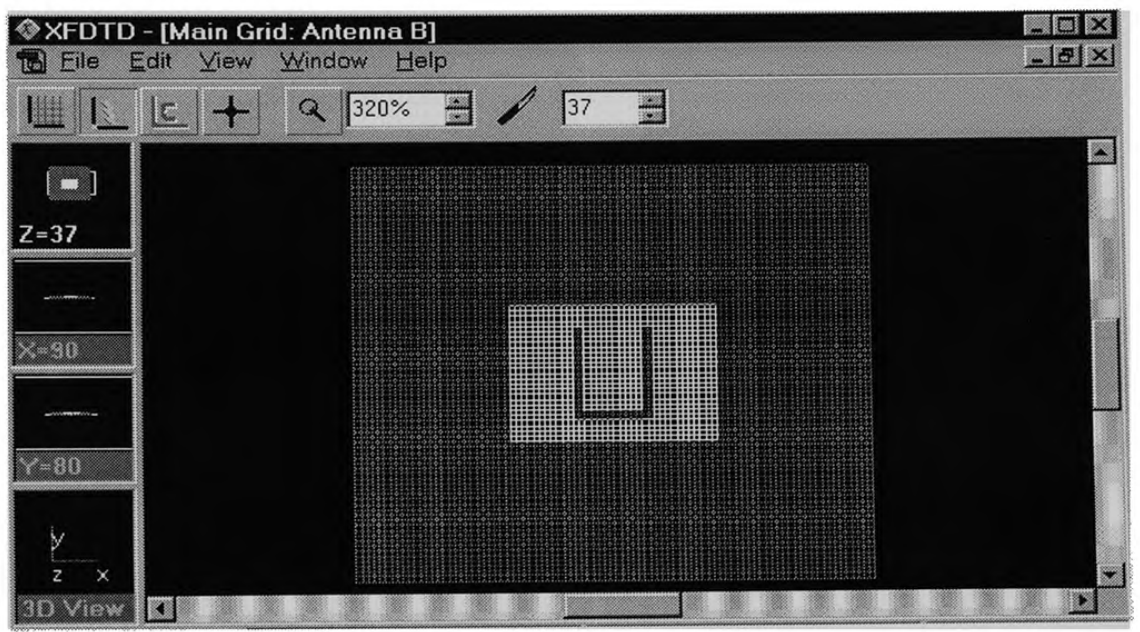

Fig.59 XFDTD geometry of coaxial fed U-slot antenna with substrate thickness of $6.4 \mathrm{~mm}, \mathrm{X}$-Y plane view

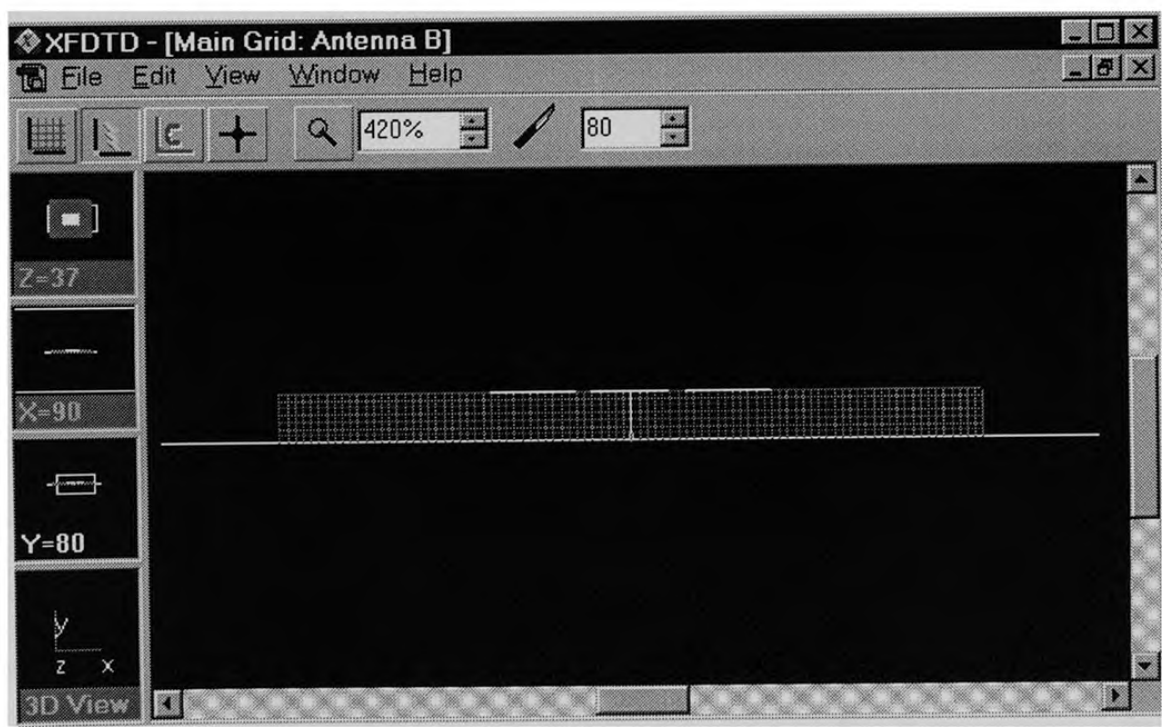

Fig.60 XFDTD geometry of coaxial fed U-slot antenna with substrate thickness of $6.4 \mathrm{~mm}, \mathrm{X}-\mathrm{Z}$ plane view 


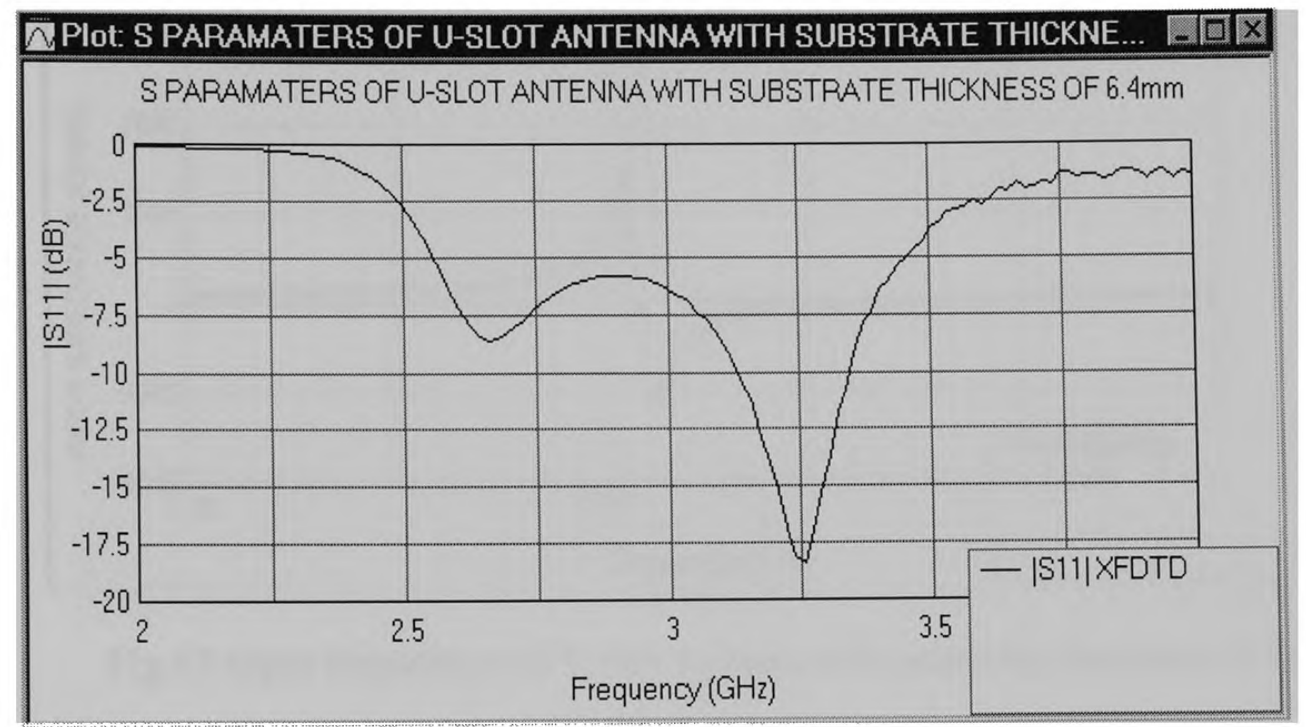

Fig.61 IS11I Vs Frequency of U-slot antenna with substrate thickness of $6.4 \mathrm{~mm}$

From the plot below, for a VSWR of 2:1, the bandwidth of the antenna is (3.62.89) $/ 3.21=0.221$ i.e., about $22.1 \%$.

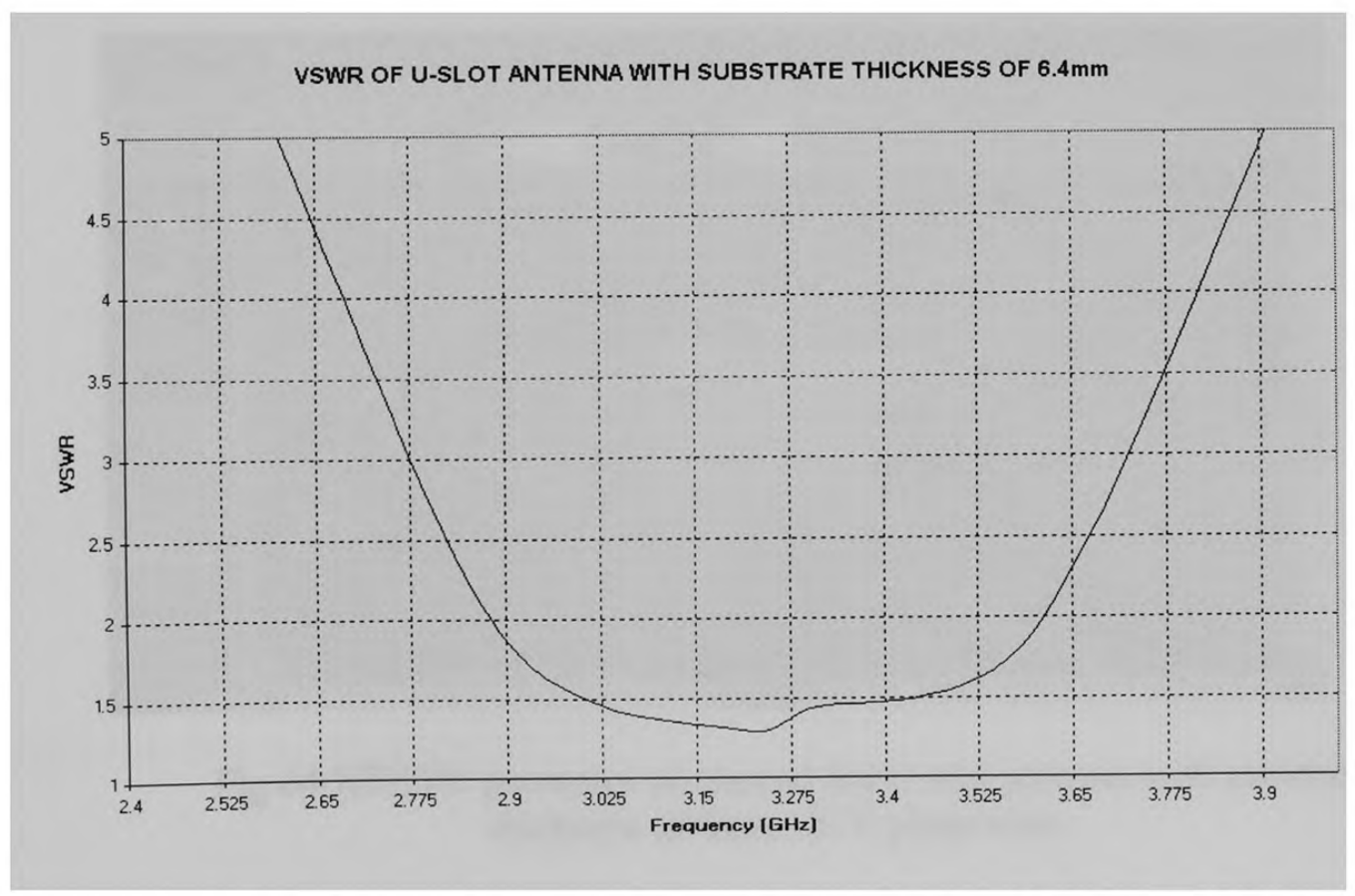

Fig.62 VSWR of U-slot antenna with substrate thickness of $6.4 \mathrm{~mm}$ 


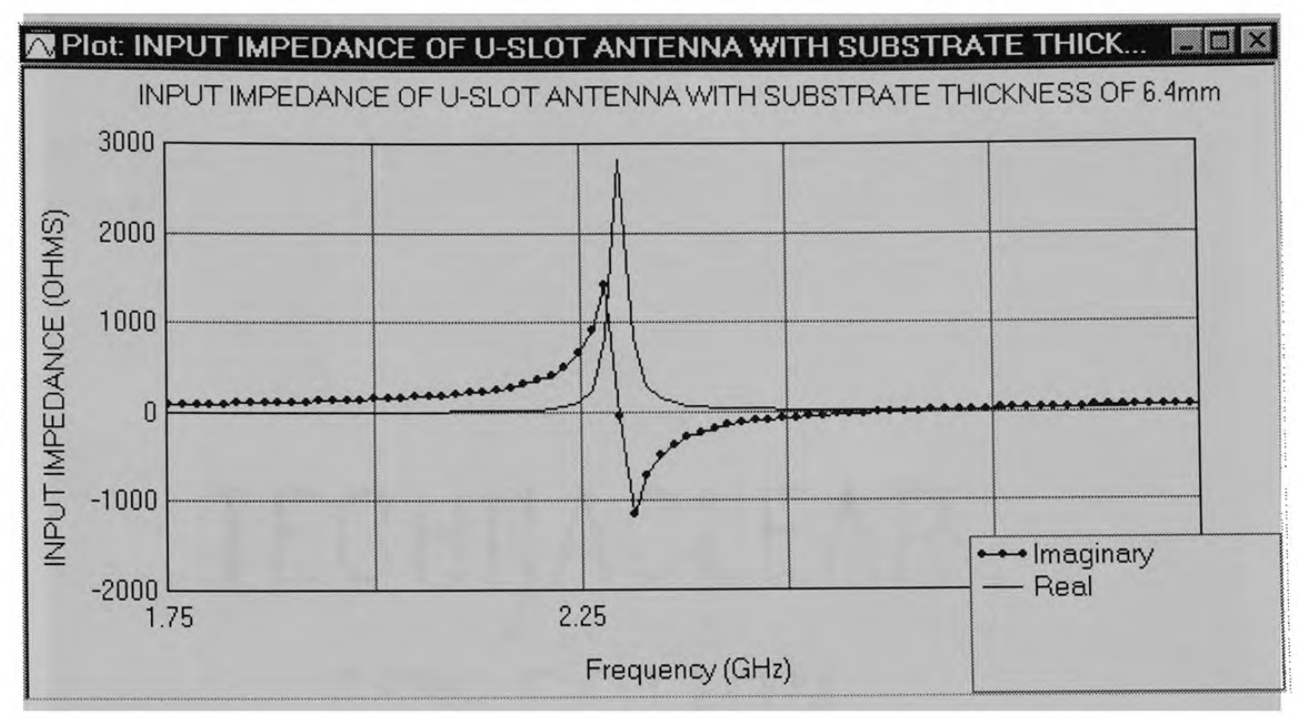

Fig.63 Input Impedance of U-slot antenna with substrate thickness of $6.4 \mathrm{~mm}$

Next the substrate thickness is increased from $6.4 \mathrm{~mm}$ to $8 \mathrm{~mm}$. All the other parameters of the antenna geometry are identical chosen for the U-slot antenna geometry.

The following figure shows the geometry in XFDTD software for U-slot antenna with substrate thickness of $8 \mathrm{~mm}$.

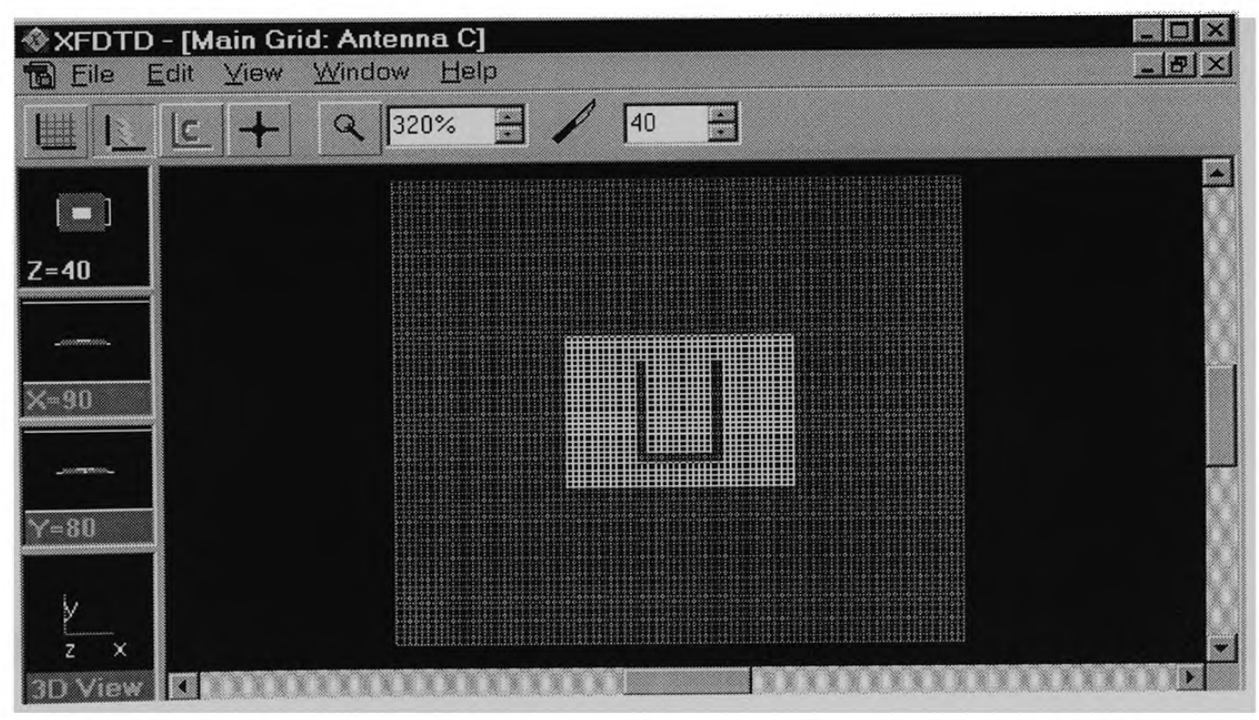

Fig.64 XFDTD geometry of coaxial fed U-slot antenna with substrate thickness of $8 \mathrm{~mm}, \mathrm{X}-\mathrm{Y}$ plane view 


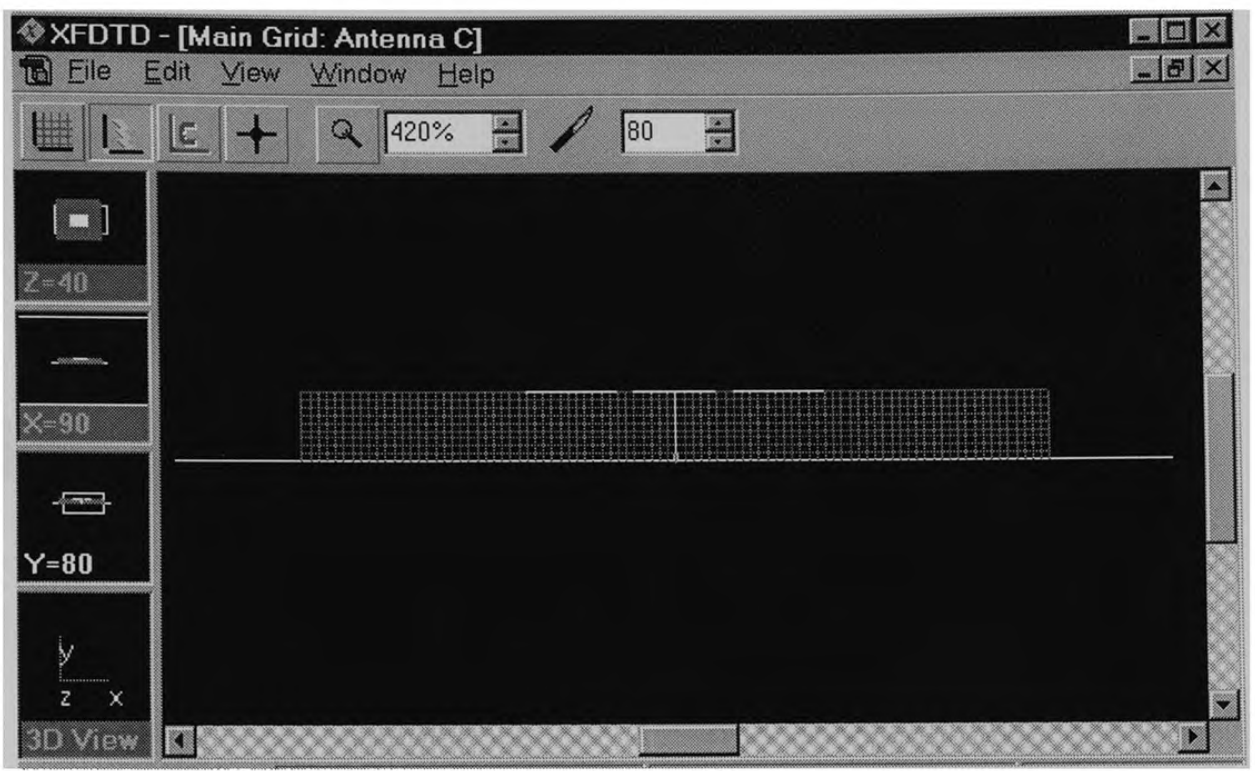

Fig.65 XFDTD geometry of coaxial fed U-slot antenna with substrate thickness of $8 \mathrm{~mm}, \mathrm{X}-\mathrm{Z}$ plane view

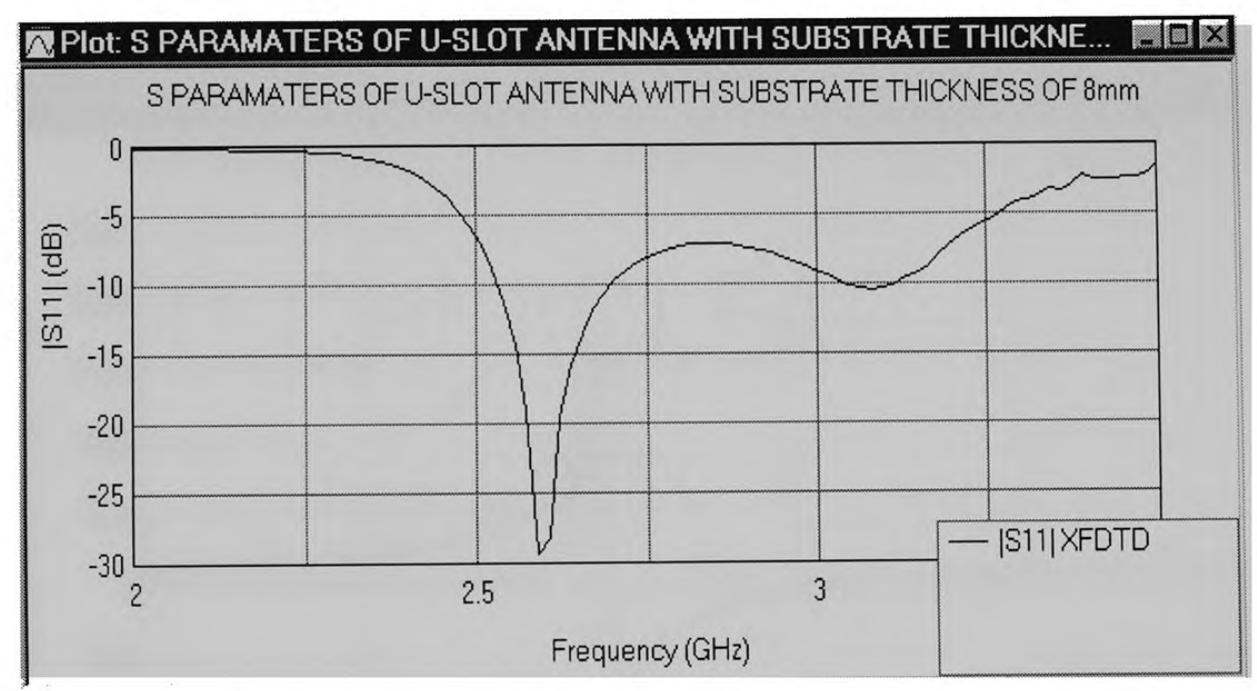

Fig.66 IS11। Vs Frequency of U-slot antenna with substrate thickness of $8 \mathrm{~mm}$

From the plot below, for a VSWR of 2:1, the bandwidth of the antenna is (2.952.32)/2.6=0.242 i.e., about $24.2 \%$. 


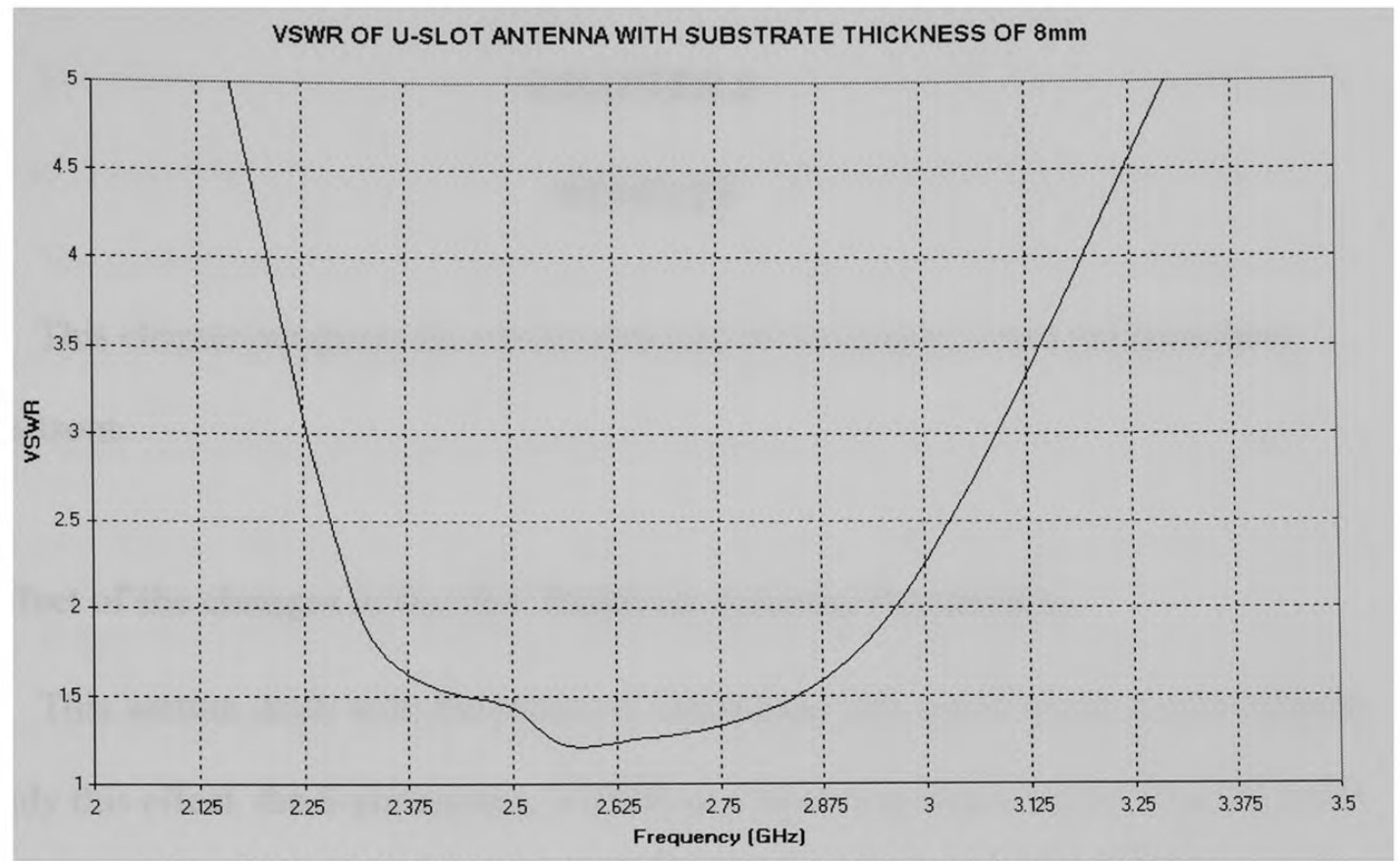

Fig.67 VSWR of U-slot antenna with substrate thickness of $8 \mathrm{~mm}$

\section{DPlot: INPUT IMPEDANCE OF U-SLOT ANTENNA WITH SUBSTRATE THICK... 口回区}

INPUT IMPEDANCE OF U-SLOT ANTENNA WITH SUBSTRATE THICKNESS OF $8 \mathrm{~mm}$

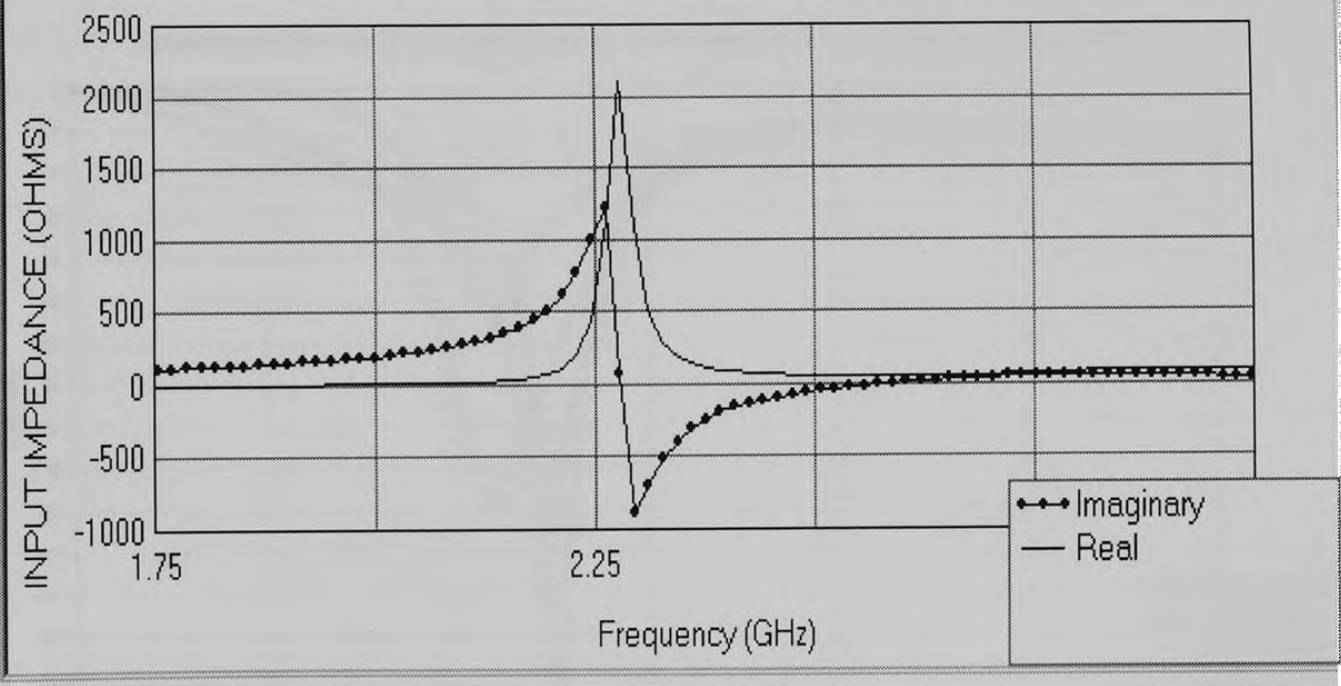

Fig.68 Input Impedance of U-slot antenna with substrate thickness of $8 \mathrm{~mm}$ 


\section{CHAPTER 5}

\section{RESULTS}

This chapter compares the results obtained in the chapter 4 and analyses these comparisons.

\subsection{Effect of the changes in the Slot Width on Antenna Parameters}

This section deals with the effect of varying the slot width of the U-slot antenna. To study this effect, the S-parameters, VSWR and Input Impedance of the Coaxial fed Uslot antenna with slot widths $8 \mathrm{~mm}, 10 \mathrm{~mm}, 12 \mathrm{~mm}$ and $14 \mathrm{~mm}$ are compared keeping the slot length constant at $20 \mathrm{~mm}$.

\subsubsection{Comparison of S-Parameters}

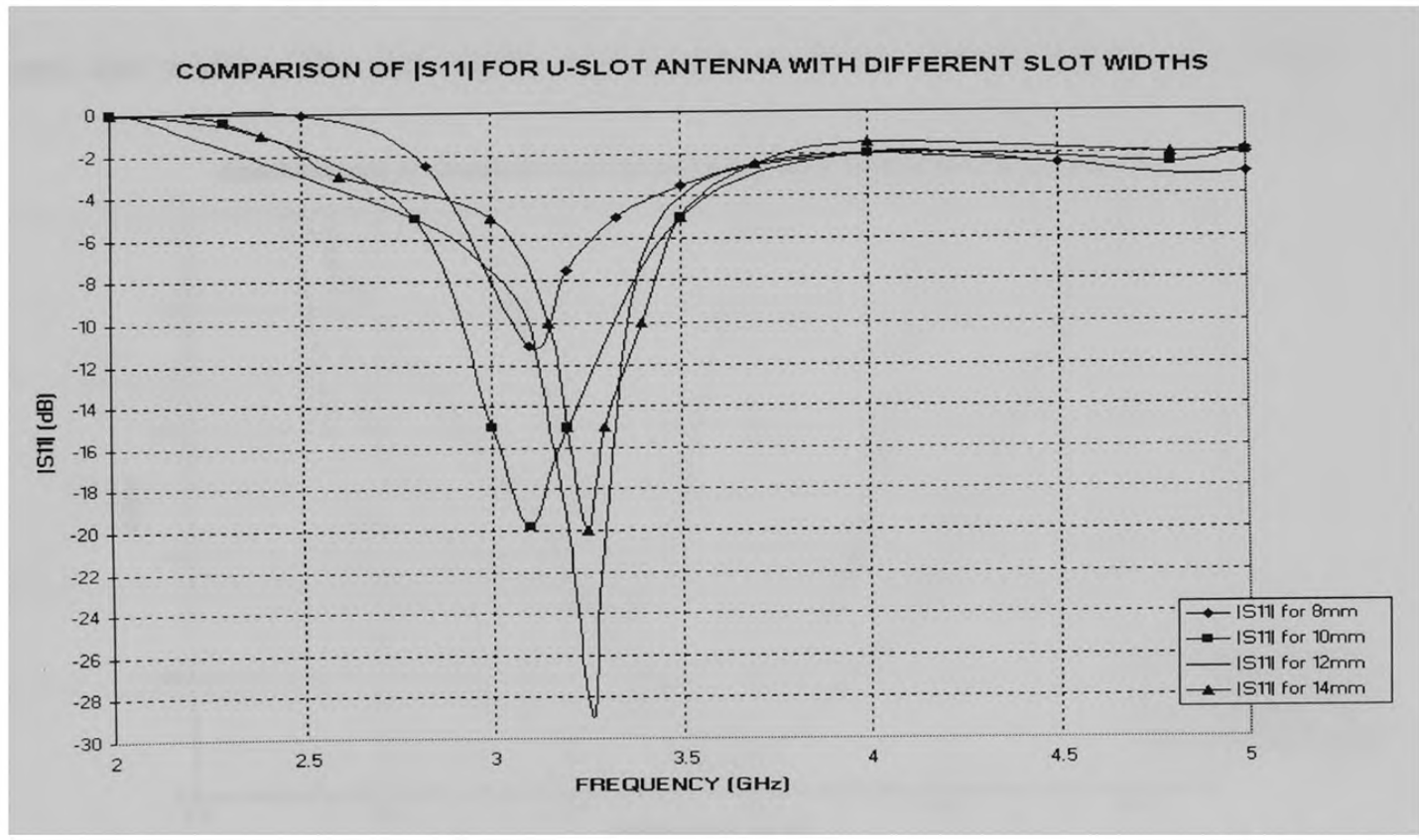

Fig.69 Comparison of S-parameters for U-slot antenna with different slot widths 
The above figure compares the S-parameters of Coaxial fed U-slot antennas with different slot widths. The slot widths in this case are $8 \mathrm{~mm}, 10 \mathrm{~mm}, 12 \mathrm{~mm}$ and $14 \mathrm{~mm}$.

The above comparison shows the variation of the bandwidth of the coaxial fed Uslot antenna with the slot width relative to the slot length. Here, $-3 \mathrm{~dB}$ bandwidth of the antenna with slot width of $8 \mathrm{~mm}$ is the least. The bandwidth is high for the slot widths of $10 \mathrm{~mm}$ and $12 \mathrm{~mm}$ relative to the slot length of $20 \mathrm{~mm}$. This variation in bandwidth is further supported by the following plot that compares the VSWR for the antennas with the slot widths of $8 \mathrm{~mm}, 10 \mathrm{~mm}, 12 \mathrm{~mm}$ and $14 \mathrm{~mm}$ keeping the slot length constant at $20 \mathrm{~mm}$.

\subsubsection{Comparison of VSWR}

The following figure shows the comparison of VSWR of the U-slot antenna with different slot widths. The slot widths in this case are $8 \mathrm{~mm}, 10 \mathrm{~mm}, 12 \mathrm{~mm}$ and $14 \mathrm{~mm}$.

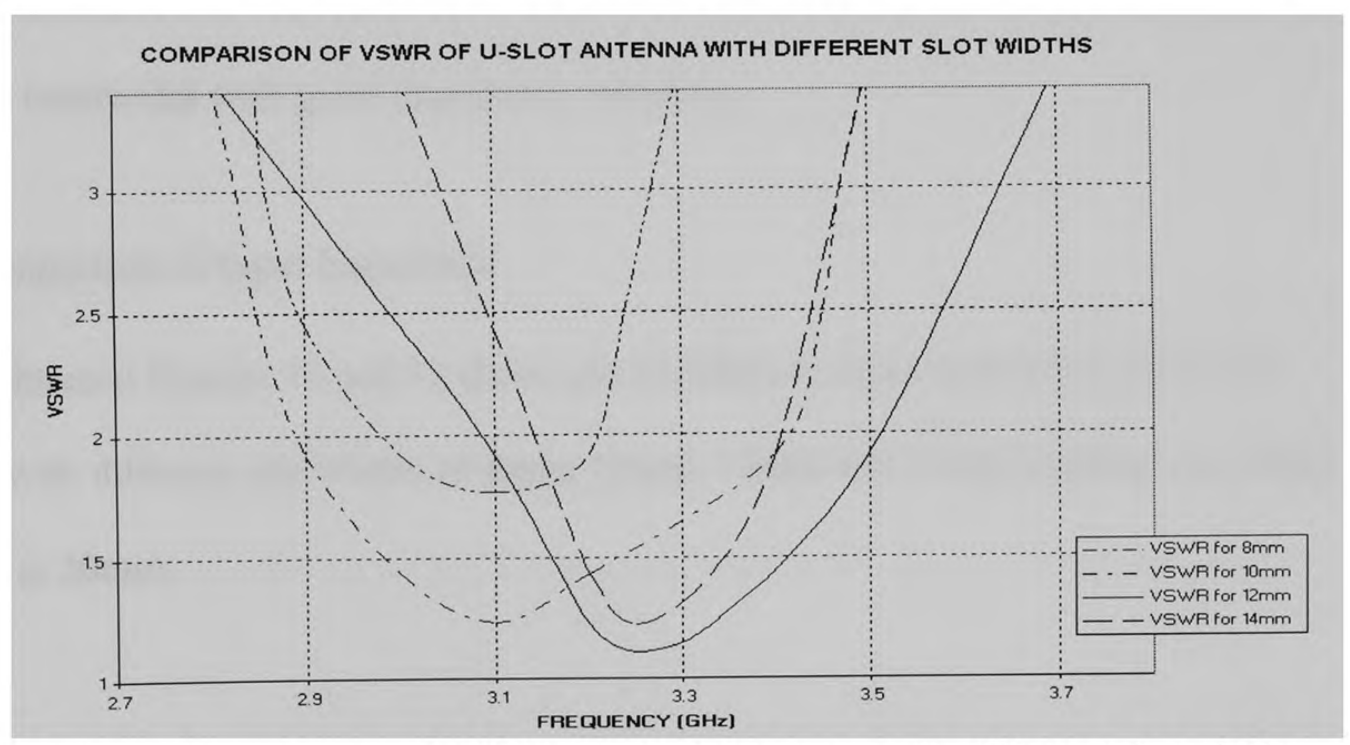

Fig.70 Comparison of VSWR for U-slot antenna with different slot widths 
The results from above plots are tabulated as follows.

$\begin{array}{cccc}\text { Slot width }(\mathrm{mm}) & \text { S11(dB) } & \text { \%Bandwidth } & \text { VSWR } \\ 8 & -11.1 & 6.4 & \\ 10 & -19.8 & 16.0 & 2.0 \\ 12 & -29.0 & 14.2 & 2.0 \\ 14 & -20.0 & 7.5 & 2.0\end{array}$

According to the above results, for a VSWR of $2: 1$ the bandwidth of the slot antenna with slot widths of $10 \mathrm{~mm}$ and $12 \mathrm{~mm}$ is more compared to other slot widths relative to the constant slot length of $20 \mathrm{~mm}$. Although the bandwidth of the antenna with slot width $10 \mathrm{~mm}(16 \%)$ is somewhat greater than the antenna with slot width $12 \mathrm{~mm}$ (14.2\%), the return loss is greater for the antenna with slot width $12 \mathrm{~mm}$ showing low reflection than the antenna with slot width $10 \mathrm{~mm}$. The VSWR is 1.11 for the $12 \mathrm{~mm}$ antenna, which is the least, and provides good impedance matching when compared to the other antennas with different slot widths. Thus a better antenna design should provide optimum bandwidth with good impedance matching.

\subsubsection{Comparison of Input Impedance}

The next Figures 71 and 72 shows the variation in input impedance for U-slot antenna with different slot widths of $8 \mathrm{~mm}, 10 \mathrm{~mm}, 12 \mathrm{~mm}$ and $14 \mathrm{~mm}$ keeping slot length constant at $20 \mathrm{~mm}$. 


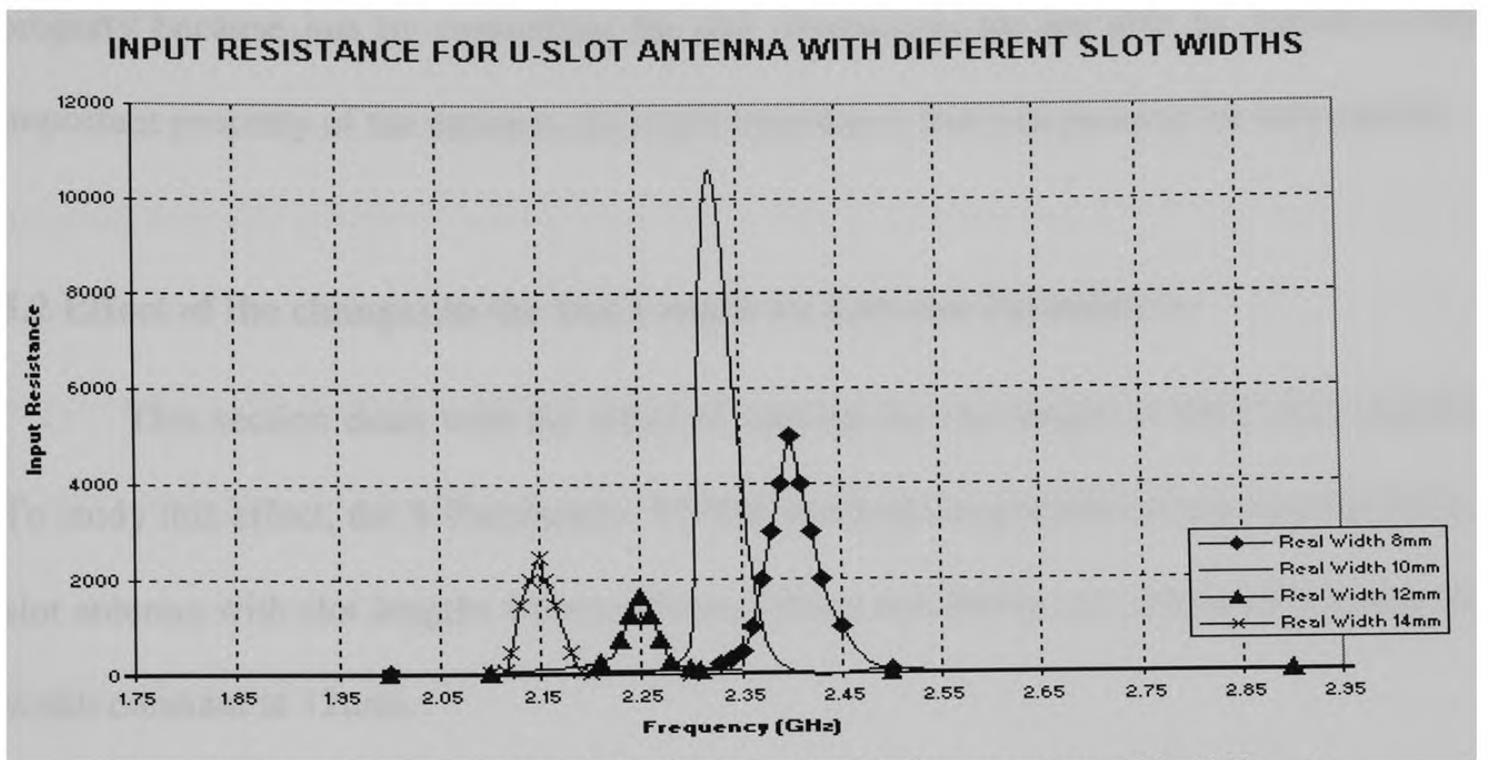

Fig.71 Comparison of Input Resistance for U-slot antenna with different slot widths

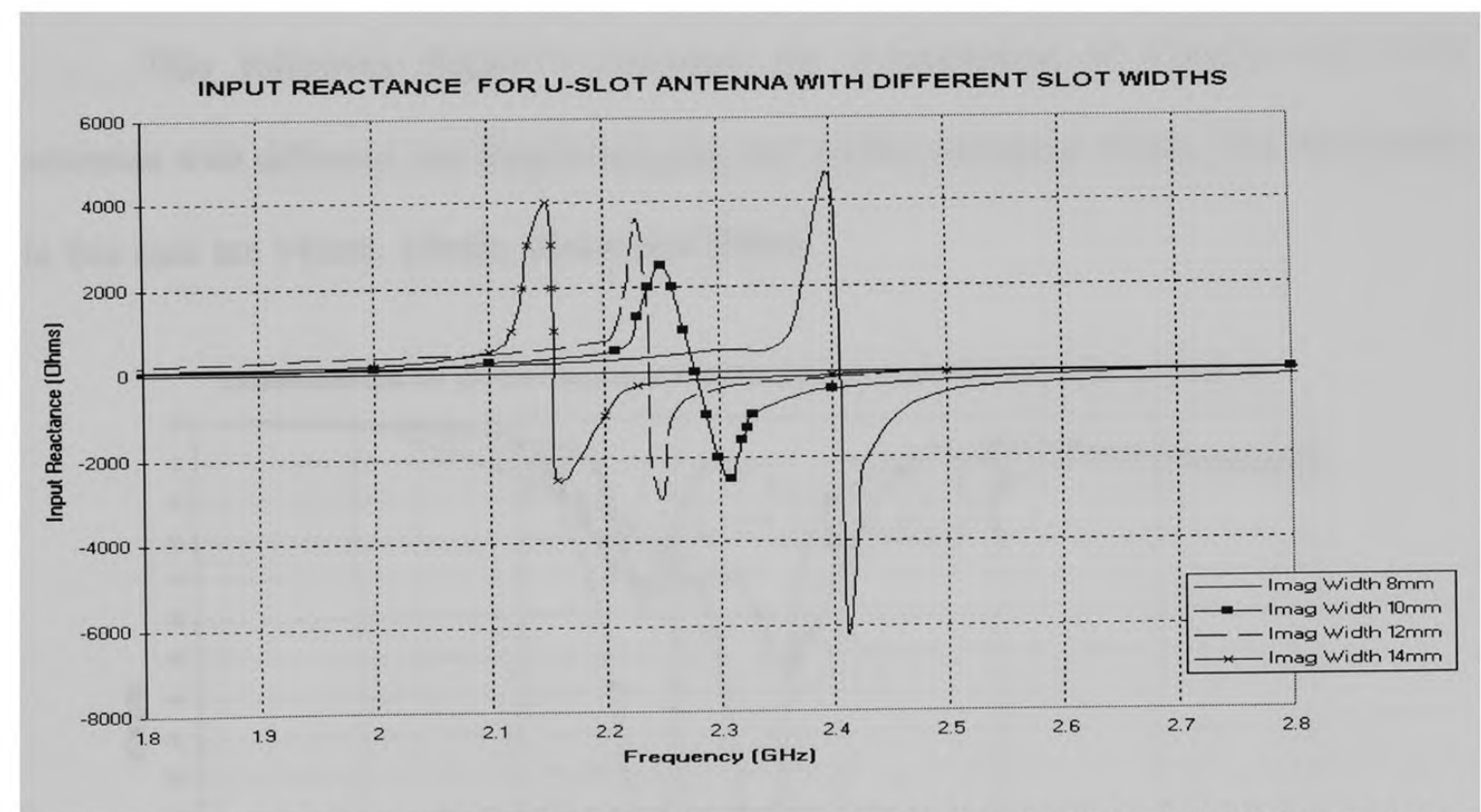

Fig.72 Comparison of Input Reactance for U-slot antenna with different slot widths

From the above set of figures, it is clearly observed that the input impedance of the U-slot antenna is varied according to different slot dimensions. This is a very useful 
property because just by controlling the slot dimensions we are able to control a very important property of the antenna, the input impedance that can prove to be very useful.

\subsection{Effect of the changes in the Slot Length on Antenna Parameters}

This section deals with the effect of varying the slot length of the U-slot antenna. To study this effect, the S-Parameters, VSWR and Input Impedance of the Coaxial fed Uslot antenna with slot lengths $14 \mathrm{~mm}, 16 \mathrm{~mm}, 18 \mathrm{~mm}$ and $20 \mathrm{~mm}$ are compared keeping slot width constant at $12 \mathrm{~mm}$.

\subsubsection{Comparison of S-Parameters}

This following Figure73 compares the S-parameters of Coaxial fed U-slot antennas with different slot lengths keeping slot width constant at $12 \mathrm{~mm}$. The slot lengths in this case are $14 \mathrm{~mm}, 16 \mathrm{~mm}, 18 \mathrm{~mm}$ and $20 \mathrm{~mm}$.

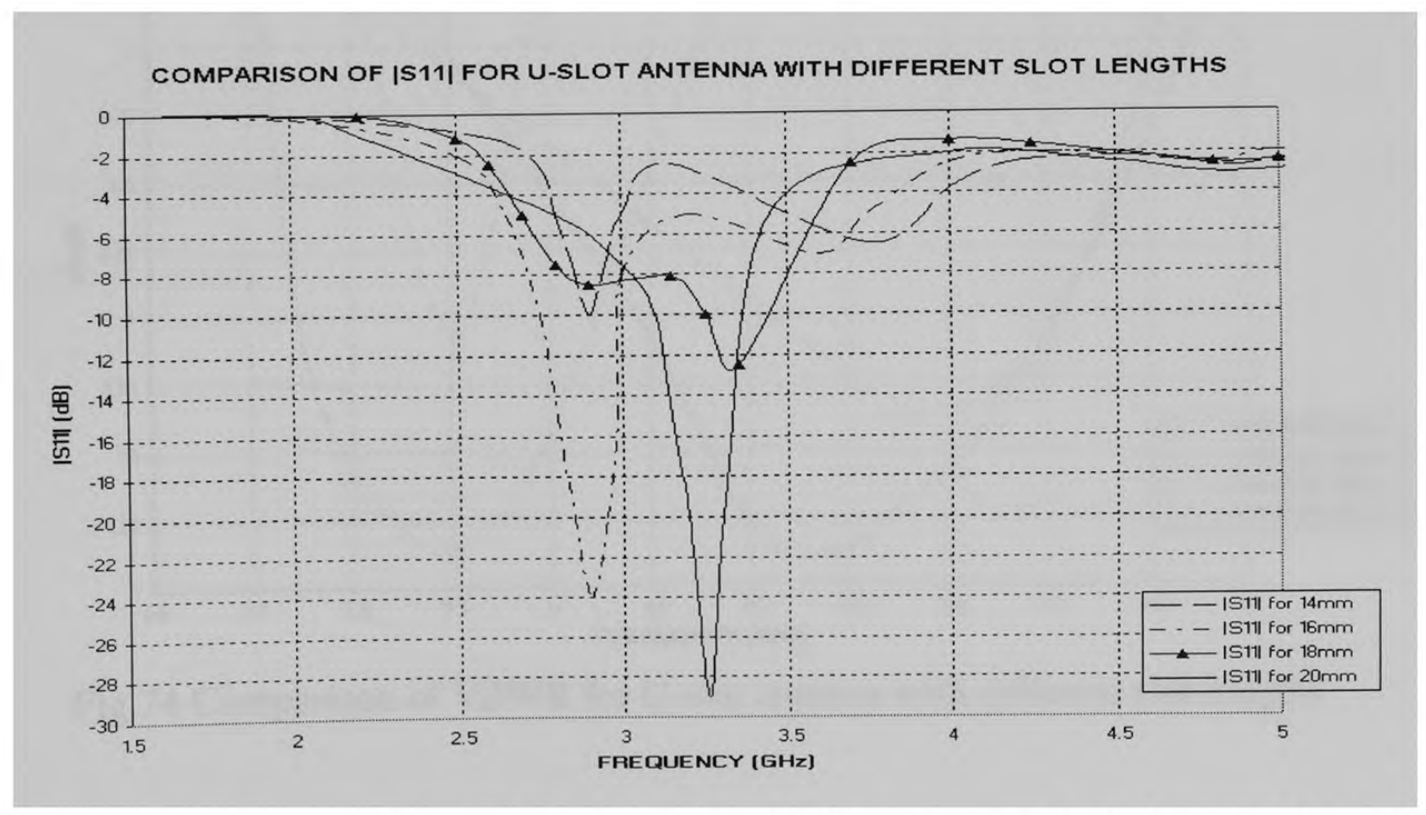

Fig.73 Comparison of S-parameters for U-slot antenna with different slot lengths 
The above comparison shows the variation of the bandwidth of the coaxial fed $\mathrm{U}$ slot antenna with the slot length relative to the slot width. Here, $-3 \mathrm{~dB}$ bandwidth of the antenna with slot length of $14 \mathrm{~mm}$ is the least. The bandwidth is high for the slot length of $20 \mathrm{~mm}$ relative to the slot width of $12 \mathrm{~mm}$. This variation in bandwidth is further supported by the following plot that compares the VSWR for the antennas with the slot lengths of $14 \mathrm{~mm}, 16 \mathrm{~mm}, 18 \mathrm{~mm}$ and $20 \mathrm{~mm}$ keeping the slot width constant at $12 \mathrm{~mm}$.

\subsubsection{Comparison of VSWR}

The following Figure74 shows the comparison of VSWR of the U-slot antenna with different slot lengths. The slot lengths in this case are $14 \mathrm{~mm}, 16 \mathrm{~mm}, 18 \mathrm{~mm}$ and $20 \mathrm{~mm}$.

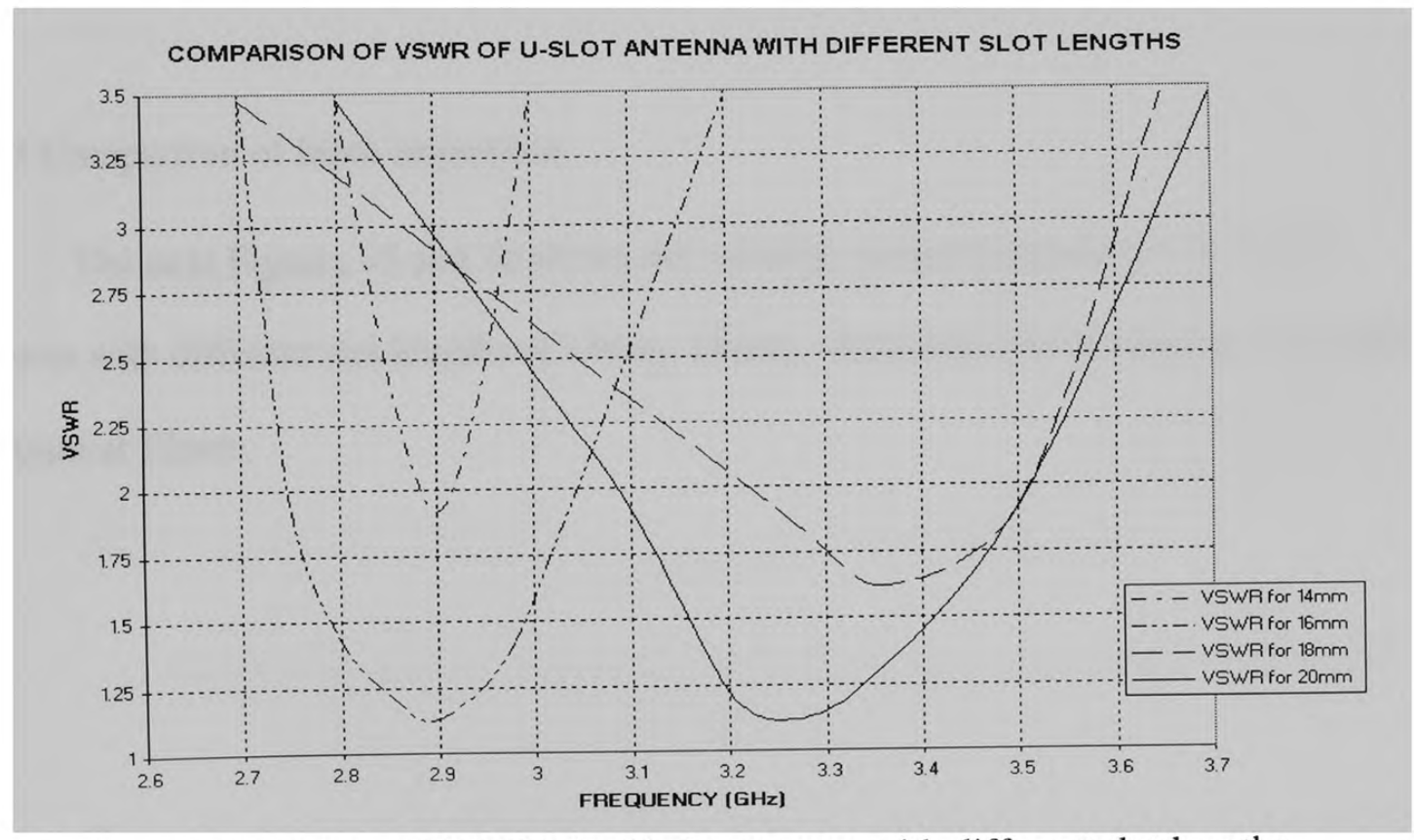

Fig.74 Comparison of VSWR for U-slot antenna with different slot lengths 
The results from above plots are tabulated as follows.

$\begin{array}{cccc}\text { Slot length }(\mathrm{mm}) & \text { S11 }(\mathrm{dB}) & \text { \%Bandwidth } & \text { VSWR } \\ & & & \\ 14 & -10.0 & 2.0 & 2.0 \\ 16 & -24.0 & 10.0 & 2.0 \\ 18 & -12.5 & 7.4 & 2.0 \\ 20 & -29.0 & 14.2 & 2.0\end{array}$

According to the above results, for a VSWR of 2:1 the bandwidth of the slot antenna with slot length of $20 \mathrm{~mm}(14.2 \%)$ is more compared to other antennas with slot lengths relative to the constant slot width of $12 \mathrm{~mm}$. The return loss is greater for this antenna for which VSWR is 1.11 , which is the least, and provides good impedance matching when compared to the other antennas with different slot lengths. Thus a better antenna design should provide optimum bandwidth with good impedance matching.

\subsubsection{Comparison of Input Impedance}

The next Figures 75 and 76 shows the variation in input impedance for U-slot antenna with different slot lengths of $14 \mathrm{~mm}, 16 \mathrm{~mm}, 18 \mathrm{~mm}$ and $20 \mathrm{~mm}$ keeping slot width constant at $12 \mathrm{~mm}$. 


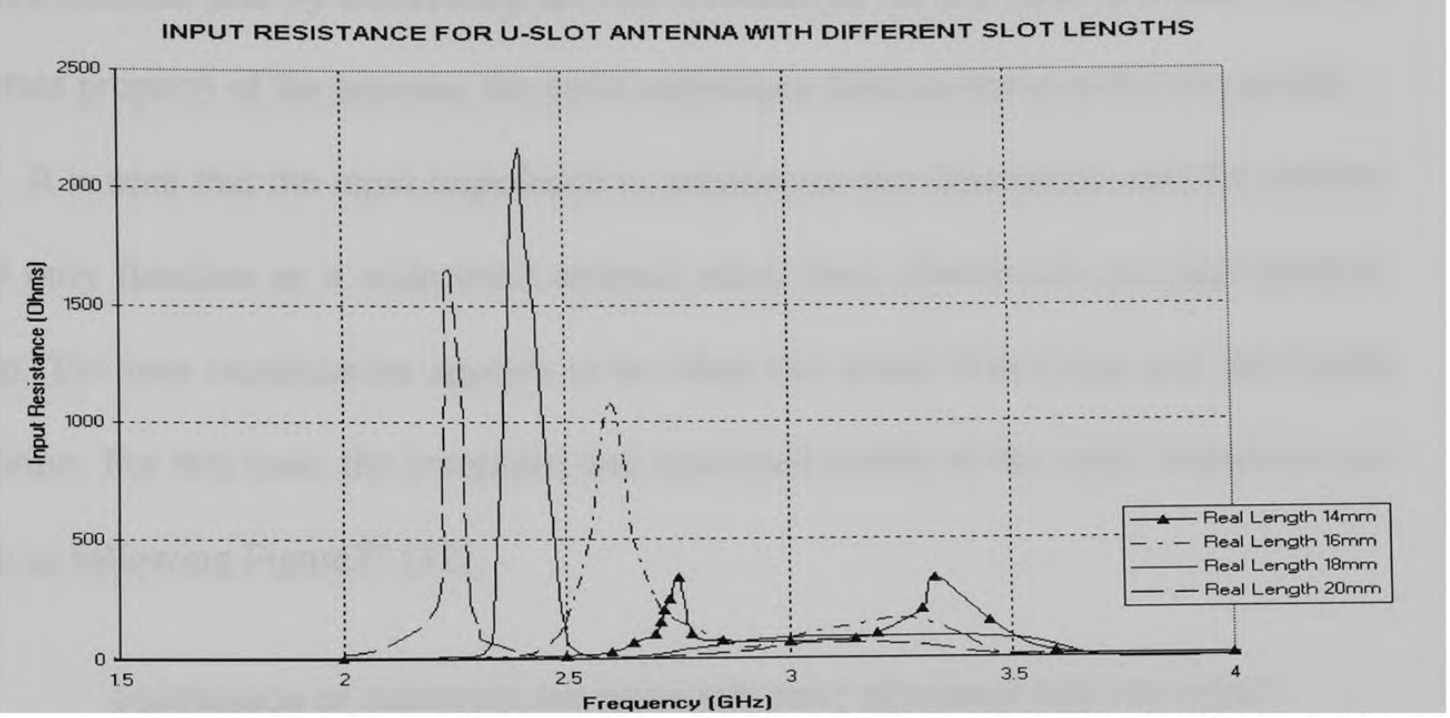

Fig.75 Comparison of Input Resistance for U-slot antenna with different slot lengths

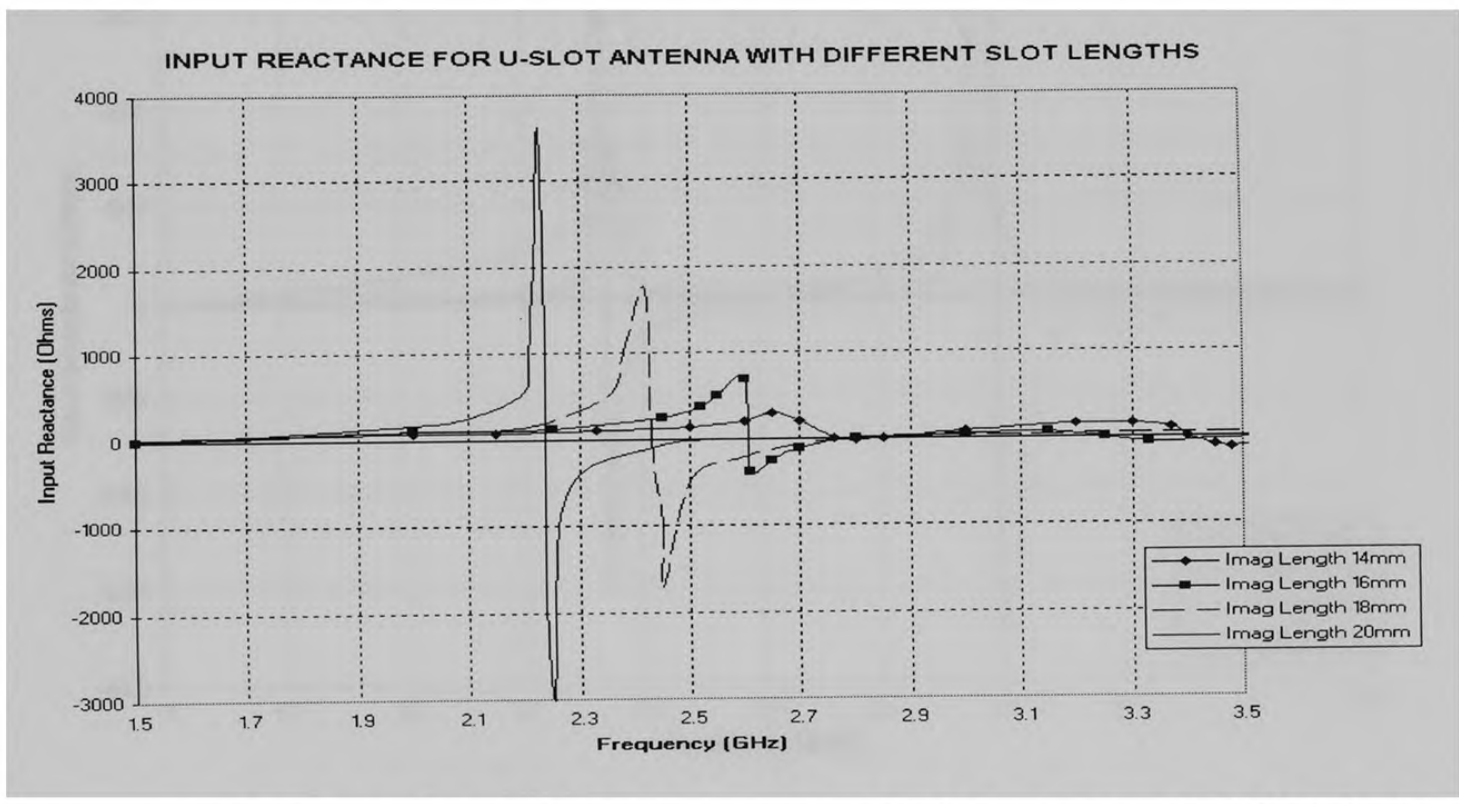

Fig.76 Comparison of Input Reactance for U-slot antenna with different slot lengths

From the above set of Figures, it is clearly observed that the input impedance of the U-slot antenna is varied according to different slot dimensions. This is a very useful 
property because just by controlling the slot dimensions we are able to control a very important property of the antenna, the input impedance that can prove to be very useful.

It is seen that the input impedance is sensitive to slot dimensions and the antenna would only function as a wide band antenna when these dimensions are appropriately chosen. The best combination appears to be when slot width $\mathrm{Ws}=12 \mathrm{~mm}$ and slot length $\mathrm{Ls}=20 \mathrm{~mm}$. For this case, the computed and measured results of the input impedance are shown in following Figure77 [12].

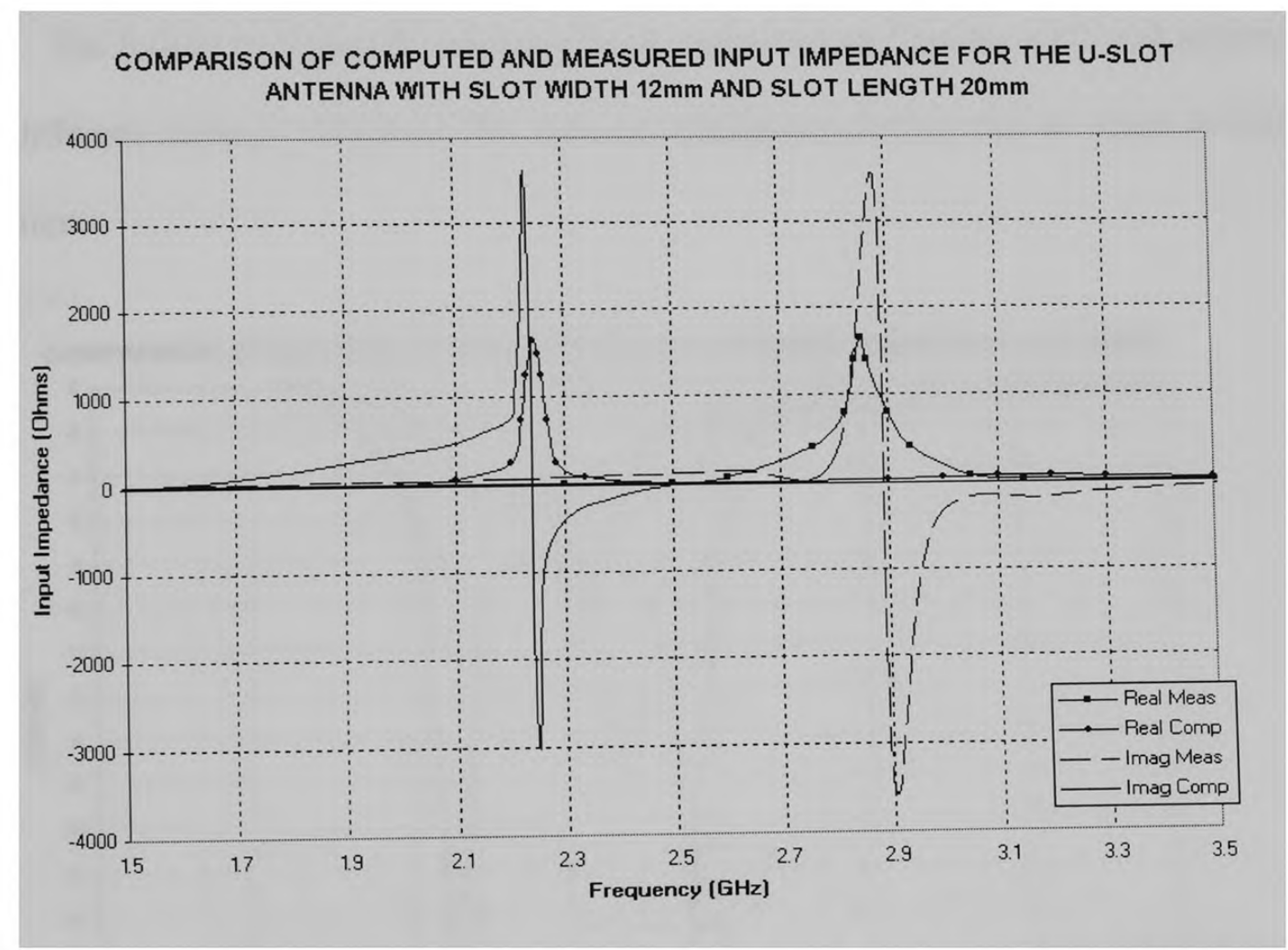

Fig.77 Comparison of Measured and Computed Input Impedance for U-slot Antenna with slot width $12 \mathrm{~mm}$ and slot length $20 \mathrm{~mm}$ 


\subsection{Effect of the changes in the Substrate Thickness on Antenna Parameters}

This section deals with the effect of varying the substrate thickness of the U-slot antenna. To study this effect, the S-parameters, VSWR, Input Impedance and bandwidth of the Coaxial fed U-slot antenna with substrate thickness of $5 \mathrm{~mm}, 6.4 \mathrm{~mm}$ and $8 \mathrm{~mm}$ are compared.

\subsubsection{Comparison of S-Parameters}

The following Figure78 compares the S-parameters of Coaxial fed U-slot antenna with different substrate thickness. The substrate thicknesses in this case are $5 \mathrm{~mm}, 6.4 \mathrm{~mm}$ and $8 \mathrm{~mm}$.

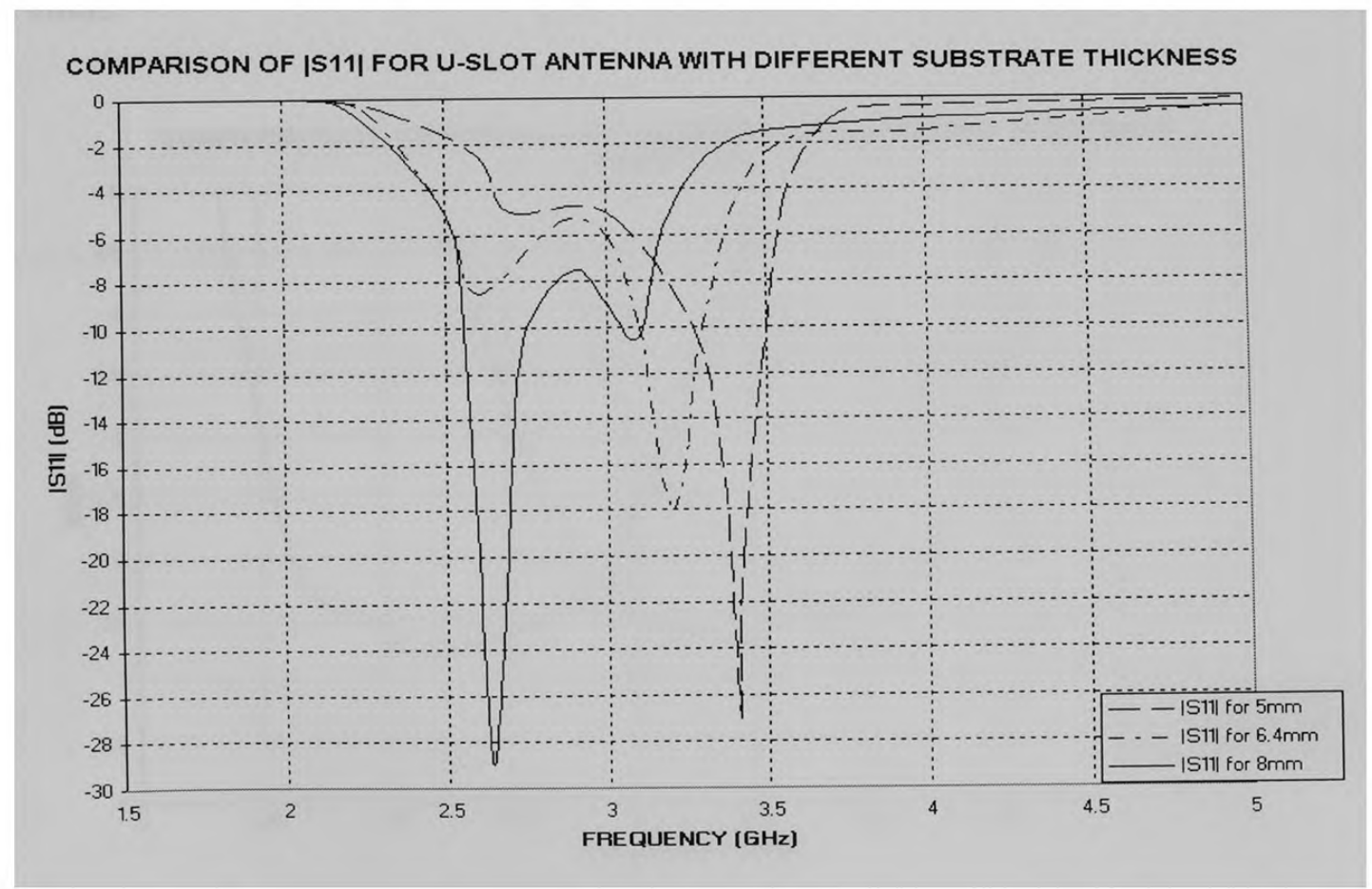

Fig.78 Comparison of S-parameters for U-slot antenna with different substrate thickness 
The above comparison indicates that the bandwidth of Coaxial fed U-slot antenna increases as the substrate thickness increases. Here $-3 \mathrm{~dB}$ bandwidth of the antenna with the substrate thickness of $5 \mathrm{~mm}$ is the least. The bandwidth increases as the substrate thickness is increased to $6.4 \mathrm{~mm}$ and further increases as the thickness is raised to $8 \mathrm{~mm}$. The following plot that compares the VSWR for antennas with the substrate thickness of $5 \mathrm{~mm}, 6.4 \mathrm{~mm}$ and $8 \mathrm{~mm}$ further supports the variation in bandwidth.

\subsubsection{Comparison of VSWR}

The following Figure79 shows the comparison of VSWR of the U-slot antenna with different substrate thickness. The substrate thicknesses in this case are $5 \mathrm{~mm}, 6.4 \mathrm{~mm}$ and $8 \mathrm{~mm}$.

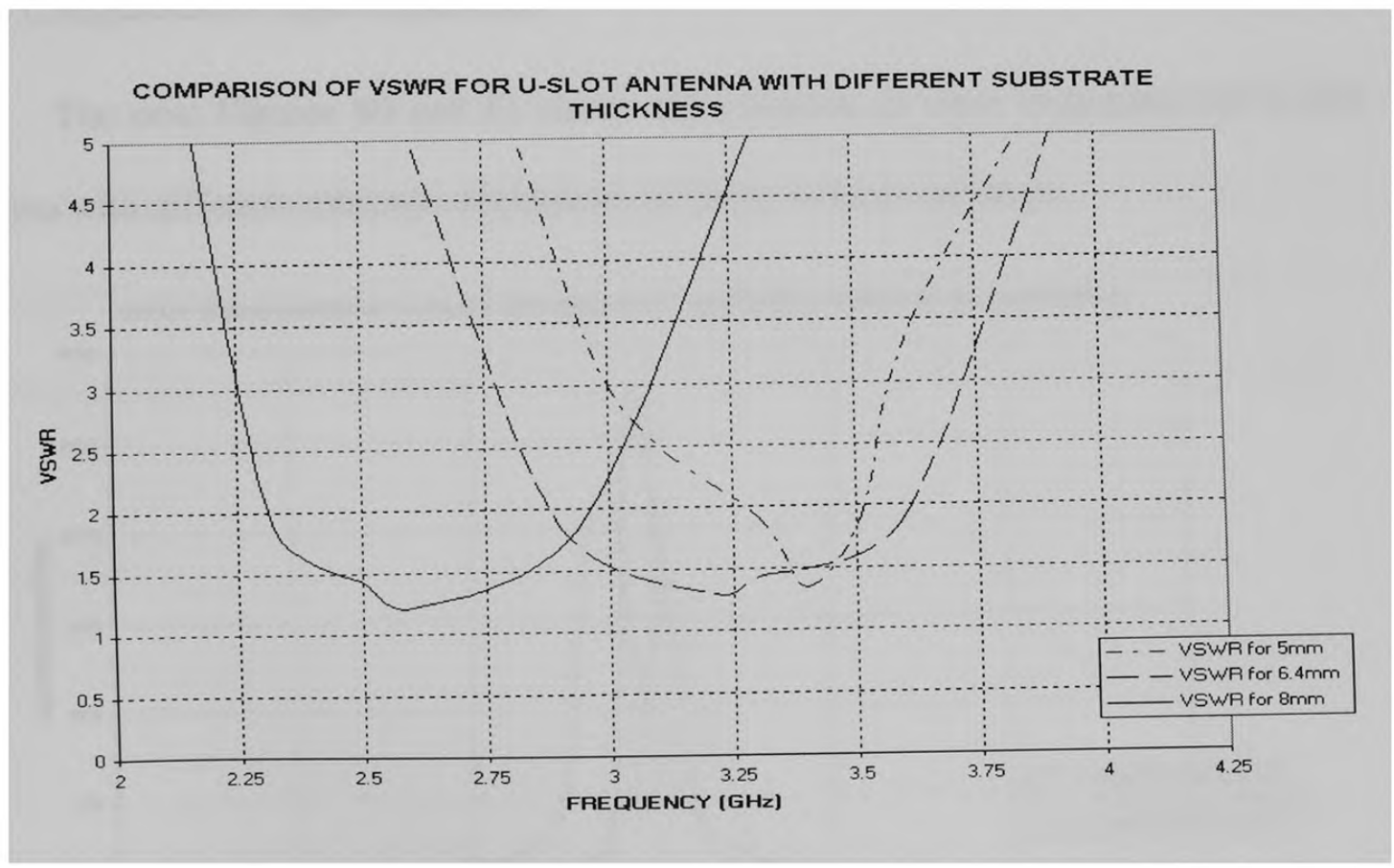

Fig.79 Comparison of VSWR for U-slot antenna with different substrate thicknesses 
The results from above plots are tabulated as follows.

$\begin{array}{cccc}\text { Substrate thickness }(\mathrm{mm}) & \text { S11(dB) } & \text { \%Bandwidth } & \text { VSWR } \\ & & & \\ 5.0 & -27.0 & 6.1 & 2.0 \\ 6.4 & -18.0 & 22.1 & 2.0 \\ 8.0 & -29.5 & 24.2 & 2.0\end{array}$

According to the above results, for a VSWR of 2:1 the bandwidth of the U-slot antenna with substrate thickness of $5 \mathrm{~mm}$ is $6.1 \%$. It has increased to $22.1 \%$ with the substrate thickness of $6.4 \mathrm{~mm}$ and it is $24.2 \%$ for a substrate thickness of $8 \mathrm{~mm}$. Thus it is obvious that the bandwidth of the antenna increases as the substrate thickness is increased.

\subsubsection{Comparison of Input Impedance}

The next Figures 80 and 81 shows the variation in input impedance for U-slot antenna with different substrate thicknesses of $5 \mathrm{~mm}, 6.4 \mathrm{~mm}$ and $8 \mathrm{~mm}$.

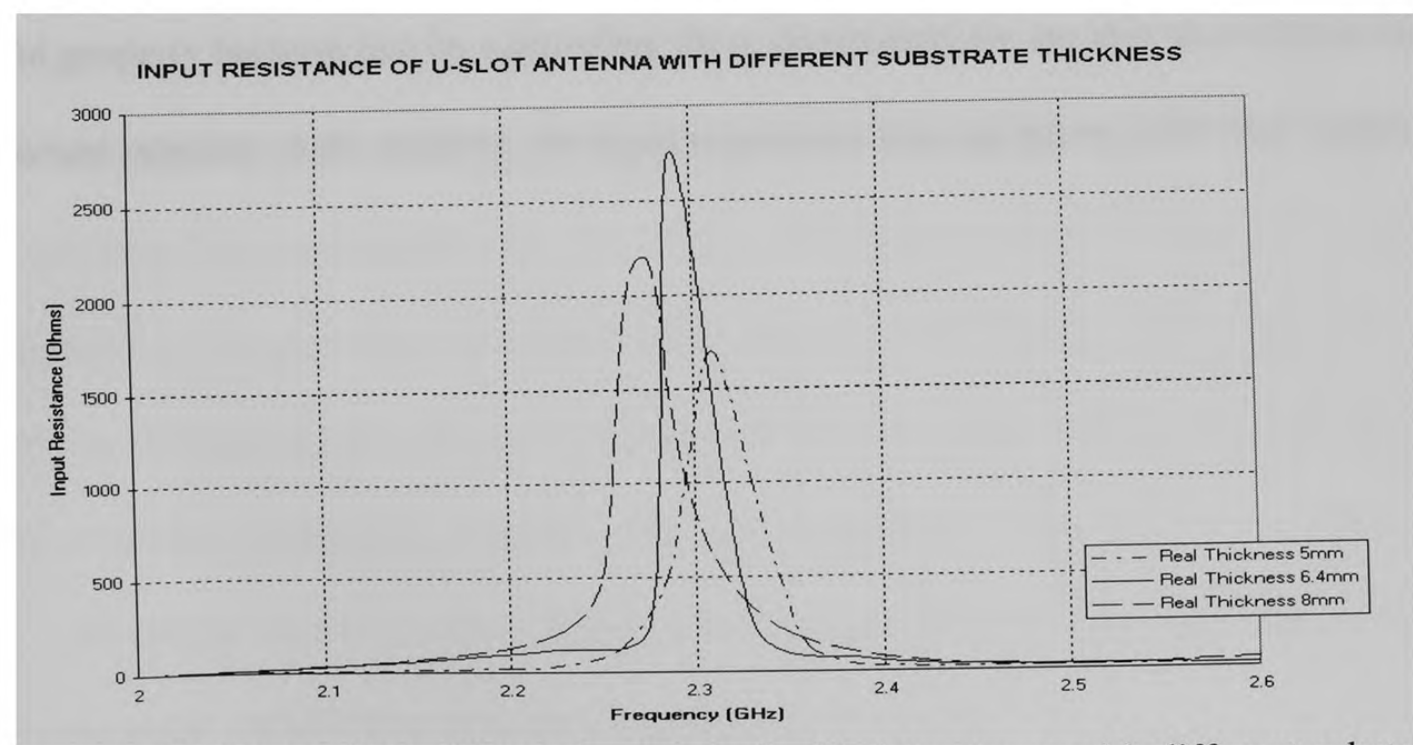

Fig.80 Comparison of Input Resistance for U-slot antenna with different substrate thicknesses 


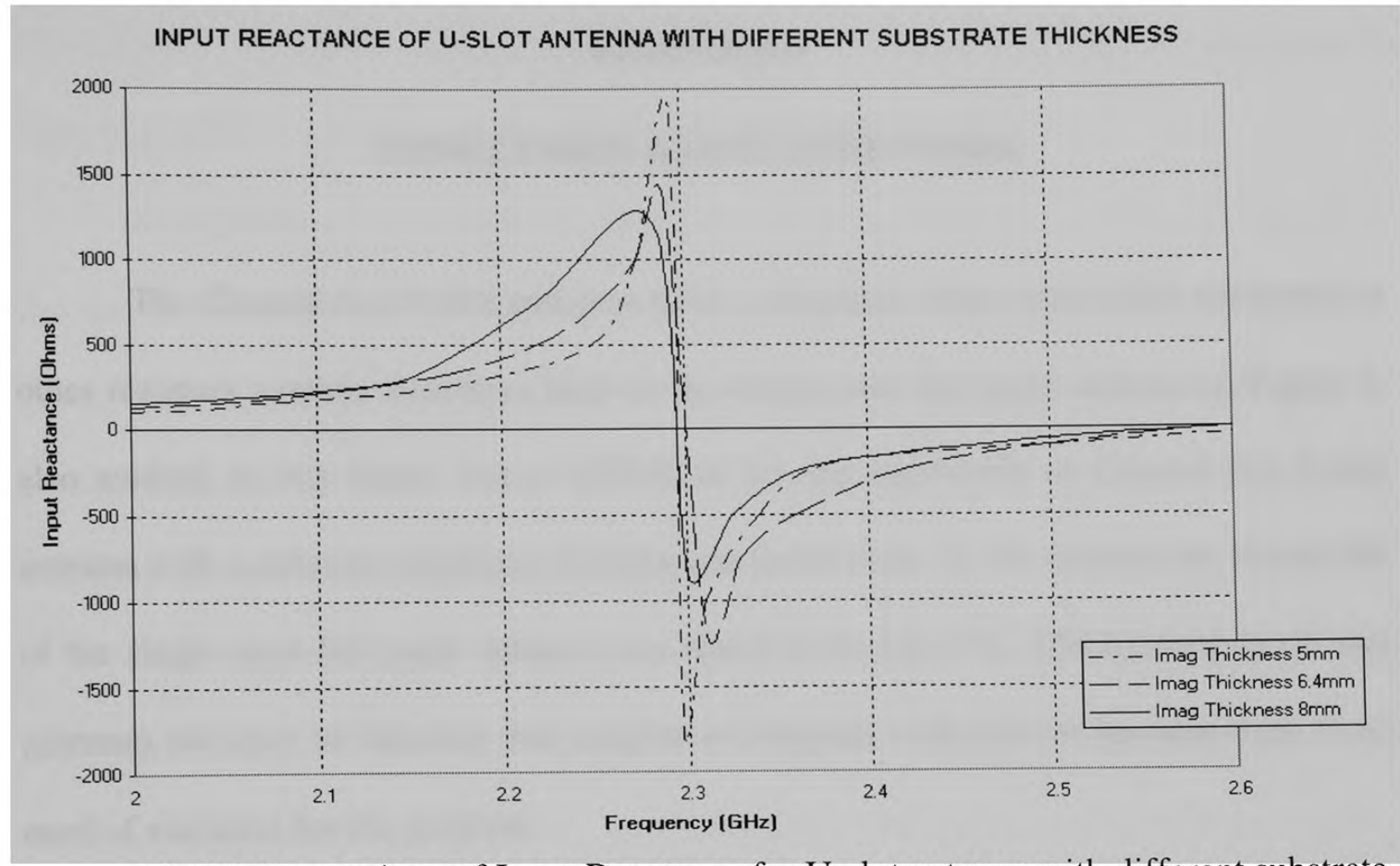

Fig.81 Comparison of Input Reactance for U-slot antenna with different substrate thicknesses

From the above set of Figures, it is clearly observed that the input impedance of the U-slot antenna is varied according to different antenna dimensions. This is a very useful property because just by controlling these dimensions we are able to control a very important property of the antenna, the input impedance that can prove to be very useful. 


\section{CHAPTER 6}

\section{CONCLUSION AND FUTURE WORK}

The Coaxial fed U-slot antennas have a relatively wider bandwidth compared to other resonant antenna structures such as the single coax fed patch antenna in Figure 3, also studied in this thesis. For a VSWR of $2: 1$ the bandwidth of Coaxial fed U-slot antenna with a substrate thickness of $8 \mathrm{~mm}$ was found to be $24.2 \%$ whereas the bandwidth of the single coax-fed patch antenna was found to be only $3 \%$. The Coaxial fed U-slot antennas are easy to fabricate and simpler to integrate with devices because there is no need of via holes for the purpose.

In this thesis a variety of Coaxial fed U-slot antennas are analyzed by the FDTD method using the XFDTD software. The results obtained in this thesis match very well with those published in paper [12].

All the results shown in these thesis are obtained by considering Duroid 5880, the dielectric material of the substrate of the antenna structure, to be a perfect dielectric. Some simulations were repeated by assigning the loss tangent value of Duroid 5880. But the variations are imperceptible to the eye. But, for the antenna researched in this thesis the actual loss tangent value of Duroid 5880 failed to cause appreciable changes in the results of simulations. So, the following conclusions are based upon the results obtained by considering the dielectric material to be a lossless, perfect dielectric.

From the results obtained in this work, it is concluded that the input impedance is sensitive to the variations in antenna dimensions as in Figures 
(71-72), (75-76), (80-81). These variations lower the resonant frequency of the antenna slightly and there is an appreciable change in bandwidth.

It is concluded that the bandwidth of the Coaxial fed U-slot antenna is related to the length and width of the slots. As can be observed from the Figures 70 and 74 the bandwidth of the antenna varies relatively to the slot dimensions. So a better combination of these dimensions should be achieved by appropriately choosing them for bandwidth widening and required impedance matching.

The results obtained in this research also indicate that the substrate thickness of the Coaxial fed U-slot antenna influences the bandwidth of the antenna significantly. For the three cases studied in this work, the bandwidth of the antenna changed appreciably with the variation in the substrate thickness as observed from Figure79.

This work concludes that it is possible to design both the input impedance and bandwidth of the coaxial fed U-slot antennas. As a practical choice for many circuits is the antenna with broadband 50-ohm input impedance, this antenna could find many applications in the microwave regime.

Future work can include the study of coaxial fed U-slot antenna arrays and their design criteria. For example the geometry of the two-element array of U-slot patches is shown in Figure 82. A foam substance of thickness and relative permittivity unity is used between the patches and the ground plane. The two patches are center fed by probes. The probes go through the holes and are connected to a microstrip line fabricated on a dielectric. These arrays have high bandwidth with good cross polarization and gain characteristics. 


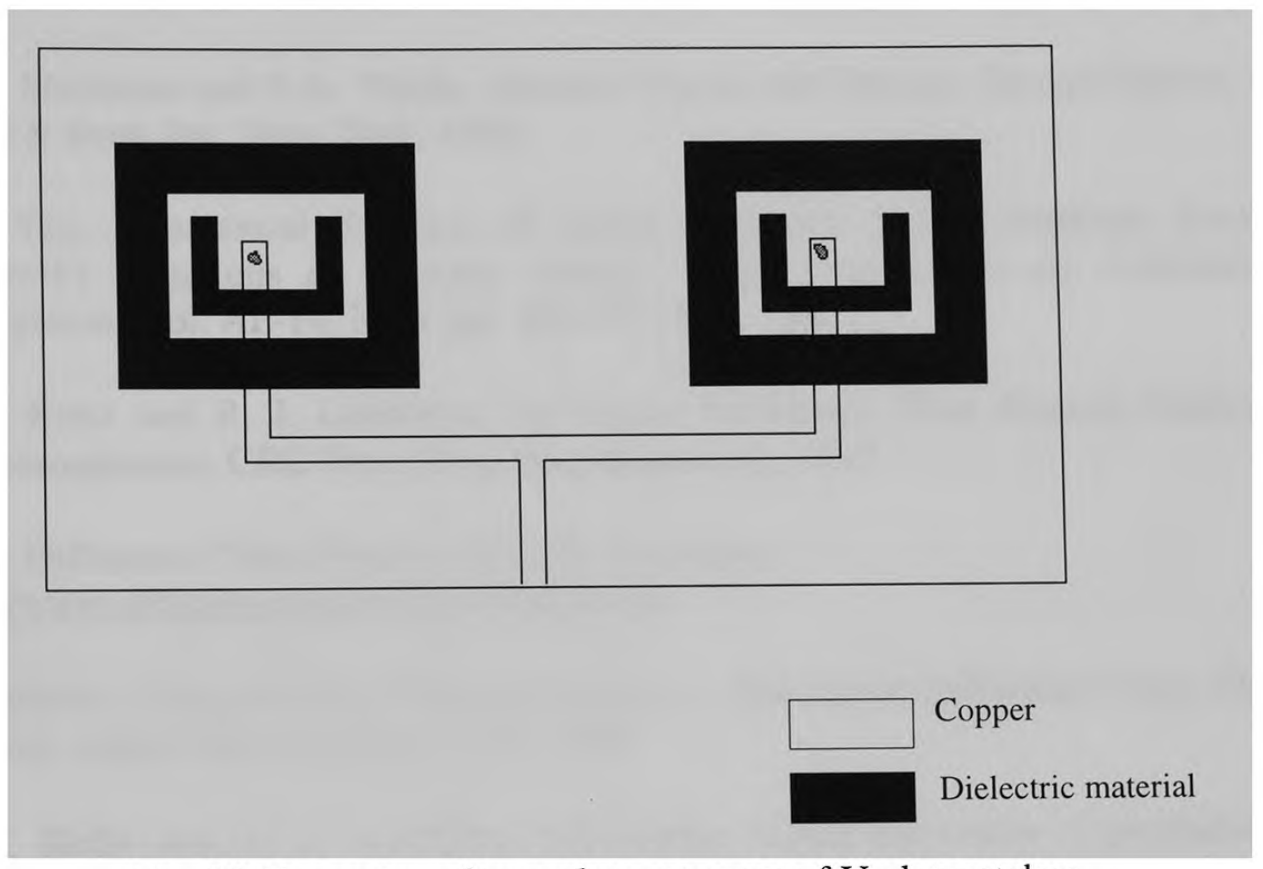

Fig. 82 Geometry of two-element array of U-slot patches 


\section{REFERENCES}

1. W. L. Stutzman and G.A. Thiele, Antenna Theory and Design. Second Edition, John Wiley \& Sons, Inc. New York, 1998.

2. K.S. Yee, "Numerical Solution of Initial Boundary Value Problems Involving Maxwell's Equations in Isotropic Media," IEEE Transactions on Antennas and Propagation, Vol. AP-14, No.3, pp. 302-307, May 1966.

3. K. S. Kunz and R. J. Luebbers, The Finite Difference Time Domain Method for Electromagnetics, CRC Press, Inc., Boca Raton, FL, 1993.

4. Finite Difference Time Domain (FDTD) Technique, http://www.sethcorp.com/technical/fdtd.html

5. A. Taflove, Computational Electrodynamics - The Finite-Difference Time Domain Method, Artech House, Boston, MA, 1995.

6. D. F. Kelly and R. J. Leubbers, "Piecewise Linear Recursive Convolution For Dispersive Media Using FDTD," IEEE Transactions on Antennas and Propagation, Vol. 44, No. 6, pp. 792-797, June 1996.

7. J. J. H Wang, Generalized Moment Methods in Electromagnetics, John Wiley \& Sons, Inc., 1991.

8. R. Garg, P. Bhartia, B. Inder, A. Ittipiboon, "Microstrip Antenna Design Handbook," Artech House. 2000.

9. C.A. Balanis, "Antenna Theory and Design," Second Edition, John Wiley \& Sons, Inc., 1997.

10. Remcom Inc., “ User's Manual for FDTD,” Version 5.0, Remcom Inc., December 1998.

11. Website for MultiSTRIP Program and Reference Manual, http://intek.e-technik.fh-kiel.de/splitt/mstrip.htm

12. K.F. Lee, K.M. Luk, K.F. Tong, S.M. Shum, T. Huynh, R.Q. Lee, “ Experimental And Simulation Studies of the Coaxial Fed U-slot Rectangular Patch Antenna," IEE Proceedings Online No. 19971334, IEE, 1997. 
13. K.F. Tong, K.M. Luk, "A Broadband U-Slot Rectangular Patch Antenna on a Microwave Substrate," IEEE Transactions on Antennas and Propagation, Vol.48, No. 6, pp. 954-960, June 2000.

14. X. Zhang and K. K. Mei, "Time Domain Finite Difference Approach to The Calculation of the Frequency Domain Characteristics of Microstrip Discontinuities," IEEE Transactions on Microwave Theory and Techniques, Vol. 36, pp.1775-1787, December 1998.

15. D. M. Sheen, S.M. Ali, M.D. Abouzhara, “ Application of Three-Dimensional FiniteDifference Time- Domain Method to The Analysis of Planar Circuit," IEEE Transactions on Microwave Theory and Techniques, Vol. 38, pp. 849-857, July 1990.

16. J. M. Martinez, “ Cross Coupling of Polarization in a Dual Coaxial Line Fed Rectangular Microstrip Patch Antenna," Master of Science, Florida International University, March 2000. 